\title{
Wet deposition of inorganic ions in 320 cities across China: spatio-temporal variation, source apportionment, and dominant factors
}

\author{
Rui Li ${ }^{1}$, Lulu Cui ${ }^{1}$, Yilong Zhao ${ }^{1}$, Ziyu Zhang ${ }^{1}$, Tianming Sun ${ }^{1}$, Junlin Li $^{1}$, Wenhui Zhou ${ }^{1}$, Ya Meng ${ }^{1}$, Kan Huang ${ }^{1}$, \\ and Hongbo $\mathbf{F u}^{1,2,3}$ \\ ${ }^{1}$ Shanghai Key Laboratory of Atmospheric Particle Pollution and Prevention, Department of Environmental Science \& \\ Engineering, Institute of Atmospheric Sciences, Fudan University, Shanghai, 200433, China \\ ${ }^{2}$ Shanghai Institute of Pollution Control and Ecological Security, Shanghai 200092, China \\ ${ }^{3}$ Collaborative Innovation Center of Atmospheric Environment and Equipment Technology (CICAEET), \\ Nanjing University of Information Science and Technology, Nanjing 210044, China
}

Correspondence: Hongbo Fu (fuhb@fudan.edu.cn)

Received: 22 January 2019 - Discussion started: 10 April 2019

Revised: 17 July 2019 - Accepted: 22 July 2019 - Published: 2 September 2019

\begin{abstract}
The acid deposition has been considered to be a severe environmental issue in China. The $\mathrm{pH}$, electrical conductivity (EC), and concentrations of water soluble ions $\left(\mathrm{NO}_{3}^{-}, \mathrm{Cl}^{-}, \mathrm{Ca}^{2+}, \mathrm{K}^{+}, \mathrm{F}^{-}, \mathrm{NH}_{4}^{+}, \mathrm{Mg}^{2+}, \mathrm{SO}_{4}^{2-}\right.$, and $\mathrm{Na}^{+}$) in the precipitation samples collected from 320 cities during 2011-2016 across China were measured. The mean concentrations of $\mathrm{F}^{-}, \mathrm{NO}_{3}^{-}$, and $\mathrm{SO}_{4}^{2-}$ were in the order of winter $\left(6.10,19.44\right.$, and $\left.45.74 \mu \mathrm{eq} \mathrm{L}^{-1}\right)>$ spring $\left(3.45,13.83\right.$, and $\left.42.61 \mu \mathrm{eq} \mathrm{L}^{-1}\right)>$ autumn $(2.67,9.73$, and $\left.28.85 \mu \mathrm{eq} \mathrm{L}^{-1}\right)>$ summer $\left(2.04,7.66\right.$, and $\left.19.26 \mu \mathrm{eq} \mathrm{L}^{-1}\right)$. Secondary ions $\left(\mathrm{SO}_{4}^{2-}, \mathrm{NO}_{3}^{-}\right.$, and $\left.\mathrm{NH}_{4}^{+}\right)$and $\mathrm{F}^{-}$peaked in the Yangtze River Delta (YRD) and Sichuan basin (SB). Crustal ions (i.e. $\mathrm{Ca}^{2+}, \mathrm{Mg}^{2+}$ ), $\mathrm{Na}^{+}$, and $\mathrm{Cl}^{-}$showed the highest concentrations in the semi-arid regions and the coastal cities. The statistical methods confirmed that the mean anthropogenic contribution ratios to $\mathrm{SO}_{4}^{2-}, \mathrm{F}^{-}, \mathrm{NO}_{3}^{-}$, and $\mathrm{NH}_{4}^{+}$at a national scale were $46.12 \%, 71.02 \%, 79.10 \%$, and $82.40 \%$, respectively. However, $\mathrm{Mg}^{2+}(70.51 \%), \mathrm{K}^{+}$ $(77.44 \%)$, and $\mathrm{Ca}^{2+}(82.17 \%)$ mostly originated from the crustal source. Both $\mathrm{Na}^{+}(70.54 \%)$ and $\mathrm{Cl}^{-}(60.42 \%)$ were closely linked to sea salt aerosols. On the basis of the stepwise regression (SR) analysis, it was proposed that most of the secondary ions and $\mathrm{F}^{-}$were closely related to gross industrial production (GIP), total energy consumption (TEC), vehicle ownership, and $\mathrm{N}$ fertilizer use, but the crustal ions $\left(\mathrm{Ca}^{2+}\right.$ and $\left.\mathrm{K}^{+}\right)$were mainly controlled by the dust events. The influence of dust days, air temperature, and wind speed
\end{abstract}

on ions increased from southeast China (SEC) to central China, and then to northwest China (NWC), whereas the influence of socioeconomic factors on acid ions $\left(\mathrm{SO}_{4}^{2-}\right.$ and $\mathrm{NO}_{3}^{-}$) displayed the higher value in east China.

\section{Introduction}

Atmospheric wet deposition generally efficiently removes aerosol particles and dissolved gaseous pollutants from the atmosphere (Garland, 1978; Al-Khashman, 2005; Migliavacca et al., 2005). However, in some regions with severe air pollution, scavenging of substantial aerosol particles alters the chemical compositions of precipitation and even aggravates acid deposition (Kuang et al., 2016). Some inorganic ions (i.e. $\mathrm{SO}_{4}^{2-}, \mathrm{NO}_{3}^{-}, \mathrm{NH}_{4}^{+}, \mathrm{Ca}^{2+}$ ) play significant roles in the terrestrial and aquatic ecosystem via wet deposition; for instance, leading to severe soil (lake) acidification (alkalization), inhibiting plant growth, and changing regional climate (Liu et al., 2011; Yan et al., 2010; Larssen and Carmichael, 2000; Larssen et al., 1999). In the past decades, China has suffered from severe air pollution along with population growth and industrialization (L. Liu et al., 2016). Therefore, the investigation of the wet deposition status of inorganic ions is of great interest to the public and policy makers (Négrel et al., 2007). 
A large number of studies mainly focused on the spatiotemporal variation in $\mathrm{S}$ and $\mathrm{N}$ deposition around the world due to their adversely ecological effects in the past decades (Gerson et al., 2016; Clemens, 2006; Zhang et al., 2010). Okuda et al. (2005) showed that the $\mathrm{SO}_{4}^{2-}$ concentration in the precipitation exhibited a slight decrease coupling with the decrease in the $\mathrm{SO}_{2}$ concentration in Tokyo during 19902012. Hunová et al. (2014) reported that the average $S$ deposition flux decreased from 181 to $100 \mathrm{~kg} \mathrm{ha}^{-1} \mathrm{yr}^{-1}$ in the Czech Republic between 1995 and 2011 on the basis of the data in 15 cities. Du et al. (2012) estimated that the wet deposition flux of inorganic nitrogen reached $3.5 \mathrm{~kg} \mathrm{~N}^{-1} \mathrm{ha}^{-1} \mathrm{yr}^{-1}$ according to the average of $151 \mathrm{moni}-$ toring stations in the United States during 1985-2012, which was significantly lower than that of China during the same period (11.11-13.87 $\mathrm{kg} \mathrm{ha}^{-1} \mathrm{yr}^{-1}$ ) (Jia et al., 2014).

Much research about the $\mathrm{S}$ and $\mathrm{N}$ deposition has been extensively performed to date in China (Jia et al., 2014; Xu et al., 2015). In the past decades, anthropogenic emissions of $\mathrm{SO}_{2}, \mathrm{NO}_{2}$, and $\mathrm{NH}_{3}$ displayed a remarkable increase along with a dramatic increase in fossil fuel and fertilizer consumption in China (Jia et al., 2014; Kuribayashi et al., 2012). It was well documented that the gaseous precursors containing $\mathrm{S}$ and $\mathrm{N}$ could be transformed into sulfates $\left(\mathrm{SO}_{4}^{2-}\right)$, nitrates $\left(\mathrm{NO}_{3}^{-}\right)$, and ammonium $\left(\mathrm{NH}_{4}^{+}\right)$during ageing in the atmosphere, thereby contributing to the formation of airborne fine particles, which were considered to be the main reason for the persistent fog and haze pollution in China (H. Wang et al., 2016; Qiao et al., 2015). At a city level, Huang et al. (2008) observed that the wet deposition fluxes of $\mathrm{SO}_{4}^{2-}, \mathrm{NH}_{4}^{+}$, and $\mathrm{Ca}^{2+}$ displayed a slight decrease from 1986 to 2006 in Shenzhen, whereas the wet deposition of $\mathrm{NO}_{3}^{-}$increased rapidly during the same period. Very recently, $\mathrm{Pu}$ et al. (2017) reported that the $\mathrm{SO}_{4}^{2-}$ concentration in the wet deposition of Shangdianzi (a regional background station of Beijing) showed a slight decrease during 2003-2014, but the $\mathrm{NO}_{3}^{-}$ concentration showed an opposite trend. At a regional scale, Pan et al. (2013) observed that the highest $\mathrm{S}$ wet deposition was concentrated in the urban and industrial region of Tianjin among 10 sites of north China (NC). Song et al. (2017) suggested that the bulk deposition fluxes were in the order of Chengdu (urban) $>$ Yanting (agricultural area) $>$ Mount Gongga (natural reserve). At a national scale, Jia et al. (2014) first found that the wet deposition of $\mathrm{N}$ in southeast China (SEC) showed a significant decrease, whereas it increased slightly in the west of China on the foundation of the data (620 monitoring sites) collected from 120 cities across China between 1990 and 2010. Following this work, L. Liu et al. (2016) further observed serious S deposition (79 monitoring sites) in SEC and southwest China (SWC). In these studies, the spatial distributions of both $\mathrm{S}$ and $\mathrm{N}$ were determined using the spatial interpolation method, which generally required substantial monitoring sites (more than 150 cities and more than 300 monitoring sites). However, these conclusions were obtained based on a small quantity of monitoring sites, which increased the uncertainties of the results. Meanwhile, the monitoring sites in these studies were mainly located in remote regions such as mountains or rural sites rather than a mixture of urban, suburban, and rural sites, which cannot accurately reflect the spatial variations in inorganic ions in China. Moreover, the spatio-temporal variations in other inorganic ions (i.e. $\mathrm{K}^{+}, \mathrm{Ca}^{+}, \mathrm{Mg}^{2+}$ ) remain unclear to date, and were also linked to the acid deposition and the haze pollution in China (Mikhailova et al., 2013; Aloisi et al., 2017; Müller et al., 2015).

Based on these field measurements, the ion levels in the deposition across China were believed to be underestimated due to the few ion species measured by previous studies (L. Liu et al., 2016), which was closely associated with various emission sources (Kuang et al., 2016). Thus, the source identification should be performed to accurately assess their contributions to the wet deposition (Larssen et al., 1999). Y. W. Liu et al. (2015) identified that $\mathrm{Cl}^{-}$and $\mathrm{NH}_{4}^{+}$in the precipitation of Tibet both originated from the marine and crustal source using the geochemical index method. On the basis of a positive matrix factorization (PMF) model, Qiao et al. (2015) showed that fossil fuel combustion and agriculture were the main sources of $\mathrm{SO}_{4}^{2-}$ and $\mathrm{NO}_{3}^{-}$in Jiuzhaigou (Sichuan Province). In new work by Leng et al. (2018), they supposed that the combustion of fossil fuels, domestic sewage, and fertilizers was the main source of $\mathrm{N}$ bearing ions on the basis of $\mathrm{N}$ isotope analysis. To date, some methods, including the geochemical index method, multivariate analyses, and isotope signatures have been utilized to identify anthropogenic versus natural sources of inorganic ions in precipitation. However, these methods suffered from some weaknesses (AlKhatib and Eisenhauer, 2017; Shi et al., 2014). For instance, the geochemical index methods cannot estimate the contribution ratios of multiple sources to $\mathrm{Ca}^{2+}$ and $\mathrm{Na}^{+}$at a spatial scale (Y. W. Liu et al., 2015). Despite the advances of multivariate analyses lowering the associated uncertainties, the multi-collinearity still disturbed the predictions of these models (Shi et al., 2014). The isotope signature method was costly and complex, especially for the unconventional stable isotopes (i.e. K, Ca) (AlKhatib and Eisenhauer, 2017), which restricted its application at a large scale. Therefore, multiple source apportionment methods should be combined in order to enhance the reliability of the results. F. Liu et al. (2015) also demonstrated that the geochemical index method coupled with multiple statistics decreased the uncertainties of results.

Apart from the source apportionment, key factor identification for ions in wet deposition is also of great importance to reduce the acid deposition. In an early study, Singh and Agrawal (2008) revealed that the significant increase in vehicle emissions contributed to the accumulation of $\mathrm{NO}_{2}$, which might be an important precursor of acid rain. Allen et al. (2015) observed that some inland cities in arid and semiarid regions were generally subjected to dust events, which could increase the $\mathrm{Ca}^{2+}$ and $\mathrm{K}^{+}$concentrations in the wet de- 


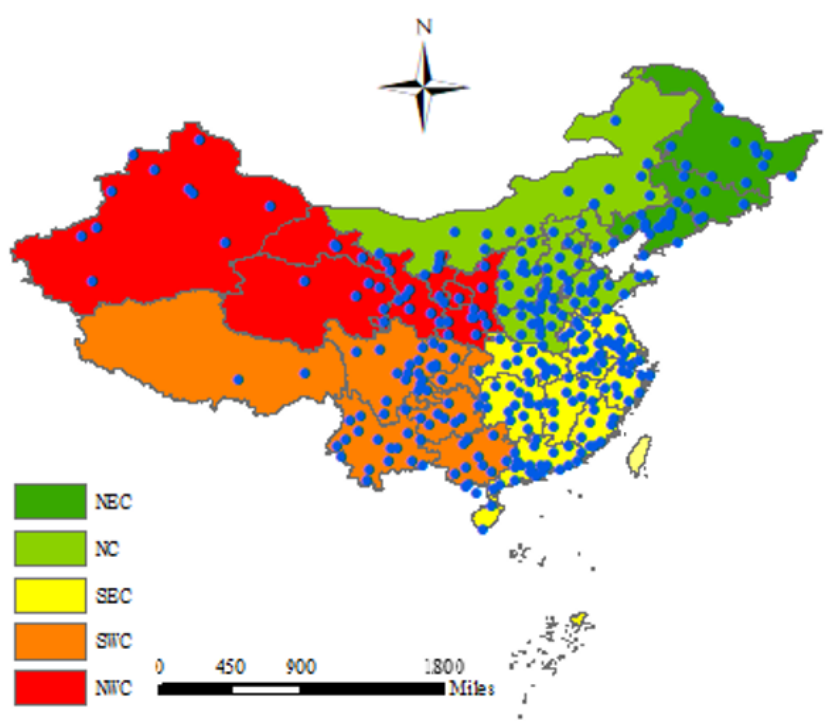

Figure 1. The spatial distribution of 320 cities and five ecological regions.

position. Following this work, H. Yu et al. (2017) found that considerable energy consumption, gross domestic production (GDP), and emitted substantial pollutants made China major regions of acid rain around the world using path analysis and correlation analysis. However, this research only assessed limited factors for inorganic ions in wet deposition (Yu et al., 2016; H. Yu et al., 2017), ignoring the contributions of other socioeconomic and natural factors. Moreover, this research mainly focused on the effects of influential factors on inorganic ions at a national scale, while they did not consider the spatial heterogeneity of the influential factors, possibly resulting in great deviation of the inorganic ions in wet deposition for the different regions.

Here, the data of nine water-soluble ions in the precipitation including $\mathrm{Ca}^{2+}, \mathrm{Cl}^{-}, \mathrm{F}^{-}, \mathrm{K}^{+}, \mathrm{Mg}^{2+}, \mathrm{Na}^{+}, \mathrm{NH}_{4}^{+}, \mathrm{NO}_{3}^{-}$, and $\mathrm{SO}_{4}^{2-}$ in the 320 cities across China were collected during 2011-2016 to examine the characteristics of the main water-soluble ions in precipitation. Specifically, the objectives of our study were (1) to reveal the spatio-temporal patterns of water-soluble ions in recent precipitation in China at a national scale; (2) to quantitatively identify the source of the water-soluble ions in the precipitation based on multiple statistical methods; and (3) to seek out the key factors for inorganic ions at a spatial scale. This study supplied the systematical data for comprehensive understanding on the inorganic composition in precipitation based on long-term field measurement, at a national scale (1282 monitoring sites distributed in 320 cities across China), which was beneficial to the implementation of appropriate strategies to promote environmental protection in China.

\section{Materials and methods}

\subsection{Site description}

The spatial distribution of field stations in the National Acid Deposition Monitoring Network (NADMN) is illustrated in Fig. 1. The selected 1282 monitoring sites are distributed in the 320 cities across 31 provinces. These cities are classified into northeast China (NEC), NC, SEC, northwest China (NWC), and southwest China (SWC) (Table S1 in the Supplement). Both NEC and NC show a typical temperate monsoon climate, while SEC presents a subtropical monsoon climate. The SWC region has the combined effects of a subtropical monsoon climate and a tropical monsoon climate. NWC has temperate continental climate and displays minor rainfall amount. NEC and NC are filled with temperate deciduous forest, whereas SEC is mainly occupied by the subtropical evergreen forest. The subtropical evergreen forest and tropical evergreen forest are spread across the SWC region. NWC is generally filled with expansive grasslands and desert. The latitudes and longitudes of all 1282 monitoring sites range from 18.25 to $50.78^{\circ} \mathrm{N}$ and from 79.57 to $129.25^{\circ} \mathrm{E}$, respectively. Annual mean rainfall ranges from 10 to $1853 \mathrm{~mm}$ and the annual mean air temperature varies between -6.9 and $24.3^{\circ} \mathrm{C}$. The monitoring sites were designed as a mixture of urban and background sites. A total of 850 monitoring sites are concentrated in urban regions, and 432 sites in suburban and rural areas are considered the background sites.

\subsection{Sampling and chemical analysis}

The real-time precipitation was collected by monitors in the field stations as a routine procedure of NADMN. Samples from each monitoring site were collected using wet deposition automatic collectors (diameter $30 \mathrm{~cm}$ ) installed at $1.5 \mathrm{~m}$ above ground level. The cover of the collection instrument opened automatically without delay when the precipitation sensor was activated and closed automatically when precipitation ceased and no water remained on the sensor surface. The sample in each rain event was collected and these samples were collected at all of the monitoring sites simultaneously. Each sample was properly collected during the precipitation event when the wet-only deposition instrument was under normal conditions. After sampling, the $\mathrm{pH}$ and $\mathrm{EC}$ values of the samples were measured immediately. The sample $\mathrm{pH}$ was measured using a $\mathrm{pH}$ meter (MP-6p, HACH, USA) at $20-25^{\circ} \mathrm{C}$. The $\mathrm{EC}$ value of the precipitation samples was determined by an EC meter (CyberScan, CON1500, USA). After the analysis of $\mathrm{pH}$ and $\mathrm{EC}$, all of the samples were contained in pre-cleaned polyethylene plastic bottles at $-18^{\circ} \mathrm{C}$ in order to prevent possible transformation by microbes. All of the plastic buckets and the polyethylene plastic bottles were cleaned with deionized water more than three times and then air-dried in a clean room prior to use. 
All of the precipitation samples were used to analyse the concentrations of the water-soluble ions including $\mathrm{NO}_{3}^{-}$, $\mathrm{Cl}^{-}, \mathrm{Ca}^{2+}, \mathrm{K}^{+}, \mathrm{F}^{-}, \mathrm{NH}_{4}^{+}, \mathrm{Mg}^{2+}, \mathrm{SO}_{4}^{2-}$, and $\mathrm{Na}^{+}$. The microporous membranes $(0.45 \mu \mathrm{m})$ were employed to remove all insoluble particulates $(<0.45 \mu \mathrm{m})$ from the precipitation samples before the analysis. The ion concentrations were determined through ion chromatography (Dionex ICS-900) equipped with a conductivity detector (ASRS-ULTRA). The CS12A column and AS11-HC column were applied to determine the cations and anions, respectively. Each sample was measured more than three times and the relative standard deviation was less than $5 \%$ for each ion. Analysis of the blank samples once a month confirmed that the cross contamination in the present research was negligible. For each ion, the analysis of simulated precipitation suggested that the relative bias was lower than $10 \%$.

\subsection{Data calculation}

The monthly and annual volume-weighted mean (VWM) concentrations were calculated based on the concentrations of specific ions and precipitation. The monthly and annual VWM concentrations were obtained as follows:

$C_{x}=\frac{\sum_{i=1}^{n}\left(C_{i}(x) \times P_{i}\right)}{\sum_{i=1}^{n} P_{i}}$,

where $C_{x}$ denotes the monthly and annual VWM concentration of the given ion; $C_{i}(x)$ is the concentration of the given ion in the precipitation $\left(\mu \mathrm{eq} \mathrm{L}^{-1}\right)$; and $P_{i}$ is the precipitation in individual sample. The monthly and annual VWM $\mathrm{pH}$ values were obtained based on the corresponding VWM concentrations of $\mathrm{H}^{+}$via Eq. (1).

The wet deposition flux of the given ion was calculated using the following Eq. (2):

$D_{\mathrm{w}}=P_{\mathrm{t}} C_{\mathrm{w}} / 100$,

where $D_{\mathrm{w}}$ is the wet deposition flux of the given ion $\left(\mathrm{kg} \mathrm{Nha}^{-1}\right) ; P_{\mathrm{t}}$ is the total number of precipitation events $(\mathrm{mm}) ; C_{\mathrm{w}}$ is the VWM concentration of each ion $\left(\mathrm{mg} \mathrm{L}^{-1}\right)$; and 100 is a unit conversion factor.

In order to obtain the contributions of various alkaline species to acid neutralization in the precipitation, the neutralization factor (NF) was calculated using the following Eqs. (3)-(5) (Kulshrestha et al., 1995).

$$
\begin{aligned}
\mathrm{NF}_{\mathrm{NH}_{4}^{+}} & =\frac{\mathrm{NH}_{4}^{+}}{\mathrm{NO}_{3}^{-}+\mathrm{SO}_{4}^{2-}} \\
\mathrm{NF}_{\mathrm{Ca}^{2+}} & =\frac{\mathrm{Ca}^{2+}}{\mathrm{NO}_{3}^{-}+\mathrm{SO}_{4}^{2-}} \\
\mathrm{NF}_{\mathrm{Mg}^{2+}} & =\frac{\mathrm{Mg}^{2+}}{\mathrm{NO}_{3}^{-}+\mathrm{SO}_{4}^{2-}}
\end{aligned}
$$

The enrichment factor (EF) has been widely applied to estimate the contribution ratios of the various sources to the major ions in previous studies (Lawson and Winchester, 1979; Cao et al., 2009; Lu et al., 2011). In the present study, an ion EF in the precipitation relative to the ion in the sea was calculated using $\mathrm{Na}$ as a reference element as follows:

$\mathrm{EF}_{\text {sea }}=\frac{\left(\mathbf{X} / \mathrm{Na}^{+}\right)_{\text {precipitation }}}{\left(\mathbf{X} / \mathrm{Na}^{+}\right)_{\text {sea }}}$,

where $\mathrm{EF}_{\text {sea }}$ is the enrichment indicator of a given ion in the precipitation relative to the ion in the sea; $\mathbf{X}$ is the ion in the precipitation; $\left(\mathbf{X} / \mathrm{Na}^{+}\right)_{\text {precipitation }}$ represents the ratio of components in the precipitation; and $\left(\mathbf{X} / \mathrm{Na}^{+}\right)_{\text {sea }}$ denotes the ratio of components in the sea (Keene et al., 1986; Turekian, 1968).

The EF value of an ion in the precipitation relative to the corresponding ion in the soil was calculated following Eq. (7):

$\mathrm{EF}_{\text {soil }}=\frac{\left(\mathbf{X} / \mathrm{Ca}^{2+}\right)_{\text {precipitation }}}{\left(\mathbf{X} / \mathrm{Ca}^{2+}\right)_{\text {soil }}}$,

where $\mathrm{EF}_{\text {soil }}$ represents the $\mathrm{EF}$ value of an ion in the precipitation relative to the corresponding ion in the soil; $\mathbf{X}$ denotes an ion in the precipitation; $\left(\mathbf{X} / \mathrm{Na}^{+}\right)_{\text {precipitation is the ratio of }}$ components in the precipitation; and $\left(\mathbf{X} / \mathrm{Na}^{+}\right)_{\text {sea }}$ denotes the ratio of components in the soil (Wei et al., 1991, 1992; Shi et al., 1996; Zhang et al., 2012; Chen et al., 1992).

In order to quantify the anthropogenic source versus natural source of ionic species in the precipitation, the fractions of anthropogenic, marine, and crustal sources contributing to the ions in the precipitation were calculated as follows:

$\mathrm{SSF}=\frac{\left(\mathbf{X} / \mathrm{Na}^{+}\right)_{\text {sea }}}{\left(\mathbf{X} / \mathrm{Na}^{+}\right)_{\text {precipitation }}} \times 100 \%$,
$\mathrm{CF}=\frac{\left(\mathbf{X} / \mathrm{Ca}^{2+}\right)_{\text {soil }}}{\left(\mathbf{X} / \mathrm{Ca}^{2+}\right)_{\text {precipitation }}} \times 100 \%$,
$\mathrm{AF}=100 \%-\mathrm{SSF}-\mathrm{CF}$,

where SSF represents the fraction of sea salt; CF denotes the crustal contribution; and AF denotes the anthropogenic fraction. SSF was recalculated as the difference between 1 and $\mathrm{CF}$ when SSF was greater than 1 ; CF was recalculated as the difference between 1 and SSF when CF was higher than 1 . 
Factor analysis (FA) has been widely employed to determine the contribution ratios of natural and anthropogenic sources to ionic species in the precipitation. First of all, FA was applied to reduce the dimension of original variables (measured ion concentrations in samples) and to extract a small number of principal components to analyse the relationships among the observed variables. All of the factors with eigenvalues over 1 were extracted based on the KaiserMeyer-Olkin (KMO) test and Bartlett's test of sphericity, and were rotated using the varimax method. The FA factor scores and all ion concentrations were treated as independent and dependent variables, respectively. The resultant regression coefficients were employed to convert the absolute factor scores and then to calculate the contribution of each PC source (Luo et al., 2015).

\subsection{The geographical weight regression (GWR) method}

Although the relationships between the independent variables and the dependent variables could be calculated using correlation analysis and multiple linear regression analysis (MLR), these methods cannot show the spatial variability of regression coefficients. Thus, the GWR method was applied to explore the effects of socioeconomic factors on wet deposition of inorganic ions in consideration of the spatial correlation. As an indicator to reflect the impacts of socioeconomic factors on inorganic ion depositions, local regression coefficients were obtained using weighted least squares with the following weighting function (Brunsdon et al., 1996):

$\beta\left(u_{i}, v_{i}\right)=\left(\mathbf{X}^{T} \mathbf{W}\left(u_{i}, v_{i}\right) \mathbf{X}\right)^{-1} \mathbf{X}^{T} \mathbf{W}\left(u_{i}, v_{i}\right) \mathbf{Y}$,

where $\beta\left(u_{i}, v_{i}\right)$ represented the local regression coefficient at city $i ; \mathbf{X}$ was the matrix of the influential factors; $\mathbf{Y}$ denoted the matrix of the wet deposition fluxes of the water-soluble ions; and $\mathbf{W}\left(u_{i}, v_{i}\right)$ was an $n$ order matrix in which the diagonal elements were the spatial weighting of the influential factors. The spatial weight function was calculated via the exponential distance decay form:

$\mathbf{W}\left(u_{i}, v_{i}\right)=\exp \left(-d^{2}\left(u_{i}, v_{i}\right) / b^{2}\right)$,

where $d\left(u_{i}, v_{i}\right)$ represented the distance between locations $i$ and $j$, and $b$ was the kernel bandwidth.

\subsection{Data source and statistical analysis}

The data of GDP, gross industrial production (GIP), $\mathrm{N}$ fertilizer use, vehicle ownership, and urban green space (UGS) during 2011-2016 were collected from the China City Statistical Book. Total energy consumption (TEC) during the period was obtained from the China Energy Statistical Yearbook, which consisted of the consumption of coal, crude oil, and natural gas. The daily meteorological factors including precipitation, maximum and minimum air temperature, wind speed, air pressure, and relative humidity (RH) during 20112016 were collected from the China Meteorological Data
Network. The daily visibility data during 2011-2016 were collected from the National Centers for Environmental Prediction (NCEP). The data of dust days were calculated based on the horizon visibility data. The days with visibility lower than $1 \mathrm{~km}$ were treated as dust days. The daily data of $\mathrm{PM}_{2.5}$, $\mathrm{PM}_{10}, \mathrm{SO}_{2}$, and $\mathrm{NO}_{2}$ were downloaded from the National Environmental Monitoring Platform (https://www.aqistudy. cn/historydata/, last access: 1 January 2014). These data at a national scale have been open access since January 2014. To match the meteorological data at a national scale, the data of air pollutants during 2014-2016 were applied to investigate the relationships of the water-soluble ions, meteorological factors, and air pollutants in the atmosphere (Table S2). In addition, stepwise regression (SR) analysis was employed to determine the key factors regulating the wet deposition fluxes of the water-soluble ions. All of the statistical analyses were performed by the software package of ArcGIS 10.2, SPSS 21.0, and Origin 8.0 for Windows 10 .

\section{Results and discussion}

\subsection{The $\mathrm{pH}$ and $\mathrm{EC}$ values in precipitation}

To obtain preliminary knowledge about precipitation characteristics, the basic physiochemical properties including $\mathrm{pH}$ and EC of the precipitation samples are presented in Fig. 2. The annual pH during 2011 and 2016 ranged from $5.45 \pm 0.27$ (mean \pm standard deviation) to $5.94 \pm 0.46$ and the mean value was 5.76 (Fig. 2a). Seinfeld (1986) estimated that the precipitation with $\mathrm{pH}$ lower than 5.60 was considered acid rain because the $\mathrm{pH}$ value of natural water in equilibrium with atmospheric $\mathrm{CO}_{2}$ was 5.60. However, the $\mathrm{CO}_{2}$ level has been increasing in recent years and thus the equilibrium $\mathrm{pH}$ has changed (McGlade and Ekins 2015). Therefore, the average $\mathrm{CO}_{2}$ concentration during 2011-2016 (396.83 ppm) around the world was applied to the present study (http://www.ipcc.ch/, last access: 1 June 2016). The ionization equation of $\mathrm{CO}_{2}$ includes $\mathrm{CO}_{2}+\mathrm{H}_{2} \mathrm{O}=\mathrm{H}_{2} \mathrm{CO}_{3}$ and $\mathrm{H}_{2} \mathrm{CO}_{3}=\mathrm{HCO}_{3}^{-}+\mathrm{H}^{+}$. The dissociation constants of two equations are $3.47 \times 10^{-2}\left(\mathrm{~K}_{0}\right)$ and $4.4 \times 10^{-7}\left(\mathrm{~K}_{1}\right)$, and $(\mathrm{c}(\mathrm{H}+))^{2}=\mathrm{K}_{0} \times \mathrm{K}_{1} \times \mathrm{P}_{\mathrm{CO}_{2}}=6.06 \times 10^{-12}$. Therefore, the equilibrium $\mathrm{pH}$ was 5.61, which was slightly higher than the current value $(\mathrm{pH}=5.60)$. Herein, $41 \%$ of the samples during the measurement showed a $\mathrm{pH}$ value below 5.61. Compared with the $\mathrm{pH}$ value of the precipitation during 1980 2000 (Wang and $\mathrm{Xu}, 2009$ ), the $\mathrm{pH}$ value of the precipitation showed a remarkable increase in recent years. For instance, the $\mathrm{pH}$ value in the precipitation of SWC increased from 3.5 to 4.0 (the mean value of 1980-2000) to 5.87 during 20112016. Although some cities in Hunan and Hubei provinces (e.g. Chengzhou, Ezhou) still suffered from severe acid deposition, the mean $\mathrm{pH}$ values (4.46) of the two provinces during 2011-2016 were slightly higher than those in 1980-2000 (3.5-4.0). It was well known that precipitation $\mathrm{pH}$ was asso- 

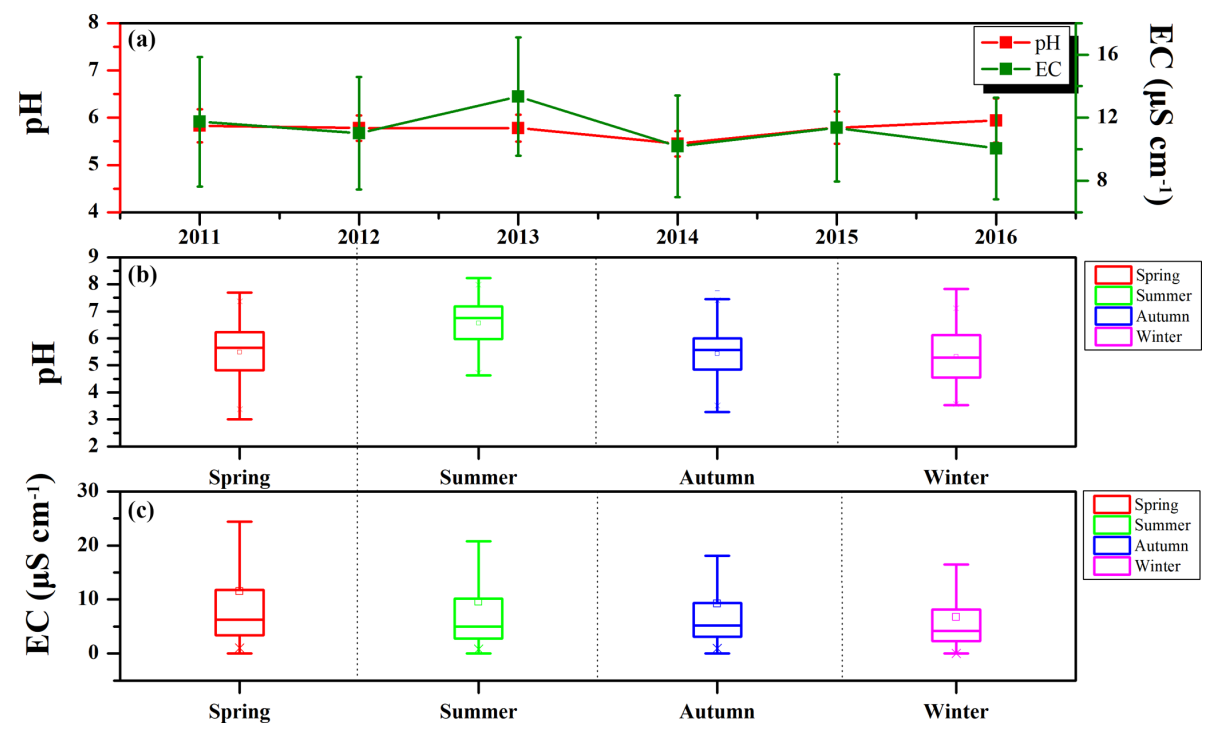

Figure 2. The inter-annual and seasonal variation in $\mathrm{pH}$ and $\mathrm{EC}$ of the precipitation in China.

ciated with the $\mathrm{SO}_{2}$ and $\mathrm{NO}_{x}$ emissions (Pu et al., 2017). Due to the implementation of $\mathrm{SO}_{2}$ control measurements since the Eleventh Five-Year Plan, the $\mathrm{SO}_{2}$ column concentration over China displayed a marked decrease after 2007 based on the Global Ozone Monitoring Experiment (GOME), reported by Gottwald and Bovensmann (2011). Based on the bottom-up method, Lu et al. (2010) also supposed that $\mathrm{SO}_{2}$ emission has begun to decrease since 2007, in good agreement with the results obtained from remote sensing. In addition, nearly all of the newly built power plants and the in-use plants have been required to be equipped with advanced selective catalytic reduction (SCR) or selective non-catalytic reduction (SNCR) since 2010 (Tian et al., 2013; Lu et al., 2011), resulting in a gradual decrease in the $\mathrm{NO}_{x}$ emission after 2010 (China Statistical Yearbook, http://data.stats.gov.cn/easyquery.htm? $\mathrm{cn}=\mathrm{C} 01$, last access: 1 January 2010). Based on the results of correlation analysis (Table S2), the $\mathrm{pH}$ value showed a significantly negative correlation with $\mathrm{SO}_{2}$ and $\mathrm{NO}_{2}$ in the ambient air, especially with the increased RH. Thus, it could be proposed that the $\mathrm{pH}$ value of the precipitation in most of the regions of China during 2011 and 2016 was significantly higher than before 2000 because the $\mathrm{SO}_{2}$ and $\mathrm{NO}_{x}$ emissions during 2011-2016 were lower than those before 2000.

The $\mathrm{pH}$ value in the precipitation at a national scale exhibited significantly seasonal variation with the highest value in summer (6.57), followed by autumn (5.64), spring (5.49), and the lowest value in winter (5.32) (Fig. 2b). The seasonal variation in $\mathrm{pH}$ values in wet deposition was supposed to be linked with the washout effect of precipitation on atmospheric particular matters (Xing et al., 2017), which was supported by the positive relevance between $\mathrm{pH}$ and precipitation $(p<0.01)$. In addition, scavenging atmospheric $\mathrm{SO}_{2}$ by precipitation may also play an important role in the seasonal variation in the $\mathrm{pH}$ values (Wu and Han, 2015). The atmo- spheric $\mathrm{SO}_{2}$ concentration was the lowest in summer and the highest in winter. The highest atmospheric $\mathrm{SO}_{2}$ and sulfate concentrations in winter of the north part of China were partially ascribed to the intensive domestic coal combustion for heating (P. Liu et al., 2016; Liu et al., 2017).

At a spatial scale across China (Fig. 3a), the $\mathrm{pH}$ value of the precipitation presented a gradual increase from SEC to $\mathrm{NC}$ and NWC. The relatively low $\mathrm{pH}$ values in the precipitation were usually observed in YRD (i.e. Huzhou, Ningbo, and Shanghai), Hunan Province (i.e. Changde, Changsha, and Loudi), Hubei Province (i.e. Wuhan), and Jiangxi Province (i.e. Nanchang, Yichun, and Jingdezhen), but the relatively high $\mathrm{pH}$ values occurred in $\mathrm{NC}$ and NWC, especially in the Xinjiang autonomous region (i.e. Changji, Altai, Ürümqi and Aksu). Among the 320 cities, the lowest value and the highest value were located in Huzhou, (3.20, Zhejiang Province) and Altai (6.82, Xinjiang autonomous region), respectively (Fig. 3). Compared with high acidity in some cities of SEC, the acidity of the precipitation in many cities of NC could be largely neutralized by some alkaline ions because the saline-alkali soils were widely distributed in NC (Wang et al., 2014). Some cities (i.e. Ürümqi and Altay) in the Xinjiang autonomous region frequently experienced local continental dust particles, diluting the precipitation acidity (Rao et al., 2015).

The annually mean EC varied from $10.18 \pm 3.21 \mu \mathrm{S} \mathrm{cm}^{-1}$ to $13.33 \pm 3.75 \mu \mathrm{S} \mathrm{cm}^{-1}$ during the period (Fig. 2a). The EC value was mainly affected by total water-soluble ions in the precipitation and rainfall amount, which indirectly reflected the cleanliness of the precipitation and the air pollution status. The decrease in EC in recent years suggested that air pollution in China has been mitigated due to the implementation of special air pollution control measures (Wang et al., 2017; X. Yang et al., 2016). The EC value also pre- 
(a)

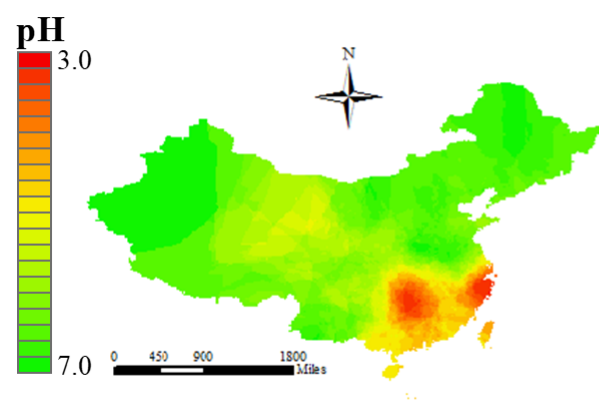

(b)

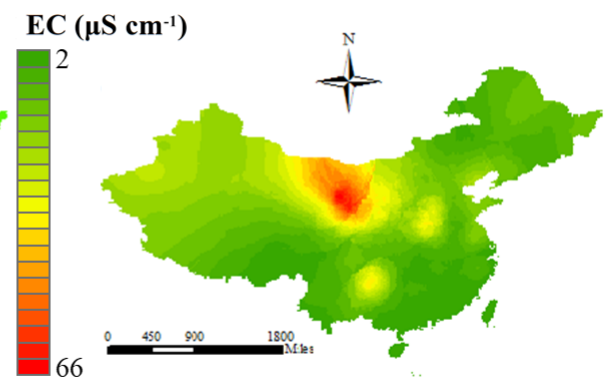

Figure 3. The spatial distribution of $\mathrm{pH}$ and $\mathrm{EC}$ of the precipitation in China.

sented distinctly seasonal variation and showed the highest value in spring (Fig. 2c), followed by ones in summer and autumn, and the lowest one in winter, which was apparently different from the seasonal $\mathrm{pH}$ variation. Among all of the inorganic ions, only $\mathrm{Ca}^{2+}$ displayed a notable relationship with EC $(p<0.01)$. It was supposed that many crustal ions such as $\mathrm{Ca}^{2+}$ could be lifted up and transported to east China by frequent dust storms in spring and summer, thereby leading to the high EC value in the precipitation ( $\mathrm{Fu}$ et al., 2014). The mean EC value exhibited a significantly spatial variation with the higher ones in Shizuishan $\left(36.60 \mu \mathrm{S} \mathrm{cm}^{-1}\right)$ and Yinchuan $\left(24.79 \mu \mathrm{S} \mathrm{cm}^{-1}\right)$ (Ningxia autonomous region), Wuwei $\left(60.01 \mu \mathrm{S} \mathrm{cm}^{-1}\right)$ (Gansu Province), Edors $\left(28.72 \mu \mathrm{S} \mathrm{cm}^{-1}\right.$ ) (Inner Mongolia autonomous region), and Aksu $\left(22.06 \mu \mathrm{S} \mathrm{cm}^{-1}\right)$ (Xinjiang autonomous region) and the lower one in some remote regions such as Lhasa $\left(3.42 \mu \mathrm{S} \mathrm{cm}^{-1}\right)$ (Tibet autonomous region), Aba (2.20 $\left.\mu \mathrm{S} \mathrm{cm}^{-1}\right)$ (Sichuan Province), and Diqing (2.46) (Yunan Province) (Fig. 3b). The lowest and highest EC values were observed in Aba $\left(2.20 \mu \mathrm{S} \mathrm{cm}^{-1}\right)$ and Wuwei $\left(60.01 \mu \mathrm{S} \mathrm{cm}^{-1}\right)$, respectively (Fig. 3). The cities in the west and north of Sichuan Province and the south of the Tibet autonomous region presented the lower EC values due to the sparse population and minimal industrial activity. Although TB has received the effects of industrial emissions and biomass burning from South Asia via a long-range atmospheric transport, most of the pollutants tended to be deposited on the south of the Himalayas except for persistent organic pollutants (POPs) (Y. Yang et al., 2016; Dong et al., 2017). The cities with higher EC were generally close to the Taklamakan and Gobi deserts. Strong winds in these deserts stirred a large amount of dust, and then caused many dust events, resulting in high loading of $\mathrm{Ca}^{2+}$ and $\mathrm{Mg}^{2+}$ (Y. Wang et al., 2016). The positive relationship between wind speed and EC also revealed that strong wind promoted the accumulation of crustal ions over China (Table S2).

\subsection{Chemical composition in precipitation}

\subsubsection{Inter-annual variation in the water-soluble ions}

The inter-annual variation in the ionic constitutes of the precipitation in China during 2011-2016 is summarized in Fig. 4. The concentrations of $\mathrm{Na}^{+}, \mathrm{NO}_{3}^{-}$, and $\mathrm{SO}_{4}^{2-}$ increased from $7.26 \pm 2.51,11.56 \pm 3.71$, and $33.73 \pm 7.59 \mu \mathrm{eq} \mathrm{L}^{-1}$ to $11.04 \pm 4.64,13.59 \pm 2.63$, and $41.95 \pm 8.64 \mu \mathrm{eq} \mathrm{L}^{-1}$ during 2011 and 2014, respectively (Fig. 4a). However, $\mathrm{Na}^{+}$, $\mathrm{NO}_{3}^{-}$, and $\mathrm{SO}_{4}^{2-}$ concentrations decreased from the highest in 2014 to $9.75 \pm 2.89,12.29 \pm 4.02$, and $30.57 \pm 7.43 \mu \mathrm{eq} \mathrm{L}-1$ in 2016. The concentrations of $\mathrm{Ca}^{2+}, \mathrm{NH}_{4}^{+}$, and $\mathrm{Mg}^{2+}$ increased from $31.59 \pm 8.29,14.84 \pm 4.63$, and $8.77 \pm 2.42$ to $58.84 \pm 10.31,41.33 \pm 10.26$, and $10.49 \pm 3.07$ during $2011-$ 2013 (Fig. 4a), whereas they decreased from the peak values in 2013 to $31.20 \pm 8.48,18.13 \pm 4.84$, and $8.93 \pm 2.92 \mu \mathrm{eq} \mathrm{L}^{-1}$ in 2016, respectively. The $\mathrm{F}^{-}$concentration exhibited a gradual decrease from 3.63 to $2.96 \mu \mathrm{eq} \mathrm{L}^{-1}$ during 2012-2016. However, the $\mathrm{K}^{+}$and $\mathrm{Cl}^{-}$concentration fluctuated during 2011 and 2016 and did not regularly display annual variation.

It was well documented that the $\mathrm{SO}_{4}^{2-}$ concentration was closely associated with the $\mathrm{SO}_{2}$ emissions because $\mathrm{SO}_{2}$ in the ambient air could be transformed into $\mathrm{SO}_{4}^{2-}$ during ageing in the atmosphere (Qiao et al., 2015). In the present study, $\mathrm{SO}_{4}^{2-}$ in the precipitation exhibited a marked correlation with $\mathrm{SO}_{2}$ in the ambient air $(p<0.01)$, especially with the increased $\mathrm{RH}$ (Table S2). The total $\mathrm{SO}_{2}$ emissions in China decreased dramatically due to the installation of flue gas desulfurization (FGD) systems and the closure of less efficient power plants in China since 2012 (R. Li et al., 2017a). At a national scale, the remarkable decrease in the $\mathrm{SO}_{4}^{2-}$ concentration has been observed since 2014, which lagged behind the decrease in $\mathrm{SO}_{2}$ emissions. Such a scenario was widely observed in some developed countries such as Japan (Okuda et al., 2005). However, some cities (i.e. Beijing and Baoding) in NC have shown notable decreases since 2012, which correspond to the decrease in total $\mathrm{SO}_{2}$ emission. It was sup- 


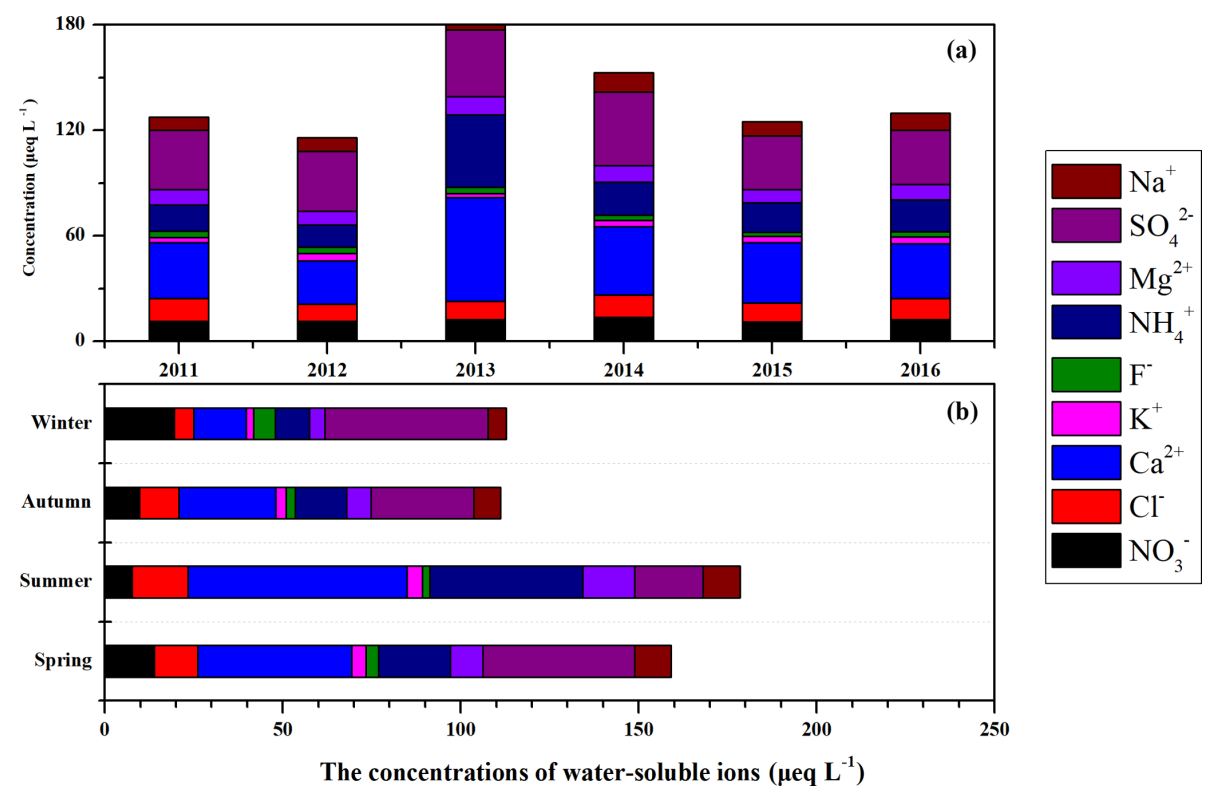

Figure 4. The temporal variation in water-soluble ions in precipitation.

posed that the electrostatic precipitators (ESP) and fabric filters (FFs) for sulfate removal were more widely applied to steel and iron plants and the cement production process, both of which were widely distributed in NC (Hua et al., 2016; $\mathrm{K}$. Wang et al., 2016). Moreover, coal has been gradually replaced by natural gas for domestic heating in Beijing, resulting in the less $\mathrm{SO}_{2}$ emission and thus decreasing the $\mathrm{SO}_{2}$ concentration in the ambient air (Pu et al., 2017). Based on the open data downloaded from the National Environmental Monitoring Platform, the annually mean $\mathrm{SO}_{2}$ concentration in Beijing decreased from 22.0 to $9.29 \mu \mathrm{g} \mathrm{m}^{-3}$ during 20142016, in good agreement with the temporal variation in $\mathrm{SO}_{4}^{2-}$ in precipitation.

The $\mathrm{NO}_{x}$ emission decreased rapidly after upgrading oil product quality standards and import denitrification facilities and the implementing low- $\mathrm{NO}_{2}$ burner technologies ( $\mathrm{Li}$ et al., 2016; Liu et al., 2017). However, the $\mathrm{NO}_{3}^{-}$concentration in the precipitation over China only displayed a slight decrease during this period, which was in good agreement with the slight decrease in national $\mathrm{NO}_{2}$ concentration in the atmosphere (Zhan et al., 2018). It suggested that stricter controls on $\mathrm{NO}_{x}$ emissions from power plants might be counteracted by the increase in power plants and energy consumption (F. Liu et al., 2015; Wang et al., 2018). In addition, it was assumed that the high $\mathrm{NO}_{3}^{-}$in the precipitation resulted from the increase in motor vehicles (Link et al., 2017). Based on the bottom-up method, the estimated $\mathrm{NO}_{x}$ emissions from vehicle exhaust in China have linearly increased by $75 \%$ since 1998 (Wu et al., 2016). Shandong suffered from the highest vehicle emissions among all of the provinces; the $\mathrm{NO}_{x}$ released from vehicle exhaust in Shandong Province increased from 477.6 to $513.8 \mathrm{Gg}$ during 2011-2014 (Sun et al., 2016), corresponding to the annual variation in $\mathrm{NO}_{3}^{-}$in the precipitation of Jinan and Linyi. The $\mathrm{NO}_{3}^{-} / \mathrm{SO}_{4}^{2-}$ value was recognized as an important index to determine the relative importance of nitrate (mobile) vs. sulfate (stationary) emission in the atmosphere (Arimoto et al., 1996). The value of $\mathrm{NO}_{3}^{-} / \mathrm{SO}_{4}^{2-}$ at the national scale was still lower than 1 , suggesting that the contribution of sulfate to the acidity of the precipitation was still higher than that of $\mathrm{NO}_{3}^{-}$. Nevertheless, the ratio in the precipitation showed a gradual increase from 0.33 to 0.40 during this period, indicating that the precipitation type in China has evolved from sulfuric acid type to a mixed type controlled by sulfuric and nitric acid.

The $\mathrm{NH}_{4}^{+}$level in the precipitation was closely linked to the $\mathrm{NH}_{3}$ emission because $\mathrm{NH}_{3}$ tended to be neutralized to form $\left(\mathrm{NH}_{4}\right)_{2} \mathrm{SO}_{4}$ and $\mathrm{NH}_{4} \mathrm{NO}_{3}$ in the atmosphere (Zhang et al., 2016). The anthropogenic emission of $\mathrm{NH}_{3}$ was mainly derived from fertilizer use, livestock manure, vehicle exhausts, and industrial processes (Kang et al., 2016). Of these, livestock manure and synthetic fertilizer application were considered the two major sources of $\mathrm{NH}_{3}$ emissions, accounting for $80 \%-90 \%$ of total emissions (Kang et al., 2016; Xu et al., 2016). Nitrogen fertilizer consumption has decreased since 2013 (http://www.stats.gov.cn/, last access: 1 January 2013), which was in good agreement with the variation in the $\mathrm{NH}_{4}^{+}$concentration in the precipitation. Therefore, the fertilizer consumption could be treated as an important factor for the $\mathrm{NH}_{4}^{+}$level in the precipitation. However, the $\mathrm{NH}_{3}$ emission from livestock manure estimated by Kang et al. (2016) showed an opposite variation to the $\mathrm{NH}_{4}^{+}$level in the precipitation collected herein. It was probably attributed to the slight decrease in air temperature in the major cities of China during 2011-2013 because the ac- 
tual $\mathrm{NH}_{3}$ emission to the atmosphere was sensitive to air temperature (Kang et al., 2016), which has been proven by the correlation analysis (Table S2). Apart from the contribution source mentioned above, soil served as a major natural source of $\mathrm{NH}_{3}$ emissions (Sun et al., 2014). Teng et al. (2017) demonstrated that urban green space made a great contribution to the $\mathrm{NH}_{3}$ amount in the atmosphere. In the present study, the urban green space in some cities such as Lianyungang (Jiangsu Province) and Qingdao (Shandong Province) showed a marked correlation with the $\mathrm{NH}_{4}^{+}$level in wet deposition.

The long-range transport of dust aerosol was considered the major source of $\mathrm{Ca}^{2+}$ and $\mathrm{Mg}^{2+}$ in the atmosphere (Fu et al., 2014). Song et al. (2016) reported that the magnitude of dust emissions in spring generally decreased in the past decades. The dust deposition and ambient $\mathrm{PM}_{10}$ concentration in the Xinjiang autonomous region also decreased dramatically during 2000-2013 (X.-X. Zhang et al., 2017). Here, $\mathrm{Ca}^{2+}$ and $\mathrm{Mg}^{2+}$ in the wet deposition of some cities such as Aksu in the Xinjiang autonomous region decreased from 32.37 to 4.80 and from 15.80 to $4.81 \mu \mathrm{eq} \mathrm{L}^{-1}$ during 2011-2016, respectively, corresponding to the decrease in dust deposition. However, the decrease in $\mathrm{Ca}^{2+}$ and $\mathrm{Mg}^{2+}$ over China significantly lagged behind the reduction of dust deposition. It was well known that the increase in soil particles and dusts due to urbanization might induce a high level of $\mathrm{Ca}^{2+}$ and $\mathrm{Mg}^{2+}$ in the wet deposition (Lyu et al., 2016). The road mileage in China increased by $25 \%$ from 2011 to 2013 , while it only showed a slight increase $(2.52 \%)$ during 2013-2016 (http://www.stats.gov.cn/, last access: 1 July 2015). Padoan et al. (2017) also demonstrated that the resuspension of road dust generally showed the highest impact on the emission of $\mathrm{Ca}$ and $\mathrm{Mg}$ elements among non-exhaust sources (i.e. tire wear, brake wear, road dust).

Both $\mathrm{K}^{+}$and $\mathrm{Cl}^{-}$were identified as the important tracers for biomass burning and fireworks (Cheng et al., 2014). Nevertheless, the $\mathrm{K}^{+}$and $\mathrm{Cl}^{-}$concentration in the precipitation did not reflect the contribution of biomass burning because biomass burning usually occurred in dry seasons (Zhou et al., 2017b). Furthermore, the $\mathrm{K}^{+}$concentration in the precipitation showed a significant relationship with crustal ions $\left(\mathrm{Ca}^{2+}(r=0.40, p<0.01)\right.$ and $\left.\mathrm{Mg}^{2+}(r=0.49, p<0.01)\right)$ (Table S2), suggesting that other sources could play an important role in the accumulation of $\mathrm{K}^{+}$and $\mathrm{Cl}^{-}$. P. Chen et al. (2017) suggested that fugitive dust is the main source of $\mathrm{K}^{+}$when the mitigation measures were seriously implemented. The minor $\mathrm{F}^{-}$in the wet deposition served as an indicator of coal combustion because fluorine was generally released from coal combustion (Chen et al., 2013). Recently, the $\mathrm{F}^{-}$emission displayed a remarkable decrease because more coal-fired power plants were equipped with FGD and dust removal equipment (Zhao and Luo, 2017), which explained the decrease in $\mathrm{F}^{-}$in the precipitation of some industrial cities such as Baoding (3.22 to 1.65 during 2012-2016),
Shijiazhuang (3.18 to 2.73 ), and Handan (3.88 to 3.53 ) in Hebei Province. $\mathrm{Na}^{+}$generally originated from the transport of sea salt aerosols and fugitive dusts and the incineration of wastes and fossil fuels (Zhao et al., 2011). The $\mathrm{Cl}^{-} / \mathrm{Na}^{+}$values in the precipitation of some coastal cities (i.e. Lishui (1.15), Jiaxing (1.20), Dandong (1.18), Wenzhou (1.18)) were similar to the marine equivalent $\mathrm{Cl}^{-} / \mathrm{Na}^{+}$ratio (1.17) (Q. Wang et al., 2015), suggesting that $\mathrm{Na}^{+}$in the precipitation of these coastal cities might be derived from the ocean. However, the $\mathrm{Cl}^{-} / \mathrm{Na}^{+}$ratios in the precipitation of some regions far from the ocean were significantly higher than the marine equivalent $\mathrm{Cl}^{-} / \mathrm{Na}^{+}$ratio due to the contribution of coal combustion (P. Liu et al., 2016; Liu et al., 2017).

\subsubsection{Seasonal variation in inorganic ions in wet deposition}

Overall, the mean concentrations of $\mathrm{SO}_{4}^{2-}, \mathrm{NO}_{3}^{-}$, and $\mathrm{F}^{-}$ in the wet deposition were in the order of winter $\left(\mathrm{SO}_{4}^{2-}\right.$, $\mathrm{NO}_{3}^{-}$, and $\mathrm{F}^{-}: 45.74,19.44$, and $\left.6.10 \mu \mathrm{eq} \mathrm{L}^{-1}\right)>$ spring (42.61, 13.83, and $\left.3.45 \mu \mathrm{eq} \mathrm{L}^{-1}\right)>$ autumn $(28.85,9.73$, and $\left.2.67 \mu \mathrm{eq} \mathrm{L}^{-1}\right)>\operatorname{summer}\left(19.26,7.66\right.$, and $\left.2.04 \mu \mathrm{eq} \mathrm{L}^{-1}\right)$ (Fig. 4b). However, the seasonally varying inorganic ions still showed the slight difference between north China and south China. The mean concentrations of $\mathrm{SO}_{4}^{2-}, \mathrm{NO}_{3}^{-}$, and $\mathrm{F}^{-}$in the precipitation of north China were the highest in winter $\left(47.88,13.79\right.$, and $\left.5.24 \mu \mathrm{eq} \mathrm{L}^{-1}\right)$, followed by spring $\left(47.02,10.18\right.$, and $\left.3.64 \mu \mathrm{eq} \mathrm{L}^{-1}\right)$, autumn $(32.20,10.08$, and $\left.2.73 \mu \mathrm{eq} \mathrm{L}^{-1}\right)$, and summer $\left(22.75,6.29\right.$, and $\left.1.69 \mu \mathrm{eq} \mathrm{L}^{-1}\right)$. However, $\mathrm{NO}_{3}^{-}$in south China showed the highest level in spring $\left(27.66 \mu \mathrm{eq} \mathrm{L}^{-1}\right)$. It was well known that $\mathrm{SO}_{4}^{2-}$ and $\mathrm{NO}_{3}^{-}$were usually generated via the oxidation of $\mathrm{SO}_{2}$ and $\mathrm{NO}_{2}$ in the atmosphere, respectively (X. Yang et al., 2016). The combustion of fossil fuels for domestic heating in winter probably promoted the accumulation of $\mathrm{SO}_{2}$ and $\mathrm{NO}_{2}$ in the atmosphere (Liu et al., 2017; Lu et al., 2010). The cities in north China showed higher $\mathrm{SO}_{4}^{2-}$ and $\mathrm{NO}_{3}^{-}$levels in the precipitation of winter compared with those in summer, which were in agreement with the seasonal variations in $\mathrm{SO}_{2}$ and $\mathrm{NO}_{2}$ concentrations in the ambient air. This reflects that the combustion of fossil fuels for domestic heating contributed to the accumulation of $\mathrm{SO}_{4}^{2-}$ and $\mathrm{NO}_{3}^{-}$and these ions were deposited via the rainfall. Nevertheless, the acidic ions in the cities of south China were not always in agreement with those in the north because coal combustion for heating in winter was not widespread. The $\mathrm{NO}_{3}^{-}$level in south China was the highest in spring due to the effects of meteorological factors. The stagnant meteorological conditions including shallow mixing layers, high atmospheric pressure, low precipitation, and low wind speed occurred frequently in winter, thereby trapping more pollutants and elevating the concentrations of $\mathrm{SO}_{2}$ and $\mathrm{NO}_{2}$ in the atmosphere (Tai et al., 2010). In contrast, strong solar radiation and turbulent eddies from ocean in summer could promote the dis- 
persion of these pollutants (Antony Chen et al., 2001). For instance, some coastal cities such as Beihai (Guangxi autonomous region) and Haikou (Hainan Province) were generally exposed to strong solar radiation and high wind speed, which significantly decreased the $\mathrm{SO}_{4}^{2-}$ and $\mathrm{NO}_{3}^{-}$concentrations in the precipitation of summer (Beihai: $\mathrm{SO}_{4}^{2-}(6.06)$ and $\mathrm{NO}_{3}^{-}$(7.37); Haikou: $\mathrm{SO}_{4}^{2-}$ (5.33) and $\mathrm{NO}_{3}^{-}$(4.96)), whereas they usually displayed the higher value in spring due to the scarce rainfall amount. The $\mathrm{F}^{-}$concentration in the precipitation displayed the similarly seasonal variation in $\mathrm{SO}_{4}^{2-}$ and $\mathrm{NO}_{3}^{-}$, which was likely associated with the higher coal consumption for domestic heating in some industrial cities of NC, NWC, and NEC (Ding et al., 2017).

The concentrations of $\mathrm{Cl}^{-}, \mathrm{Ca}^{2+}, \mathrm{K}^{+}, \mathrm{NH}_{4}^{+}, \mathrm{Mg}^{2+}$, and $\mathrm{Na}^{+}$exhibited the highest values in summer, followed by those in spring and autumn, and the lowest values in winter. The higher concentration of $\mathrm{NH}_{4}^{+}$in the precipitation collected in summer was probably linked to agricultural activities. The widespread utilization of fertilizer in summer has been observed over China (Zhang et al., 2011; Tao et al., 2016), which could increase the $\mathrm{NH}_{3}$ emission. In addition, the $\mathrm{NH}_{3}$ emission was sensitive to the air temperature and generally increased with the temperature (Kang et al., 2016). The $\mathrm{NH}_{3}$ released from agricultural activities could transform to $\mathrm{NH}_{4}^{+}$, especially under the condition of high $\mathrm{RH}$ (Li et al., 2013). Thus, the high $\mathrm{NH}_{3}$ emission and rapid photochemical reaction contribute to the higher $\mathrm{NH}_{4}^{+}$in the precipitation in summer. However, $\mathrm{K}^{+}, \mathrm{Ca}^{2+}$, and $\mathrm{Mg}^{2+}$ displayed higher concentrations in spring and summer, which was probably related to the high loading of fugitive dusts (Y. Zhang et al., 2017). Lyu et al. (2016) demonstrated that the high temperature coupled with strong wind caused the lower water content in the road, leading to higher tendency of dust resuspension in the Wuhan summer. In the present study, these crustal ions in the precipitation also showed higher values in summer in Wuhan. The high concentration of $\mathrm{Na}^{+}$ and $\mathrm{Cl}^{-}$in spring and summer was probably attributed to the evaporation of sea salt under the condition of high air temperature (Grythe et al., 2014). It was found that $\mathrm{Na}^{+}$in summer was 5.1-10.3 times that in winter in some coastal cities such as Qingdao (5.96) (Shandong Province), Qinhuangdao (9.65) (Hebei Province), and Sanya (6.83) (Hainan Province).

\subsubsection{Spatial distribution of water-soluble ions across China}

At a spatial scale, the annual mean concentrations of $\mathrm{NO}_{3}^{-}$, $\mathrm{Cl}^{-}, \mathrm{Ca}^{2+}, \mathrm{K}^{+}, \mathrm{F}^{-}, \mathrm{NH}_{4}^{+}, \mathrm{Mg}^{2+}, \mathrm{SO}_{4}^{2-}$, and $\mathrm{Na}^{+}$ranged from 0.20 to $47.98 \mu \mathrm{eq} \mathrm{L}^{-1}$, from 0.27 to $80.86 \mu \mathrm{eq} \mathrm{L}^{-1}$, from 0.59 to $157.15 \mu \mathrm{eq} \mathrm{L} \mathrm{L}^{-1}$, from 0.15 to $23.43 \mu \mathrm{eq} \mathrm{L} \mathrm{L}^{-1}$, from 0.11 to $11.64 \mu \mathrm{eq} \mathrm{L} \mathrm{L}^{-1}$, from 0.20 to $84.24 \mu \mathrm{eq} \mathrm{L} \mathrm{L}^{-1}$, from 0.28 to $39.30 \mu \mathrm{eq} \mathrm{L}^{-1}$, from 0.29 to $191.95 \mu \mathrm{eq} \mathrm{L} \mathrm{L}^{-1}$, and from 0.15 to $39.50 \mu \mathrm{eq} \mathrm{L}^{-1}$ during 2011-2016, respec- tively. All of these water-soluble ions displayed significant spatial variation, as shown in Figs. 5 and 6.

The mean concentrations of the secondary ions $\left(\mathrm{NO}_{3}^{-}\right.$, $\mathrm{NH}_{4}^{+}$, and $\mathrm{SO}_{4}^{2-}$ ) showed the highest values in YRD (Changzhou (34.53, 73.40, and $80.47 \mu \mathrm{eqL} \mathrm{L}^{-1}$ ) (Fig. 5ac) and Nanjing $\left(35.62,17.12\right.$, and $\left.49.51 \mu \mathrm{eq} \mathrm{L}^{-1}\right)$ and $\mathrm{SB}$ (Chengdu (38.08, 65.19, and $57.16 \mu \mathrm{eq} \mathrm{L}^{-1}$ ) and Leshan $\left(25.32,38.99\right.$, and $\left.61.24 \mu \mathrm{eq} \mathrm{L}^{-1}\right)$ ), followed by values in NC (Jinan $\left(11.67,16.57\right.$, and $\left.58.28 \mu \mathrm{eq} \mathrm{L}^{-1}\right)$ and Anyang (20.46, 41.32, and $22.01 \mu \mathrm{eq} \mathrm{L}^{-1}$ ), and the lowest values in TB $\left(0.50,0.91\right.$, and $\left.1.44 \mu \mathrm{eq} \mathrm{L}^{-1}\right)$ (Lhasa). Many secondary ions exhibited high concentrations in YRD because of intensive energy consumption and industrial activities (Zhou et al., 2017a). For instance, the total energy consumption of the Jiangsu Province was second to Hebei Province among all of the provinces in China (Wang, 2014). The $\mathrm{SO}_{2}$ and $\mathrm{NO}_{x}$ emissions from cement plants and iron and steel industries in Jiangsu and Zhejiang provinces were significantly higher than those in other provinces (Hua et al., 2016; K. Wang et al., 2016), which was coincident with the spatial agglomeration of the $\mathrm{SO}_{2}$ and $\mathrm{NO}_{2}$ concentrations in the ambient air of these provinces. It has been reported that the acid deposition pattern has moved from SWC to SEC since the 2000s (H. Yu et al., 2017). However, SB still possessed high concentrations of secondary ions in the precipitation because of high $\mathrm{S}$ content in the local consumed coals (Ren et al., 2006). In addition, the unique topographic conditions and unfavourable diffusion conditions facilitated the deposition of regionally transported pollutants stuck by the Qin Mountains and Daba Mountains (Kuang et al., 2016), although the energy consumption of Sichuan Province was much less than that in other provinces (Tian et al., 2013). Moreover, the steady increase in use of fertilizer and livestock manure coupled with high air temperature made $\mathrm{SB}$ one of the $\mathrm{NH}_{3}$ emission hotspots (L. Li et al., 2017). Nevertheless, some remote areas in NWC and SWC such as Lhasa and Aba showed lower secondary ions due to sparse population and anthropogenic activities (Li et al., 2007). In these regions, these secondary ions were mainly derived from a crustal source, and then deposited concurrently in rainfall events (Niu et al., 2014). In addition, relatively extensive anthropogenic activities such as increased vehicle exhaust might promote the emissions of secondary ions in the tourist season (Qiao et al., 2017). For instance, the number of tourists in Lhasa has been increasing to 11 million until 2015 (http://www.xinhuanet.com/fortune/ 2016-01/13/c_1117763885.htm, last access: 1 April 2015), which could boost the slight increase in secondary ions in the wet deposition.

$\mathrm{F}^{-}$showed the higher concentrations in $\mathrm{NC}$, YRD, and SB because many coal-fired power plants and iron and steel industries were mainly concentrated in Hebei and Jiangsu provinces (F. Liu et al., 2015) (Fig. 6a). In addition, Hebei and Jiangsu were two provinces with much higher coal consumption ( $\mathrm{R}$. Li et al., 2017b), which could release large 

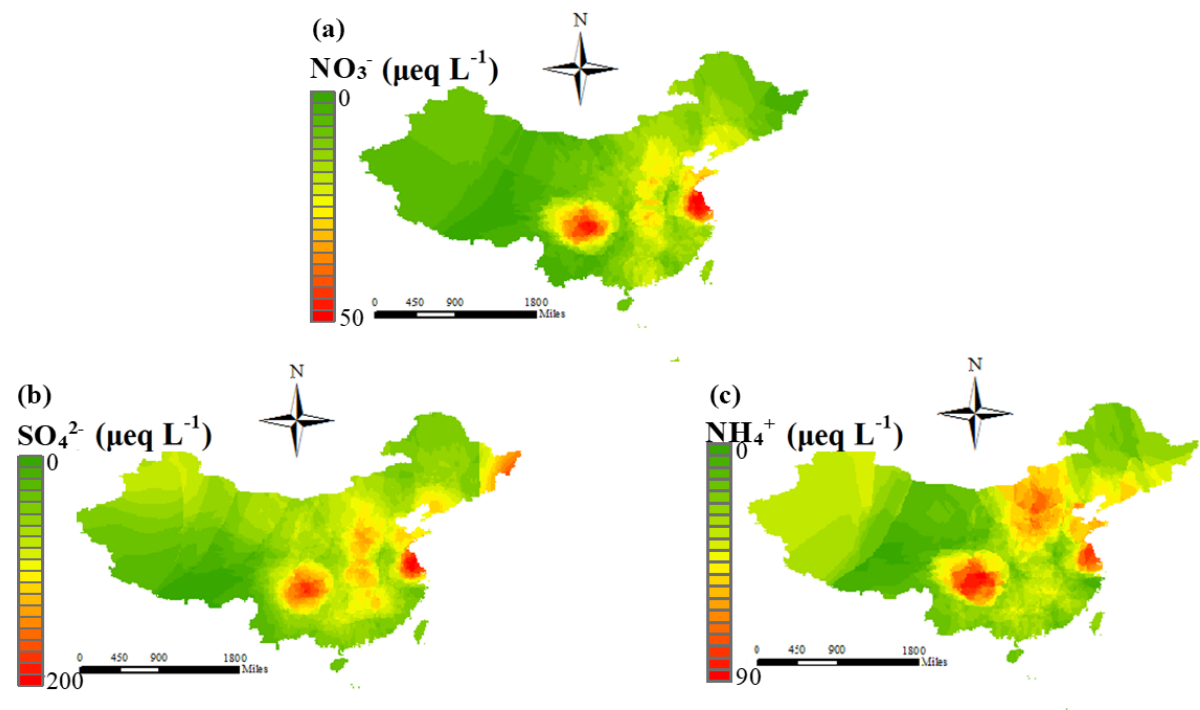

Figure 5. The spatial variation in $\mathrm{NO}_{3}^{-}, \mathrm{NH}_{4}^{+}$, and $\mathrm{SO}_{4}^{2-}$ in precipitation.

(a)
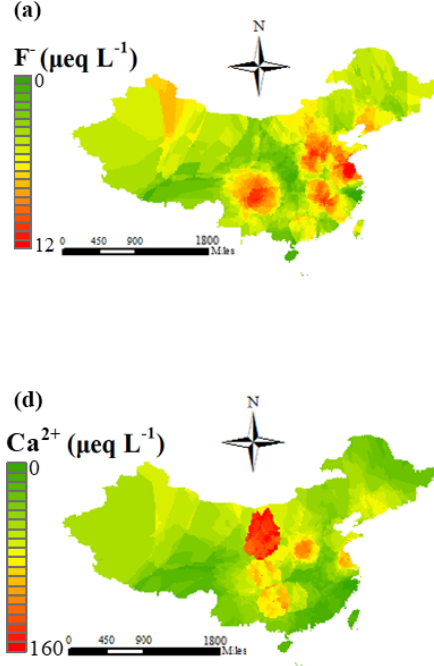

(b)

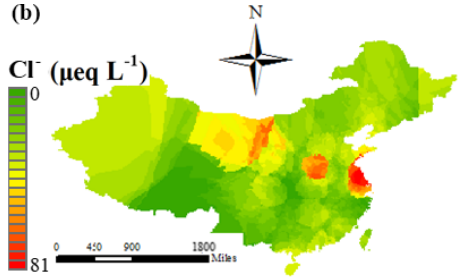

(e)

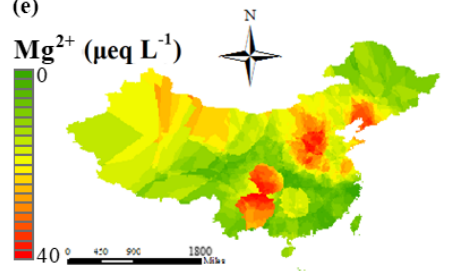

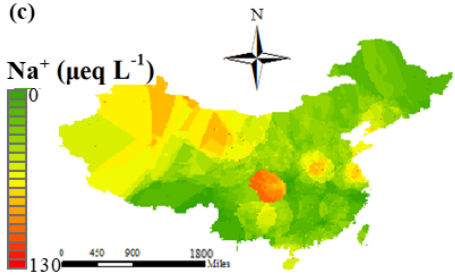

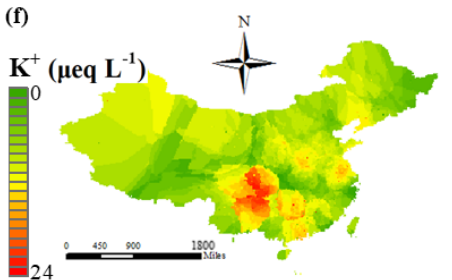

Figure 6. The spatial distribution of $\mathrm{Ca}^{2+}, \mathrm{Cl}^{-}, \mathrm{F}^{-}, \mathrm{K}^{+}, \mathrm{Mg}^{2+}$, and $\mathrm{Na}^{+}$in precipitation.

quantities of $\mathrm{F}^{-}$to the atmosphere. Although the power plants and iron and steel industries were relatively scarce in SB, many large phosphorite mines might increase the $\mathrm{F}^{-}$concentration in the precipitation (Wu et al., 2014). As one of the largest phosphorite mines over China, Jinhe phosphorite mine was close to Chengdu, which significantly increased the $\mathrm{F}^{-}$concentration in the precipitation of Chengdu $\left(9.21 \mu \mathrm{eq} \mathrm{L}^{-1}\right)$. Moreover, the high abundance of $\mathrm{F}^{-}$in the local coal (Mianyang: 269.25 $\mu \mathrm{g} \mathrm{g}^{-1}$, Guang'an: $1061 \mu \mathrm{g} \mathrm{g}^{-1}$ ) also contributed to the $\mathrm{F}^{-}$emissions (Dai and Ren, 2006; S. Wang et al., 2016; Ren et al., 2006). In addition, the $\mathrm{F}^{-}$in the precipitation showed remarkable relevance with $T_{\max }$ based on the correlation analysis $(r=0.12$, $p<0.05)$. The annually mean air temperature in SB $\left(17.2^{\circ}\right)$ was slightly higher than that in Hebei $\left(14.3^{\circ}\right)$ and Jiangsu $\left(16.4^{\circ}\right)$ provinces, thereby boosting the $\mathrm{F}^{-}$emission.

The high concentrations of $\mathrm{Cl}^{-}$were mainly concentrated on coastal cities such as Shanghai, Lianyungang (Jiangsu Province), and Qingdao (Shandong Province) (Fig. 6b), indicating the effect of sea salt sourced from the ocean $(\mathrm{Gu}$ et al., 2011; Allen et al., 2015; Grythe et al., 2014). The high $\mathrm{Na}^{+}$concentration not only focused on these coastal cities (Fig. 6c), but was also enriched in some arid and semi-arid cities such as Jinchang $\left(35.08 \mu \mathrm{eq} \mathrm{L}^{-1}\right)$ and Gannan $\left(25.51 \mu \mathrm{eq} \mathrm{L}^{-1}\right)$ (Gansu Province). It was assumed that windblown dust originating from Taklimakan Desert could 
play a vital role in the enrichment of $\mathrm{Na}^{+}$in Inner Mongolia and Hexi corridor because these regions were located in the downwind direction of dust (Engelbrecht et al., 2016). Meanwhile, the evaporation of salt lakes in west China might promote $\mathrm{Na}^{+}$enrichment in the precipitation (Bian et al., 2017). In addition, the dust event also promoted the elevation of $\mathrm{Ca}^{2+}$, especially in Jiayuguan and Guyuan (Gansu Province) (Fig. 6d), both of which were located in the Hexi corridor (Allen et al., 2015). $\mathrm{Mg}^{2+}$ presented a higher value in some cities (Handan: $36.63 \mu \mathrm{eq} \mathrm{L}^{-1}$, Liupanshui: $39.30 \mu \mathrm{eq} \mathrm{L}^{-1}$ ) in Hebei Province and Guizhou Province (Fig. 6e). The soil in Guizhou Province possessed the highest $\mathrm{Mg}$ concentration (843.33 mg kg${ }^{-1}$ ) in China (Li et al., 1992), where the $\mathrm{Mg}^{2+}$ stored in the soils could be lifted into the atmosphere by strong wind coupled with severe stony desertification (Jiang et al., 2014). Although the Mg concentration in the soil of Hebei Province was slightly lower compared with that of Guizhou Province, the bioavailable Mg concentration peaked in Hebei Province (Hao et al., 2016), but could be inclined to resuspend into the atmosphere and then deposit with the rainfall in the warm season.

\subsubsection{Neutralization capacity of alkaline ions}

In order to reveal the most important ion for neutralization $\left(\mathrm{Ca}^{2+}, \mathrm{NH}_{4}^{+}\right.$, and $\left.\mathrm{Mg}^{2+}\right)$ in the precipitation, the relative proportion of three NFs in all of the cities is summarized in Fig. 7. The triangular diagram showed that the contribution of the three ions was in the order of $\mathrm{Ca}^{2+}(51.84 \%)>\mathrm{NH}_{4}^{+}$ $(34.14 \%)>\mathrm{Mg}^{2+}(14.02 \%)$. The $\mathrm{NF}$ ratios of $\mathrm{NH}_{4}^{+}$and $\mathrm{Ca}^{2+}$ in China displayed the highest values in summer, followed by spring and autumn, and the lowest value in winter (Fig. 7a). It was supposed that strong acid neutralization was mainly brought about by the alkaline ions via high rainfall. In addition, the neutralization capacity of the alkaline ions was higher in spring due to the effects of dust events (X. Wang et al., 2015). In the present study, the $\mathrm{NFs}$ of $\mathrm{NH}_{4}^{+}$and $\mathrm{Ca}^{2+}$ in Beijing $\left(\mathrm{NH}_{4}^{+}: 0.57, \mathrm{Ca}^{2+}: 0.17\right)$ and Baoding $\left(\mathrm{NH}_{4}^{+}: 0.56\right.$, $\left.\mathrm{Ca}^{2+}: 0.19\right)$ showed markedly higher values in spring. Zhai and $\mathrm{Li} \mathrm{(2003)}$ also observed that most frequent dust storms generally occurred in NC in spring. However, the NFs of $\mathrm{Mg}^{2+}(0.70)$ showed the highest value in winter. Aside from the temporal difference of neutralization, the NFs presented a significant spatial variation in China (Fig. 7b). The high NFs of $\mathrm{Ca}^{2+}$ were mainly concentrated on some cities in NWC such as Bayingolin (0.57) because these arid and semi-arid regions were exposed to periodic Asian dust intrusions ( $\mathrm{Y}$. Yu et al., 2017). In the case of the typical dust events, the content of crustal species such as $\mathrm{Ca}$ increased substantially (Chen et al., 2015). Compared with the other regions, the NFs of $\mathrm{NH}_{4}^{+}$showed the higher values in some cities of SWC such as Chengdu (0.55). Kang et al. (2016) demonstrated that the $\mathrm{NH}_{3}$ emissions in Sichuan Province were significantly higher than those in other provinces of China, accounting for more than $10 \%$ of the total emission from livestock manure. The
NFs of $\mathrm{Mg}^{2+}$ peaked in $\mathrm{NC}$, which was in good agreement with the higher concentration of $\mathrm{Mg}^{2+}$ in the wet deposition of NC. The higher concentration of bioavailable $\mathrm{Mg}^{2+}$ in the soil was beneficial to increase the neutralization capacity of $\mathrm{Mg}^{2+}$ in the wet deposition (Hao et al., 2016), although the $\mathrm{SO}_{2}$ and $\mathrm{NO}_{2}$ emissions in $\mathrm{NC}$ were significantly higher than those in other regions (Fu et al., 2016).

\subsection{Comparisons of $\mathrm{pH}, \mathrm{EC}$, and inorganic ion concentrations with previous studies}

The annual mean $\mathrm{pH}, \mathrm{EC}$, and inorganic ion levels in the precipitation of some metropolitan areas across China are summarized in Table 1. The mean $\mathrm{pH}$ values of most cities in SEC and SWC (i.e. Shanghai: 4.39 and Wuhan: 4.68) were lower than those in some remote areas such as Jiuzhaigou (5.95) and Yulong mountain (5.94) (Qiao et al., 2018; Niu et al., 2014), while the average $\mathrm{pH}$ values of some cities in $\mathrm{NC}$ and NWC such as Zhengzhou (6.09) and Ürümqi (6.13) were slightly higher than those in remote areas. It was assumed that the remote areas were less affected by anthropogenic sources except local tourist activities, while high aerosol emissions were mainly centred on some metropolitan areas of SEC and SWC. The $\mathrm{pH}$ of the precipitation in Zhengzhou ( $\mathrm{pH}=6.09)$ (Henan Province) and Ürümqi $(\mathrm{pH}=6.13$ ) (Xinjiang autonomous region) showed high values compared with some remote regions because of the strong neutralization capacity of alkaline ions (Wang et al., 2014). In addition, the $\mathrm{pH}$ values in the wet deposition of most metropolitan areas in China were also lower than those in some developing countries (e.g. Guaíba: 5.92, Petra: 6.80) (Table 1). It was supposed that $\mathrm{SO}_{2}$ and $\mathrm{NO}_{x}$ emitted from industrial and vehicle emissions in China could be higher than those in some countries such as Brazil and Jordan (Wu and Han, 2015). In addition, higher abundance of the neutralizing components in Jordan tended to increase $\mathrm{pH}$ of the precipitation. On the other hand, the $\mathrm{pH}$ values of the wet deposition in most cities of China were significantly higher than those in some cities of developed countries such as Sardinia $(\mathrm{pH}=5.18)$ (Italy) and Adirondack $(\mathrm{pH}=4.50)$ (United States). It was assumed that many Western countries were faced with severe acid issues due to rapid industrialization before 2002 (Sickles II and Shadwick, 2015). In addition, the annual mean rainfall amount in some cities of east China was higher than that in Sardinia and Adirondack, which could dilute the acidity of the precipitation (Tsai et al., 2011). The mean EC in the wet deposition of most cities over China was approximate to that in some remote regions (i.e. Yulong mountain, Jiuzhaigou), and some foreign cities such as Guaíba, Brazil. However, Lanzhou $\left(\mathrm{EC}=58.06 \mu \mathrm{S} \mathrm{cm}^{-1}\right)$ (Gansu Province) and Petra $\left(\mathrm{EC}=160 \mu \mathrm{S} \mathrm{cm}^{-1}\right)$ (Jordan) showed remarkably higher values than other cities, suggesting that the dust cyclones from Taklamakan and Khamaseen played vital roles in EC and chemical composition in the precipitation (Abed et al., 2009). 


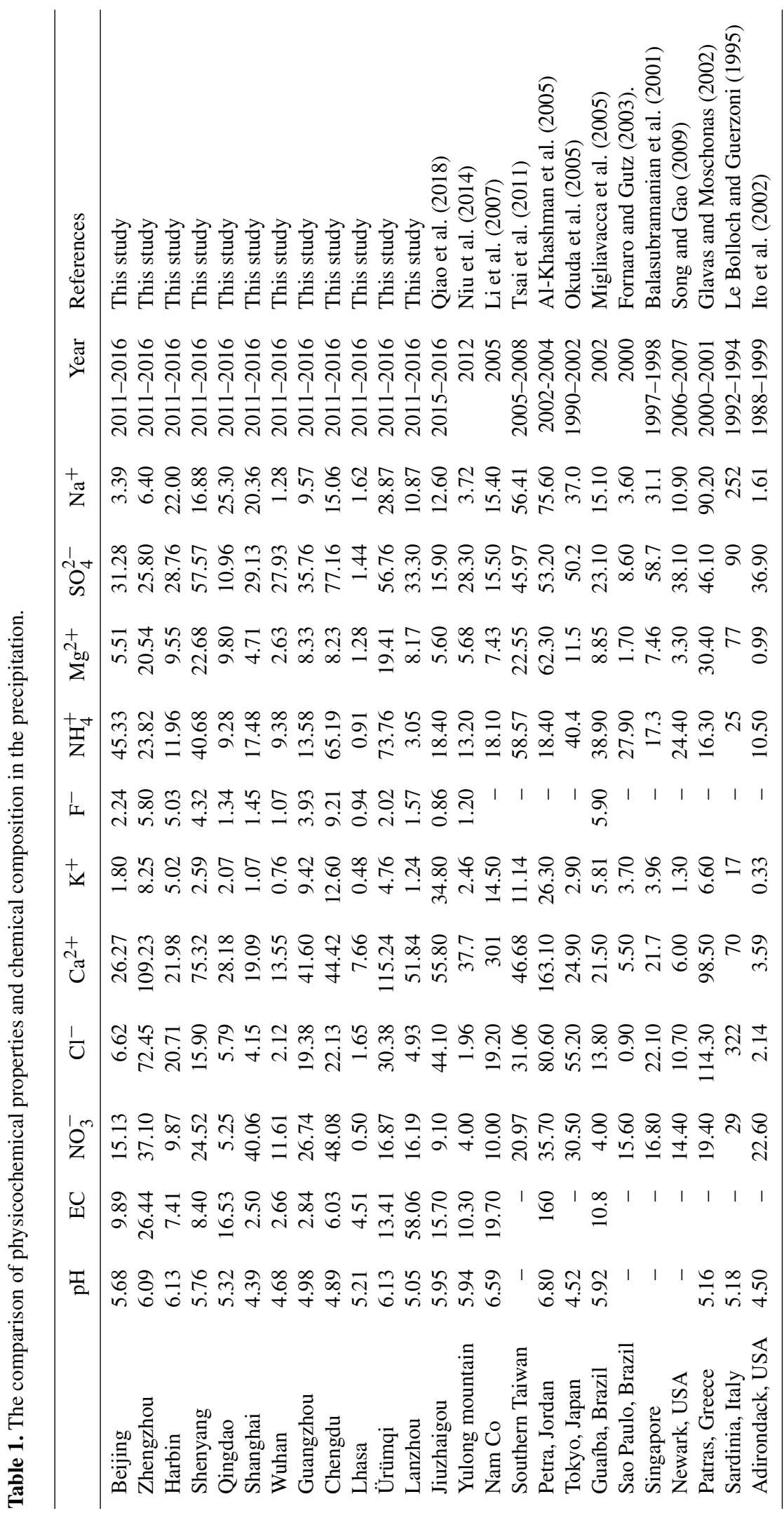


(a)

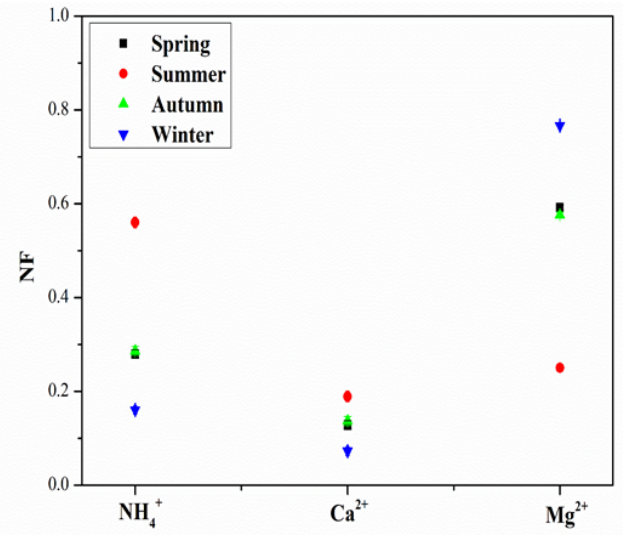

Figure 7. The triangular diagrams of NF for the main alkaline ions.

The concentrations of $\mathrm{NO}_{3}^{-}, \mathrm{SO}_{4}^{2-}$, and $\mathrm{NH}_{4}^{+}$in most cities of China except Qingdao (Shandong Province) and Lhasa (Tibet autonomous region) were significantly higher than those in some natural reserve areas such as Jiuzhaigou, Yulong mountain, and Nam Co (Qiao et al., 2018; Niu et al., 2014) (Table 1), suggesting the local point and non-point emissions in these cities played important roles in the concentrations of inorganic ions in the precipitation. However, the concentrations of these inorganic ions in most cities were lower than those in foreign cities such as Singapore, Petra (Jordan), Tokyo, and Newark (United States) (Balasubramanian et al., 2001; Al-Khashman et al., 2005; Okuda et al., 2005; Song and Gao, 2009), indicating the effects of restricting emissions of air pollutants since the Chinese Twelfth Five-Year Plan (L. Liu et al., 2016). However, some cities including Shenyang (Liaoning Province) and Chengdu (Sichuan Province) were still faced with severe acid deposition. On the whole, the concentrations of the crustal ions $\left(\mathrm{Ca}^{2+}\right.$ and $\left.\mathrm{Mg}^{2+}\right)$ were in the order of the arid and semi-arid cities/regions (Nam Co, Ürümqi, Lanzhou, and Petra) $>$ the inland cities and natural reserve regions (Chengdu and $\mathrm{Yu}-$ long mountain) $>$ the coastal cities (i.e. Guaíba, Singapore, and Tokyo). Kang et al. (2016) reported that the Tibetan Plateau has been frequently affected by dust events under the condition of climate change in the past decades, which probably increased the $\mathrm{Ca}^{2+}$ and $\mathrm{Mg}^{2+}$ levels in Nam Co. However, it should be noted that some coastal cities such as Patras (Greece) and Sardinia (Italy) possessed higher $\mathrm{Ca}^{2+}$ and $\mathrm{Mg}^{2+}$ levels, which was probably attributed to the long transport of the dust from of the Sahara desert (Kabatas et al., 2014). Cabello et al. (2016) demonstrated that African air masses mostly reached some coastal cities of the Mediterranean on the basis of back-trajectory analysis.

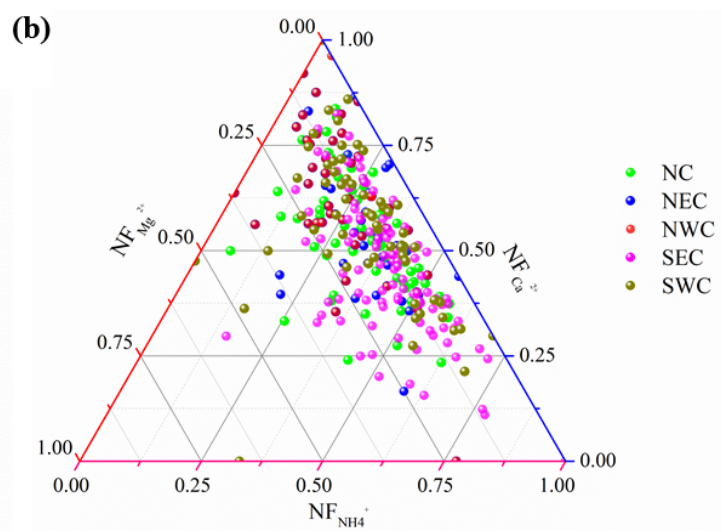

Table 2. The mean enrichment factor relative to sea and soil, and the source contribution (\%) of major ions in China (SSF denotes sea salt fraction, $\mathrm{CF}$ represents the crustal source, AF indicates the anthropogenic fraction).

\begin{tabular}{lrrrrr}
\hline & $\mathrm{EF}_{\text {sea }}$ & $\mathrm{EF}_{\text {soil }}$ & $\mathrm{SSF}$ & $\mathrm{CF}$ & $\mathrm{AF}$ \\
\hline $\mathrm{NO}_{3}^{-}$ & 3507.49 & 59.36 & 0 & 0.02 & 99.98 \\
$\mathrm{Cl}^{-}$ & 1.13 & 169.88 & 88.31 & 0.59 & 11.10 \\
$\mathrm{Ca}^{2+}$ & 231.56 & 1.00 & 0.06 & 99.94 & 0 \\
$\mathrm{~K}^{+}$ & 16.16 & 0.83 & 4.88 & 95.12 & 0 \\
$\mathrm{~F}^{-}$ & 5864.28 & 9.96 & 0.02 & 10.04 & 89.94 \\
$\mathrm{NH}_{4}^{+}$ & 10.51 & 86.31 & 0.10 & 0.01 & 99.89 \\
$\mathrm{Mg}^{2+}$ & 10.18 & 0.55 & 2.94 & 97.06 & 0 \\
$\mathrm{SO}_{4}^{2-}$ & 7.22 & 5.13 & 13.85 & 19.50 & 66.65 \\
$\mathrm{Na}^{+}$ & 1.00 & 1.83 & 64.66 & 35.34 & 0 \\
\hline
\end{tabular}

\subsection{Source apportionment of ions in precipitation across China}

\subsubsection{PEF and geochemical index method}

The mean values of EFs (seawater and soil), SSF, and CF in all of the cities are listed in Table 2. The water-soluble ion was treated to be enriched relative to the reference source when the EF value of the ion was significantly higher than 1.00 , whereas it was considered to be diluted when the EF value of the ion was not much higher than 1.00. In the present study, the mean $\mathrm{EF}_{\text {sea }}$ values for $\mathrm{Na}^{+}, \mathrm{Cl}^{-}, \mathrm{SO}_{4}^{2-}, \mathrm{NH}_{4}^{+}, \mathrm{K}^{+}$, $\mathrm{Mg}^{2+}, \mathrm{Ca}^{2+}, \mathrm{NO}_{3}^{-}$, and $\mathrm{F}^{-}$over China were $1.00,1.13,7.22$, $10.51,16.16,18.18,231.56,3507.49$, and 5864.28, suggesting that $\mathrm{Cl}^{-}$and $\mathrm{Na}^{+}$in the precipitation were enriched in the marine origin at a national scale. The mean $\mathrm{EF}_{\text {soil }}$ of $\mathrm{Mg}^{2+}, \mathrm{K}^{+}, \mathrm{Ca}^{2+}, \mathrm{Na}^{+}, \mathrm{SO}_{4}^{2-}, \mathrm{F}^{-}, \mathrm{NO}_{3}^{-}, \mathrm{NH}_{4}^{+}$, and $\mathrm{Cl}^{-}$ reached $0.55,0.83,1.00,1.83,5.13,9.96,59.36,86.31$, and 169.88 , indicating that $\mathrm{Ca}^{2+}, \mathrm{K}^{+}$, and $\mathrm{Mg}^{2+}$ originated from a crustal source. $\mathrm{EF}_{\text {sea }}$ for $\mathrm{SO}_{4}^{2-}$ and $\mathrm{NO}_{3}^{-}$showed significant spatial variability and they presented higher values in YRD 
and SB (significantly higher than 1) (Fig. 8a-b), which suggested that both of the ions were not mainly sourced from the sea source. However, $\mathrm{EF}_{\text {sea }}$ for $\mathrm{SO}_{4}^{2-}$ in some cities such as Nujiang (0.92) and Nanchong (0.81) were lower than 1. It was assumed that the Indian monsoon played an important role in the wet deposition of $\mathrm{SO}_{4}^{2-}$ ( $\mathrm{Gu}$ et al., 2016). Except $\mathrm{SO}_{4}^{2-}$ and $\mathrm{NO}_{3}^{-}, \mathrm{EF}_{\text {sea }}$ for other ions showed relatively uniform distribution at a national scale. $\mathrm{EF}_{\text {sea }}$ values for $\mathrm{NH}_{4}^{+}, \mathrm{F}^{-}, \mathrm{Ca}^{2+}, \mathrm{K}^{+}$, and $\mathrm{Mg}^{2+}$ in most of the cities were higher than 1 (Figs. 8c and S1), indicating the effects of an anthropogenic source or crustal source. The $\mathrm{EF}_{\text {sea }}$ for $\mathrm{Cl}^{-}$ presented a lower value in many coastal cities such as Beihai (0.53) and Haikou (0.52), while they were significantly higher than 1 in some inland cities such as Daqing (13.11). The spatial variability of $\mathrm{EF}_{\text {sea }}$ for $\mathrm{Cl}^{-}$confirmed the spatial difference of $\mathrm{Cl}^{-} / \mathrm{Na}^{+}$between coastal cities and inland ones mentioned above. Compared with $\mathrm{EF}_{\text {sea }}$, the $\mathrm{EF}_{\text {soil }}$ of ions generally displayed remarkable spatial variation. The $\mathrm{EF}_{\text {soil }}$ of $\mathrm{SO}_{4}^{2-}, \mathrm{NO}_{3}^{-}, \mathrm{F}^{-}$, and $\mathrm{Cl}^{-}$showed notably higher values in SEC, implicating the effects of industrial activity (Figs. 8a-b and $\mathrm{S} 2 \mathrm{a}-\mathrm{b}$ ). The $\mathrm{EF}_{\text {soil }}$ of $\mathrm{NH}_{4}^{+}$presented a markedly higher value in the eastern region of Inner Mongolia and Heilongjiang Province such as Hegang (325.69) (Fig. 8c) because intensive grazing contributed to $\mathrm{NH}_{3}$ emissions (Kobbing et al., 2014). It was interesting to note that the $\mathrm{EF}_{\text {soil }}$ of $\mathrm{Na}^{+}$showed a higher value in some cities around Qinghai Lake and the evaporation of a salt lake could contribute to the higher $\mathrm{EF}_{\text {soil }}$ of $\mathrm{Na}^{+}$(Fig. S2c). The $\mathrm{EF}_{\text {soil }}$ values of crustal ions such as $\mathrm{Mg}^{2+}$ and $\mathrm{K}^{+}$in NWC were close to 1 , reflecting the contributions of dust events and soils (Fig. S2e-f).

Based on the $\mathrm{EF}_{\text {sea }}$ and $\mathrm{EF}_{\text {soil }}$, the estimated SSF, CF, and AF of ions are depicted in Figs. 9, S3, and S4. The mean $\mathrm{SSF}$ values of $\mathrm{NO}_{3}^{-}, \mathrm{F}^{-}, \mathrm{Ca}^{2+}, \mathrm{NH}_{4}^{+}, \mathrm{Mg}^{2+}, \mathrm{K}^{+}, \mathrm{SO}_{4}^{2-}, \mathrm{Cl}^{-}$, and $\mathrm{Na}^{+}$were $0 \%, 0.02 \%, 0.06 \%, 0.10 \%, 2.94 \%, 4.88 \%$, $13.85 \%, 88.31 \%$, and $100 \%$, respectively. The average CF values of $\mathrm{NH}_{4}^{+}, \mathrm{NO}_{3}^{-}, \mathrm{Cl}^{-}, \mathrm{F}^{-}, \mathrm{SO}_{4}^{2-}, \mathrm{Na}^{+}, \mathrm{K}^{+}, \mathrm{Mg}^{2+}$, and $\mathrm{Ca}^{2+}$ reached $0.01 \%, 0.02 \%, 0.59 \%, 10.04 \%, 19.50 \%$, $35.34 \%, 95.12 \%, 97.06 \%$, and $99.94 \%$, respectively. The $\mathrm{AF}$ value was considered to be the contribution ratio of each ion except $\mathrm{SSF}$ and $\mathrm{CF}$. The $\mathrm{AF}$ values of $\mathrm{Ca}^{2+}, \mathrm{K}^{+}, \mathrm{Mg}^{2+}$, $\mathrm{Na}^{+}, \mathrm{Cl}^{-}, \mathrm{SO}_{4}^{2-}, \mathrm{F}^{-}, \mathrm{NH}_{4}^{+}$, and $\mathrm{NO}_{3}^{-}$reached $0 \%, 0 \%$, $0 \%, 0 \%, 11.10 \%, 66.65 \%, 89.94 \%, 99.89 \%$, and $99.98 \%$, respectively. The results suggested that $\mathrm{NO}_{3}^{-}, \mathrm{SO}_{4}^{2-}, \mathrm{NH}_{4}^{+}$, and $\mathrm{F}^{-}$were mainly sourced from anthropogenic activities based on minor SSF and CF. It was well documented that the combustion of fossil fuels, iron and steel industrial emissions, and vehicle exhaust were main sources of $\mathrm{SO}_{4}^{2-}$ and $\mathrm{NO}_{3}^{-}$across China (Song et al., 2006; X. Yang et al., 2016). In the present study, the $\mathrm{AF}$ values of $\mathrm{NO}_{3}^{-}$in all cities were higher than $90 \%$, and those of $\mathrm{SO}_{4}^{2-}$ in half of the cities were higher than $60 \%$. In addition, the utility of nitrogen fertilization and human and livestock excretions were treated as the main source of $\mathrm{NH}_{4}^{+}$emission over China (Cao et al., 2009).
Herein, $82.5 \%$ of cities across China showed the higher AF value of $\mathrm{NH}_{4}^{+}(>90 \%) . \mathrm{Ca}^{2+}, \mathrm{K}^{+}$, and $\mathrm{Mg}^{2+}$ were mainly derived from crustal origin based on high $\mathrm{CF}$ values. Although the $\mathrm{K}^{+}$concentration in the fine particles was usually sourced from biomass burning, the component in the coarse particles generally resulted from soil erosion and dust resuspension (Cao et al., 2009). The higher CF values of $\mathrm{K}^{+}$in most cities in China such as Aksu (Xinjiang autonomous region) and Bayin (Gansu Province) suggested that wet deposition has become the main removal mechanism for $\mathrm{K}^{+}$in coarse particles (Lim et al., 1991). The $\mathrm{Na}^{+}$and $\mathrm{Cl}^{-}$ions mainly originated from a sea source because they were the main components of sea salt and sea spray aerosol (Prather et al., 2013), which was also supported by the higher SSF value.

At a spatial scale, the highest $\mathrm{AF}$ values of $\mathrm{NO}_{3}^{-}, \mathrm{SO}_{4}^{2-}$, $\mathrm{NH}_{4}^{+}$, and $\mathrm{F}^{-}$were mainly concentrated in east China and SWC (Figs. 9a-c, S3a-c), which was similar to the spatial variation in population. The emissions of aerosols and their precursors released by human activities were mainly concentrated in east China (Fu and Chen, 2016), thereby leading to high AF values of these secondary ions. Indeed, many cities in NC such as Handan and Shijiazhuang showed the higher AF value, which revealed the effects of power plants, non-ferrous smelting, and ore mining. The SSF value of $\mathrm{Cl}^{-}$was high in Xinjiang and Qinghai provinces (i.e. Altay and Haibei), SWC (i.e. Chengdu and Guang'an) (Fig. S3de), and some coastal cities (i.e. Ningbo and Shanghai). The higher SSF values of $\mathrm{Cl}^{-}$in SWC and coastal cities of east China were mainly controlled by atmospheric transport driven by the Indian monsoon and East Asia monsoon, respectively (Gu et al., 2016). However, it was assumed that the higher SSF value of $\mathrm{Cl}^{-}$in the region close to Qinghai Lake could be linked to the evaporation of saline (Bian et al., 2017). However, the relatively higher $\mathrm{CF}$ value of $\mathrm{Cl}^{-}$ was centred on the Ningxia autonomous region and Shaanxi Province, which was frequently exposed to Aeolian dust, especially under the process of wind erosion (Lyu et al., 2017). As the typical crustal ions, $\mathrm{K}^{+}$and $\mathrm{Mg}^{2+}$ in most regions of China generally showed high $\mathrm{CF}$ values, especially in some cities of SWC (i.e. Guiyang, Zunyi, Zhaotong) (Fig. S4ad). It was supposed that the severe soil erosion and loss and rocky desertification frequently observed on the Yungui Plateau contributed to the higher $\mathrm{CF}$ value in this region (Jiang et al., 2014). The SSF of $\mathrm{K}^{+}$and $\mathrm{Mg}^{2+}$ showed high values in some coastal cities (i.e. Sanya and Ningbo) and some cities of NWC such as Haibei (Qinghai). The evaporation of salt in the East China Sea and Qinghai Lake could play a vital role in $\mathrm{K}^{+}$and $\mathrm{Mg}^{2+}$ in these areas (Bian et al., 2017).

It should be noted that the geochemical index method showed some uncertainties for the estimation of SSF, CF, and AF. First of all, the background values of $\mathrm{Na}^{+}$in the sea and $\mathrm{Ca}^{2+}$ in the soil displayed higher uncertainty, which varied significantly with the study areas. Unfortunately, the back- 

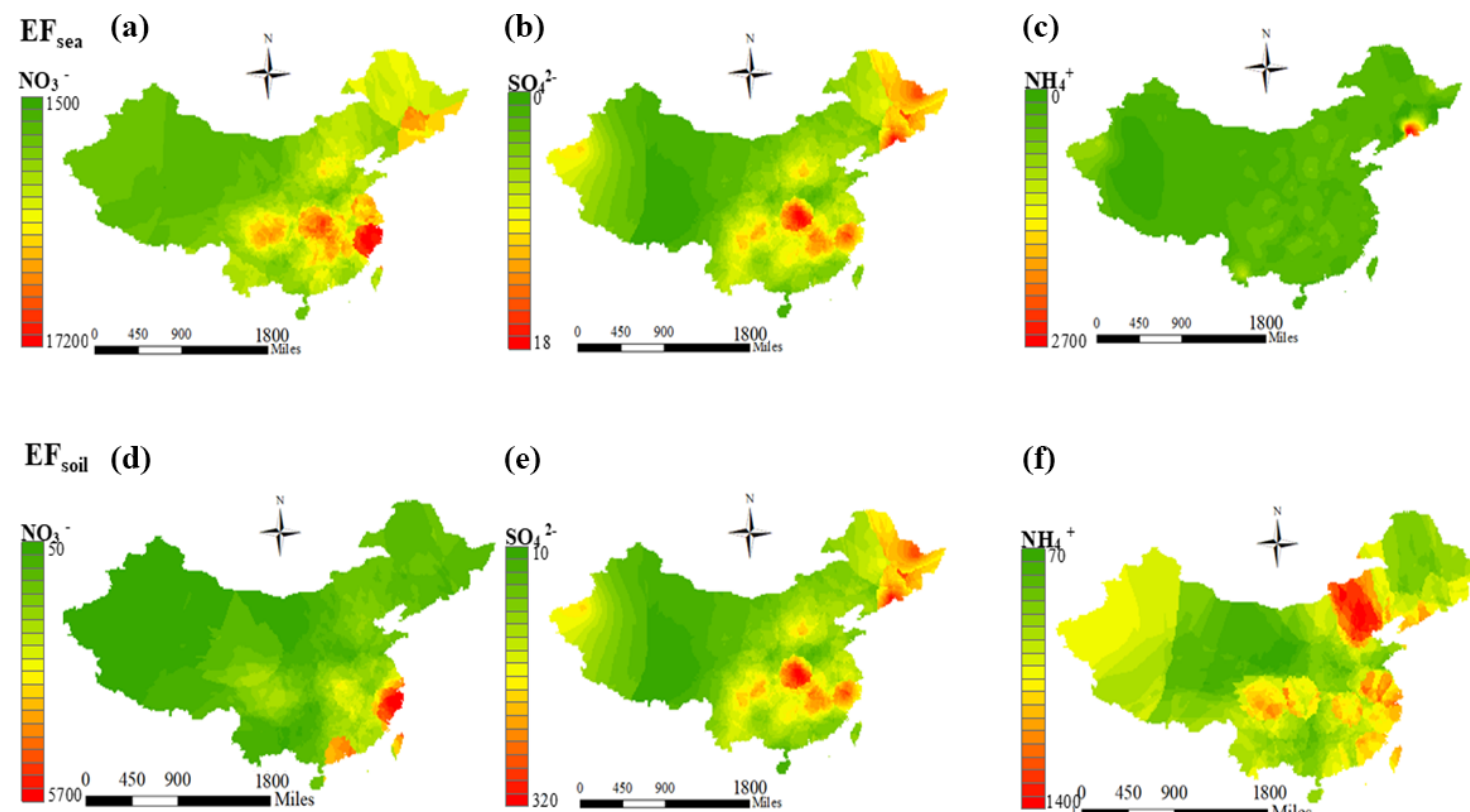

(f)

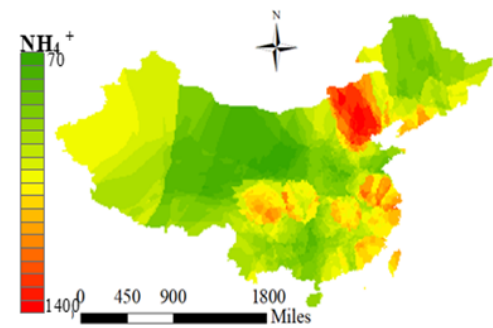

Figure 8. The $\mathrm{EF}_{\text {sea }}$ and $\mathrm{EF}_{\text {soil }}$ of $\mathrm{NO}_{3}^{-}, \mathrm{SO}_{4}^{2-}$, and $\mathrm{NH}_{4}^{+}$.
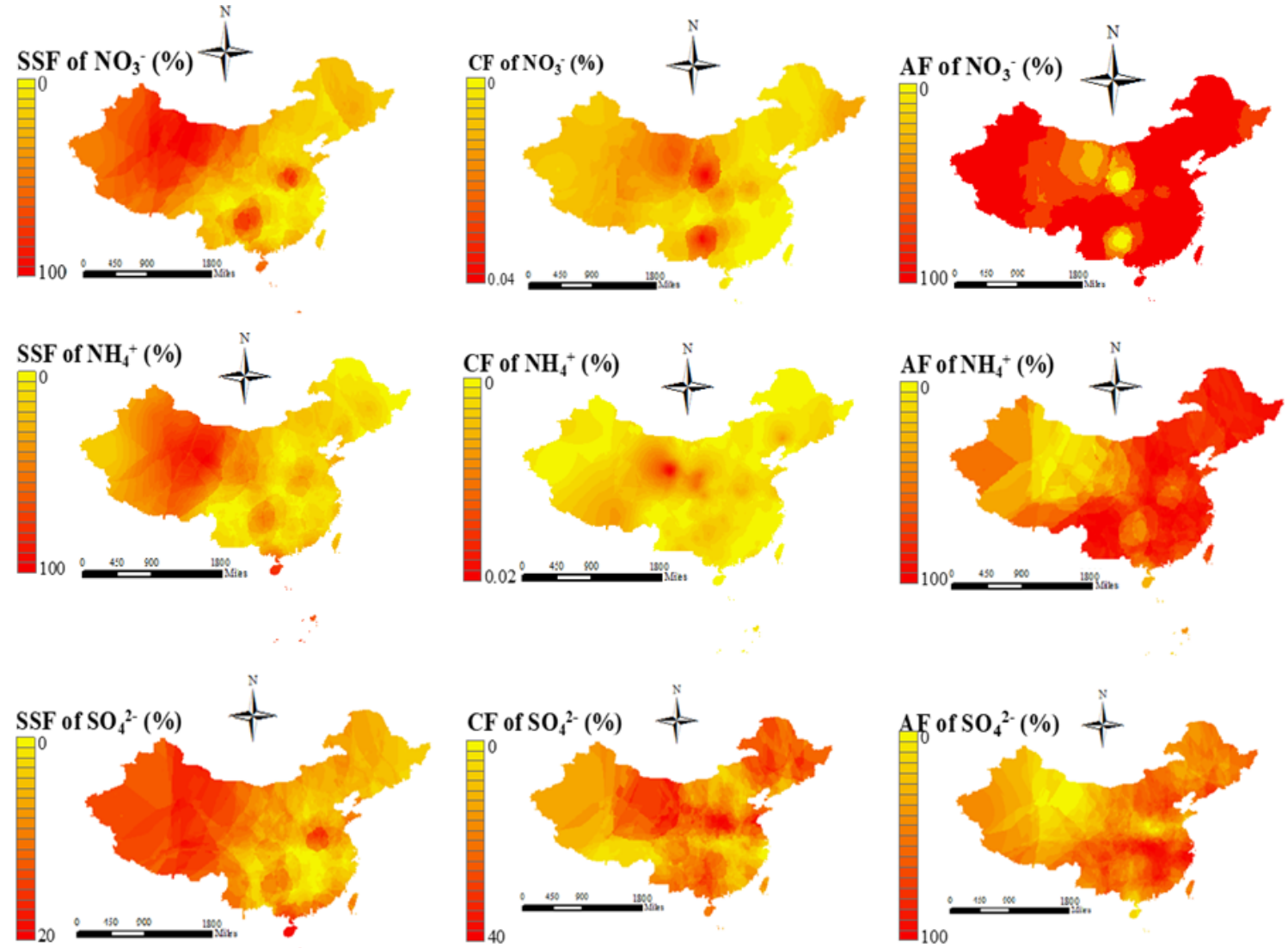

Figure 9. The spatial variation in $\mathrm{SSF}, \mathrm{CF}$, and $\mathrm{AF}$ for $\mathrm{NO}_{3}^{-}, \mathrm{NH}_{4}^{+}$, and $\mathrm{SO}_{4}^{2-}$ in precipitation. 
ground values of $\mathrm{Na}^{+}$and $\mathrm{Ca}^{2+}$ over China were absent. In addition, the source classification might be not very accurate because many other sources such as forest fire and volcanic eruption were ignored.

\subsubsection{The FA-MLR analysis}

In order to enhance the reliability of source identification, the FA method was also utilized to identify the source of chemical compositions in the precipitation. The FA results of four seasons are summarized in Table 3. Three principal components were extracted from the rainwater samples, all of which explained $85.6 \%$ of the total variance. The KaiserMeyer-Olkin indicator (0.85) was higher than 0.7, suggesting that three factors extracted in the present study were reasonable. Factor 1 grouped $\mathrm{NO}_{3}^{-}, \mathrm{F}^{-}, \mathrm{NH}_{4}^{+}$, and $\mathrm{SO}_{4}^{2-}$, accounting for $52.3 \%$ of the variance, which was generally associated with dense anthropogenic activities (Nayebare et al., 2016; X. Zhang et al., 2017). Factor 2 displayed high loadings of $\mathrm{Na}^{+}$and $\mathrm{Cl}^{-}$, indicating the effects of sea salt and sea spray aerosol (Gupta et al., 2015). The result was also in good agreement with the high SSF value of $\mathrm{Na}^{+}$and $\mathrm{Cl}^{-}$ supported by the geochemical index method. Factor 3 occupied $9.54 \%$ of the total variance and was dominated by $\mathrm{Ca}^{2+}, \mathrm{Mg}^{2+}$, and $\mathrm{K}^{+}$. The former two ions were considered to be important indicators of crustal origin or windblown dust source, and were commonly stored in soils and dusts (Kchih et al., 2015). $\mathrm{K}^{+}$was also observed in urban fugitive dusts, although it was generally considered an important fingerprint of biomass burning (Shen et al., 2016). As a whole, the result of FA was coincident with that obtained from the EF and geochemical index methods.

Although the key origins were isolated via the FA method, the contribution ratios of these sources to the water-soluble ions were still unknown. Thus, the FA-MLR method was further applied to quantify the contribution ratio of several sources to these ions in 320 cities over China (Fig. 10ad). In four seasons, the mean contributions of the anthropogenic sources $\left(\mathrm{NO}_{3}^{-}, \mathrm{SO}_{4}^{2-}, \mathrm{NH}_{4}^{+}\right.$, and $\mathrm{F}^{-}: 79.10 \%$, $46.12 \%, 82.40 \%$, and $71.02 \%$ ) were significantly higher than those of sea source $(13.76 \%, 31.71 \%, 11.09 \%$, and $11.52 \%)$ and crustal origin $(7.14 \%, 22.17 \%, 6.52 \%$, and $17.46 \%$ ) for $\mathrm{NO}_{3}^{-}, \mathrm{SO}_{4}^{2-}, \mathrm{NH}_{4}^{+}$, and $\mathrm{F}^{-}$. Nevertheless, the contribution ratio was in the order of crustal origin $\left(\mathrm{K}^{+}\right.$, $\mathrm{Ca}^{2+}$, and $\mathrm{Mg}^{2+}: 77.44 \%, 82.17 \%$, and $\left.70.51 \%\right)>$ anthropogenic source $(13.91 \%, 10.20 \%$, and $18.36 \%)>$ sea source $\left(8.65 \%, 7.64 \%\right.$, and $11.14 \%$ ) for $\mathrm{K}^{+}, \mathrm{Ca}^{2+}$, and $\mathrm{Mg}^{2+}$. The sea source was the dominant factor for the accumulation of $\mathrm{Na}^{+}$and $\mathrm{Cl}^{-}$in the rainwater, followed by the crustal origin and the anthropogenic source. In addition, the contribution ratios of three sources showed a slight variation in different seasons (Fig. 10). For instance, the contribution ratio of sea source to most inorganic ions, especially $\mathrm{Na}^{+}$and $\mathrm{Cl}^{-}$, was the highest in summer, followed by spring and autumn, and the lowest in winter because the intense evaporation of sea
Table 3. The loading matrix of precipitation in four seasons in China.

\begin{tabular}{|c|c|c|c|c|}
\hline Season & Variable & $\mathrm{F} 1$ & $\mathrm{~F} 2$ & F3 \\
\hline \multirow[t]{9}{*}{ Overall } & $\mathrm{NO}_{3}^{-}$ & 0.71 & 0.24 & 0.45 \\
\hline & $\mathrm{Cl}^{-}{ }^{3}$ & 0.43 & 0.64 & -0.12 \\
\hline & $\mathrm{Ca}^{2+}$ & 0.42 & -0.22 & 0.75 \\
\hline & $\mathrm{K}^{+}$ & 0.39 & 0.18 & 0.72 \\
\hline & $\mathrm{F}^{-}$ & 0.68 & -0.20 & 0.45 \\
\hline & $\mathrm{NH}_{4}^{+}$ & 0.74 & 0.35 & 0.13 \\
\hline & $\mathrm{Mg}^{2+}$ & -0.41 & 0.10 & 0.66 \\
\hline & $\mathrm{SO}_{4}^{2-}$ & 0.63 & 0.23 & 0.14 \\
\hline & $\mathrm{Na}^{+}$ & -0.02 & 0.65 & 0.45 \\
\hline \multirow[t]{9}{*}{ Spring } & $\mathrm{NO}_{3}^{-}$ & 0.76 & 0.11 & -0.32 \\
\hline & $\mathrm{Cl}^{-}$ & -0.33 & 0.59 & 0.26 \\
\hline & $\mathrm{Ca}^{2+}$ & 0.32 & -0.16 & 0.80 \\
\hline & $\mathrm{K}^{+}$ & -0.36 & 0.06 & 0.78 \\
\hline & $\mathrm{F}^{-}$ & 0.70 & -0.10 & 0.20 \\
\hline & $\mathrm{NH}_{4}^{+}$ & 0.68 & 0.29 & -0.46 \\
\hline & $\mathrm{Mg}^{2+}$ & -0.38 & 0.42 & 0.69 \\
\hline & $\mathrm{SO}_{4}^{2-}$ & 0.77 & 0.31 & 0.22 \\
\hline & $\mathrm{Na}^{+}$ & -0.04 & 0.72 & 0.46 \\
\hline \multirow[t]{9}{*}{ Summer } & $\mathrm{NO}_{3}^{-}$ & 0.63 & 0.24 & -0.33 \\
\hline & $\mathrm{Cl}^{-}$ & 0.42 & 0.66 & -0.38 \\
\hline & $\mathrm{Ca}^{2+}$ & 0.44 & -0.26 & 0.85 \\
\hline & $\mathrm{K}^{+}$ & -0.37 & 0.19 & 0.70 \\
\hline & $\mathrm{F}^{-}$ & 0.54 & -0.32 & 0.48 \\
\hline & $\mathrm{NH}_{4}^{+}$ & 0.59 & 0.33 & -0.47 \\
\hline & $\mathrm{Mg}^{2+}$ & 0.32 & -0.38 & 0.60 \\
\hline & $\mathrm{SO}_{4}^{2-}$ & 0.56 & 0.36 & 0.34 \\
\hline & $\mathrm{Na}^{+}$ & -0.09 & 0.75 & 0.49 \\
\hline \multirow[t]{9}{*}{ Autumn } & $\mathrm{NO}_{3}^{-}$ & 0.73 & -0.14 & 0.38 \\
\hline & $\mathrm{Cl}^{-}$ & -0.39 & 0.62 & 0.29 \\
\hline & $\mathrm{Ca}^{2+}$ & 0.32 & -0.16 & 0.80 \\
\hline & $\mathrm{K}^{+}$ & 0.45 & -0.09 & 0.68 \\
\hline & $\mathrm{F}^{-}$ & 0.68 & -0.15 & 0.28 \\
\hline & $\mathrm{NH}_{4}^{+}$ & 0.69 & 0.42 & -0.45 \\
\hline & $\mathrm{Mg}^{2+}$ & -0.29 & 0.32 & 0.71 \\
\hline & $\mathrm{SO}_{4}^{2-}$ & 0.68 & -0.29 & 0.23 \\
\hline & $\mathrm{Na}^{+}$ & -0.14 & 0.69 & -0.37 \\
\hline \multirow[t]{9}{*}{ Winter } & $\mathrm{NO}_{3}^{-}$ & 0.79 & 0.23 & -0.36 \\
\hline & $\mathrm{Cl}^{-}$ & -0.38 & 0.49 & 0.29 \\
\hline & $\mathrm{Ca}^{2+}$ & 0.39 & -0.35 & 0.65 \\
\hline & $\mathrm{K}^{+}$ & -0.39 & 0.08 & 0.72 \\
\hline & $\mathrm{F}^{-}$ & 0.75 & 0.08 & -0.24 \\
\hline & $\mathrm{NH}_{4}^{+}$ & 0.73 & 0.26 & -0.42 \\
\hline & $\mathrm{Mg}^{2+}$ & 0.35 & -0.49 & 0.75 \\
\hline & $\mathrm{SO}_{4}^{2-}$ & 0.79 & 0.22 & 0.36 \\
\hline & $\mathrm{Na}^{+}$ & -0.16 & 0.54 & 0.33 \\
\hline
\end{tabular}




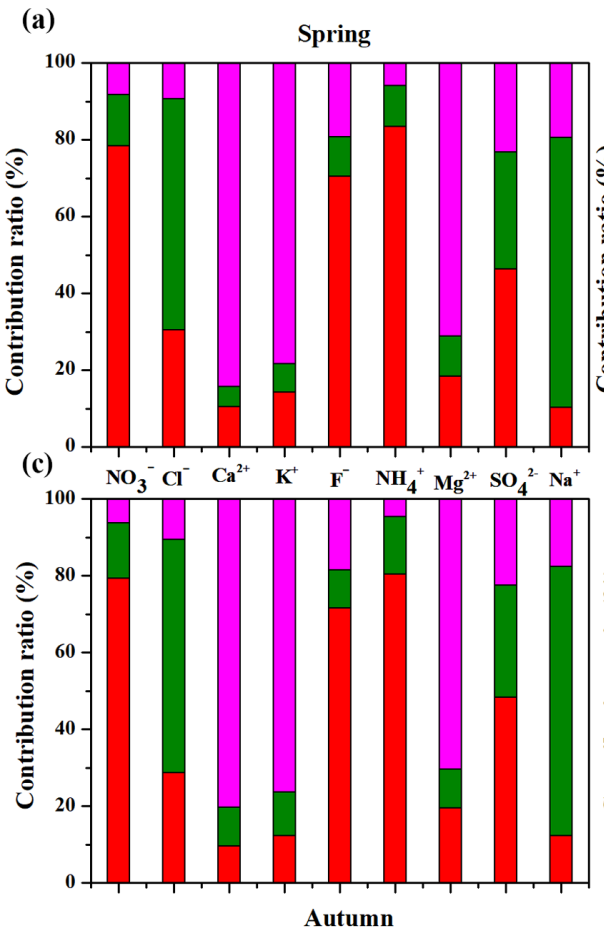

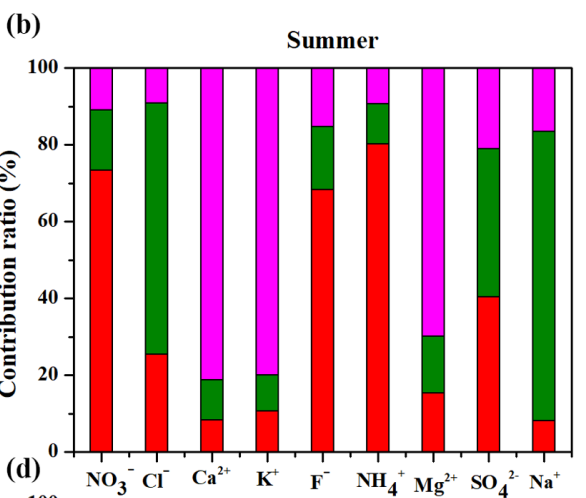

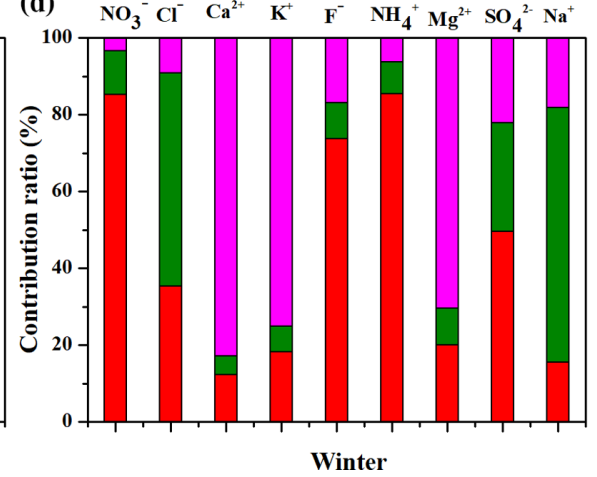

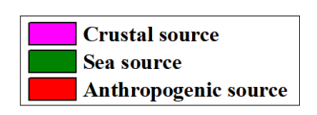

Figure 10. The seasonal difference of contribution ratios of anthropogenic sources, crustal sources, and sea sources.

salt in summer was inclined to release more ions to the atmosphere (Teinilä et al., 2014). The contribution ratio of anthropogenic activities presented a notable increase from summer to winter for $\mathrm{SO}_{4}^{2-}$ because of dense coal combustion $\left(20 \mathrm{~kg} \mathrm{coal} \mathrm{m}^{-2}\right)$ for domestic heating in winter (Zhao et al., 2016).

\subsection{The deposition flux of the water-soluble ions and their key factors}

At a national scale, the annual mean deposition fluxes of $\mathrm{NO}_{3}^{-}, \mathrm{Cl}^{-}, \mathrm{Ca}^{2+}, \mathrm{K}^{+}, \mathrm{F}^{-}, \mathrm{NH}_{4}^{+}, \mathrm{Mg}^{2+}, \mathrm{SO}_{4}^{2-}$, and $\mathrm{Na}^{+}$over China were $13.25,8.44,13.80,2.49,1.15$, 5.90, 2.27, 33.41, and $4.39 \mathrm{~kg} \mathrm{ha}^{-1} \mathrm{yr}^{-1}$ during 2011-2016. The deposition fluxes of $\mathrm{NO}_{3}^{-}, \mathrm{Ca}^{2+}, \mathrm{K}^{+}, \mathrm{NH}_{4}^{+}$, and $\mathrm{Na}^{+}$increased from 13.67 to $14.83 \mathrm{~kg} \mathrm{ha}^{-1} \mathrm{yr}^{-1}, 13.32$ to $16.99 \mathrm{~kg} \mathrm{ha}^{-1} \mathrm{yr}^{-1}, 2.47$ to $2.79 \mathrm{~kg} \mathrm{ha}^{-1} \mathrm{yr}^{-1}, 5.21$ to $6.48 \mathrm{~kg} \mathrm{ha}^{-1} \mathrm{yr}^{-1}$, and 4.17 to $5.74 \mathrm{~kg} \mathrm{ha}^{-1} \mathrm{yr}^{-1}$ from 2011 to 2013 , respectively. However, they decreased to 13.65 , $11.01,2.52,5.90$, and $3.69 \mathrm{~kg} \mathrm{ha}^{-1} \mathrm{yr}^{-1}$ in 2016 . The wet deposition fluxes of $\mathrm{F}^{-}$and $\mathrm{Mg}^{2+}$ over China decreased from 1.27 to $0.96 \mathrm{~kg} \mathrm{ha}^{-1} \mathrm{yr}^{-1}$ and 2.76 to $1.85 \mathrm{~kg} \mathrm{ha}^{-1} \mathrm{yr}^{-1}$ during 2012-2014, respectively. However, they began to increase slightly to 1.17 and 2.15 in 2016 , respectively. The wet deposition fluxes of $\mathrm{Cl}^{-}$and $\mathrm{SO}_{4}^{2-}$ showed a gradual decrease from 9.80 and $38.87 \mathrm{~kg} \mathrm{ha}^{-1} \mathrm{yr}^{-1}$ to 8.09 and $26.54 \mathrm{~kg} \mathrm{ha}^{-1} \mathrm{yr}^{-1}$ during 2011-2016, respectively. On average, the wet deposition flux of $\mathrm{NO}_{3}^{-}$was higher by a factor of 2.25 than that of $\mathrm{NH}_{4}^{+}$, which was in contrast to the re- sults of the dry deposition reported by Xu et al. (2015). All of the water-soluble ions showed the highest wet deposition fluxes in summer, followed by spring and autumn, and the lowest in winter, which was probably attributed to the high washout effect due to rain in summer (Jia et al., 2014). Based on the results of the correlation analysis, the precipitation showed a significant relationship with the deposition fluxes of the water-soluble ions $(p<0.05)$. In addition, the wet deposition fluxes of the water-soluble ions showed significant spatial variation, which was in good agreement with the spatial distribution of the water-soluble ion concentrations except for $\mathrm{Ca}^{2+}$ (Fig. S5).

In order to determine the dominant factors affecting the wet deposition fluxes of the water-soluble ions across China, GDP, GIP, TEC, $\mathrm{N}$ fertilizer use, vehicle ownership, UGS, dust days, many meteorological factors (i.e. $T_{\max }, T_{\min }$, WS), and air pollutants (i.e. $\mathrm{SO}_{2}$ and $\mathrm{NO}_{2}$ ) were introduced as the explanatory variables. The SR analysis results are depicted in Table 4. GIP, vehicle ownership, $\mathrm{NO}_{2}, T_{\min }$, and wind speed served as the key factors affecting the wet deposition of $\mathrm{NO}_{3}^{-}$at a national scale. The atmospheric emission of $\mathrm{NO}_{x}$ from coal-fired power plants was estimated at about $7489.6 \mathrm{kt}$ in 2010 , although many newly built power plants were equipped with advanced low $\mathrm{NO}_{x}$ burner (LNB) systems (Tian et al., 2013). Zhang et al. (2014) estimated that $\mathrm{NO}_{x}$ from vehicle emissions reached $4570 \mathrm{kt}$ in $2008 \mathrm{nd}$ were considered the second $\mathrm{NO}_{x}$ source only to industrial activities. The $\mathrm{NO}_{x}$ released from anthropogenic activity could 
Table 4. The results of the stepwise regression method.

\begin{tabular}{|c|c|c|c|c|c|}
\hline $\begin{array}{l}\text { Dependent } \\
\text { variables }\end{array}$ & $\begin{array}{l}\text { Independent } \\
\text { variables }\end{array}$ & $\begin{array}{r}\text { Partial regression } \\
\text { coefficients }\end{array}$ & $R^{2}$ & $t$ value & $p$ value \\
\hline $\mathrm{NO}_{3}^{-}$ & $\begin{array}{l}\text { GIP } \\
\text { Vehicle ownership } \\
\mathrm{NO}_{2} \\
T_{\text {min }} \\
\text { Wind speed }\end{array}$ & $\begin{array}{r}8.42 \times 10^{-8} \\
0.03 \\
0.34 \\
0.15 \\
-1.49\end{array}$ & 0.62 & $\begin{array}{r}4.03 \\
-2.39 \\
4.29 \\
1.34 \\
-1.69\end{array}$ & $\begin{array}{l}0.00 \\
0.01 \\
0.00 \\
0.02 \\
0.03\end{array}$ \\
\hline $\mathrm{Cl}^{-}$ & Dust days & 0.12 & 0.52 & 2.14 & 0.04 \\
\hline $\mathrm{Ca}^{2+}$ & $\begin{array}{l}\mathrm{PM}_{10} \\
\text { Dust days }\end{array}$ & $\begin{array}{r}0.36 \\
132.74\end{array}$ & 0.56 & $\begin{array}{l}3.26 \\
2.99\end{array}$ & $\begin{array}{l}0.00 \\
0.00\end{array}$ \\
\hline $\mathrm{K}^{+}$ & Dust days & 2.09 & 0.49 & 2.03 & 0.02 \\
\hline $\mathrm{F}^{-}$ & GIP & $0.54 \times 10^{-7}$ & 0.50 & 2.31 & 0.02 \\
\hline $\mathrm{NH}_{4}^{+}$ & $\begin{array}{l}\mathrm{N} \text { fertilizer use } \\
\mathrm{UGS} \\
\mathrm{NO}_{2}\end{array}$ & $\begin{array}{r}0.14 \\
1.33 \times 10^{-4} \\
0.25\end{array}$ & 0.48 & $\begin{array}{l}2.46 \\
1.79 \\
1.98\end{array}$ & $\begin{array}{l}0.02 \\
0.04 \\
0.03\end{array}$ \\
\hline $\mathrm{Mg}^{2+}$ & Dust days & 2.36 & 0.43 & 1.65 & 0.05 \\
\hline $\mathrm{SO}_{4}^{2-}$ & $\begin{array}{l}\text { TEC } \\
\mathrm{N} \text { fertilizer use }\end{array}$ & $\begin{array}{r}2.80 \times 10^{-5} \\
3.36\end{array}$ & 0.64 & $\begin{array}{l}3.07 \\
3.59\end{array}$ & $\begin{array}{l}0.00 \\
0.00\end{array}$ \\
\hline $\mathrm{Na}^{+}$ & Dust days & 2.46 & 0.46 & 1.69 & 0.04 \\
\hline
\end{tabular}

enhance $\mathrm{NO}_{2}$ concentration in ambient air, which could also be transformed to $\mathrm{NO}_{3}^{-}$via oxidation in the atmosphere, especially under conditions of high temperature and low WS (Zhang et al., 2016). The wet deposition of $\mathrm{NH}_{4}^{+}$was affected by $\mathrm{N}$ fertilizer use, UGS, and $\mathrm{NO}_{2}$ over China. Russel et al. (1998) recommended early that $\mathrm{NH}_{4}^{+}$in the precipitation was most likely derived from $\mathrm{N}$ fertilizer use via isotope techniques coupled with back trajectory analysis. In addition, Teng et al. (2017) demonstrated that the emissions from UGS were identified to contribute to the atmospheric $\mathrm{NH}_{3}$ significantly during $60 \%$ of the sampling times, which could increase the $\mathrm{NH}_{4}^{+}$concentration in the precipitation due to the photochemical reaction. The wet deposition flux of $\mathrm{SO}_{4}^{2-}$ was closely associated with TEC in 320 cities of China. It was supposed that the $\mathrm{SO}_{2}$ emissions were dependent on the use of coal and petroleum (Lu et al., 2010). While terrestrial petroleum emissions have declined in recent years, the emissions from international shipping have offset the decrease in terrestrial petroleum (Smith et al., 2011). In the present study, the deposition of some crustal ions was linked to dust days because they were mainly derived from dust storms or soil (Deshmukh et al., 2011; Zhang et al., 2011). $\mathrm{F}^{-}$deposition was associated with GIP due to the contributions of coal-fired power plant fly ash and industrial raw material (Kong et al., 2011).

The GWR method was used to calculate the local regression coefficients in order to determine the dominant factor affecting the deposition of water-soluble ions at a regional scale (Figs. 11 and S6). The mean $R^{2}$ of the GWR method was 0.50 over China, and the $p$ value was lower than 0.05 , which suggested that the GWR method could be applicable to the study. The local regression coefficient of dust days for crustal ions including $\mathrm{Ca}^{2+}, \mathrm{Cl}^{-}, \mathrm{K}^{+}$, and $\mathrm{Mg}^{2+}$ increased from SEC to NWC (Fig. S6a-e), suggesting that dust days played a significant role in the crustal ions in NWC due to high intensity of dust deposition and extremely high WS (X.-X. Zhang et al., 2017). The influence of GIP on $\mathrm{F}^{-}$ and $\mathrm{NO}_{3}^{-}$increased from west China to east China and displayed a higher value in some cities of YRD (i.e. Shanghai, Hangzhou) because many coal-fired power plants, cement plants, and municipal solid waste incineration plants are located in YRD (Hua et al., 2016; Tian et al., 2012; Tian et al., 2014) (Figs. S6f and 11a). The influence of $\mathrm{N}$ fertilizer use on $\mathrm{NH}_{4}^{+}$was concentrated on some cities of NEC such as Jiamusi (Heilongjiang Province) (Fig. 11bc), Harbin (Heilongjiang Province), and Changchun (Jilin Province) because the largest commodity grain base was located in Heilongjiang and Jilin provinces, leading to higher $\mathrm{N}$ fertilizer use (Cheng and Zhang, 2005). In contrast to the effects of GIP, the TEC influence increased gradually from SEC to NWC, and showed the highest value in the Xinjiang autonomous region (i.e. Altay) (Fig. 11d). It has been demonstrated that an inverted U-shaped curve (environment Kuznets curve) between per capita GDP and energy consumption was generally observed during the development of the economy (Song et al., 2013; Yang et al., 2017). The en- 
(a)

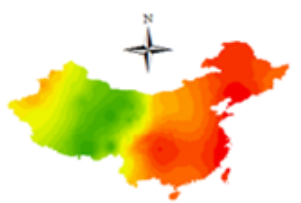

(b)
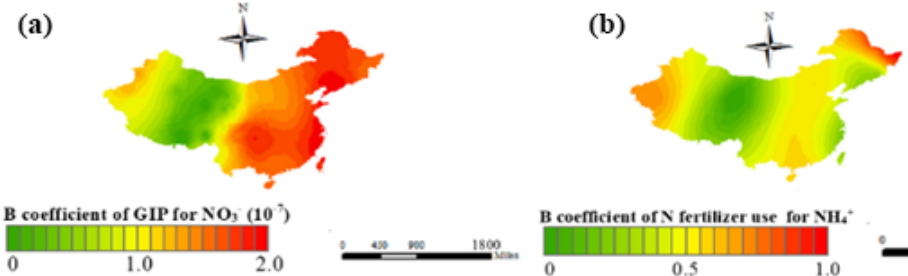

B coefficieat of $\mathrm{N}$ fertilizer use for $\mathrm{NH}$.

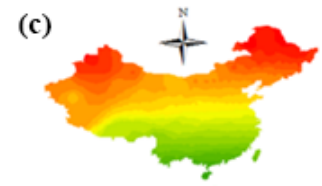

(d)

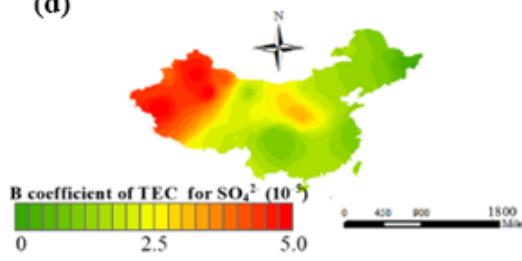

$\frac{\text { B coefficient of UGS for } \mathrm{NH}_{4}}{2.0}$
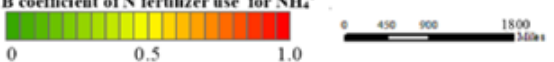

(e)
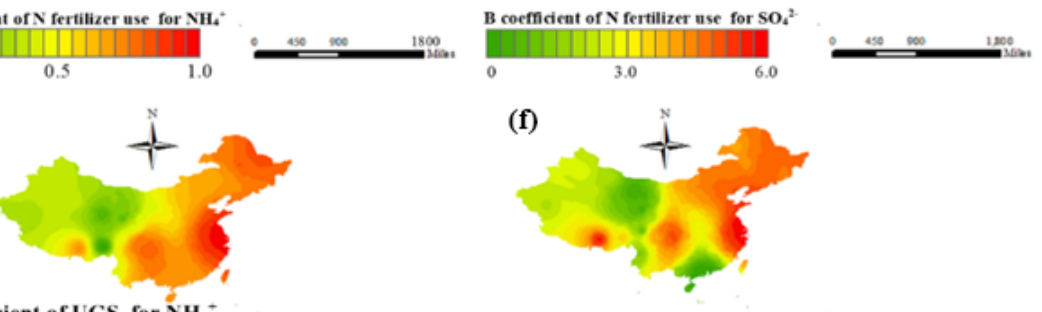

(f)

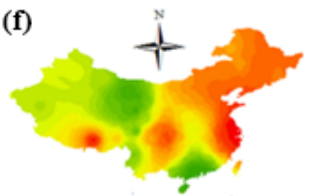

(h)
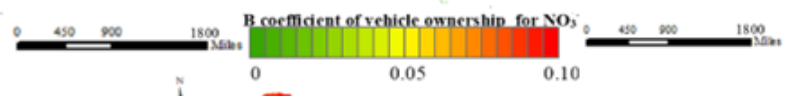
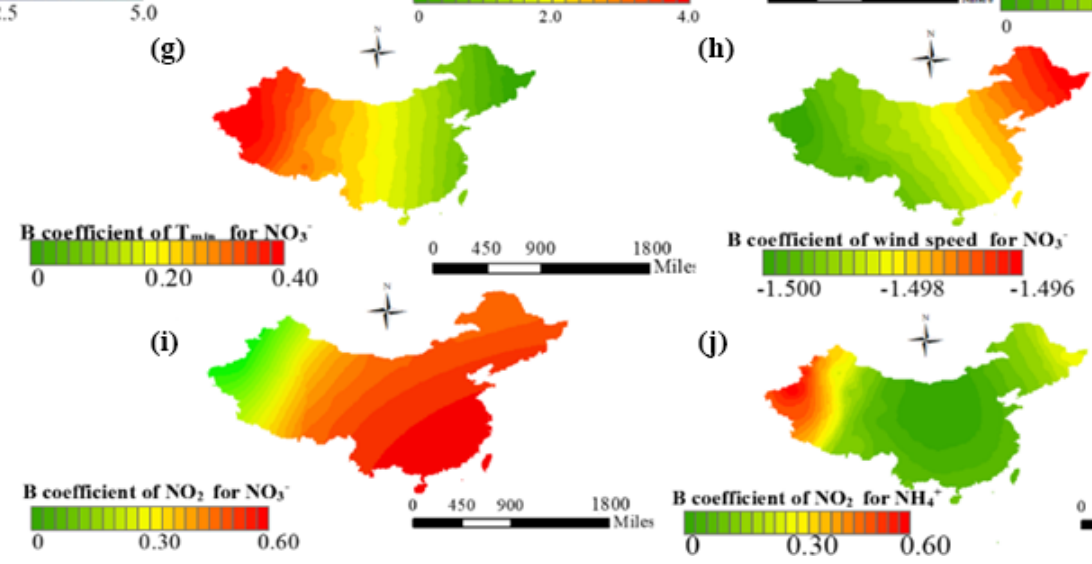

\begin{tabular}{ccc}
\multicolumn{3}{c}{ B coefricient of wind speed for $\mathrm{NO}_{3}$} \\
-1.500 & -1.498 & -1.496 \\
& &
\end{tabular}

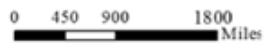

(j)

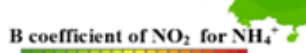

coeficient of $\mathrm{NO}_{2}$ for $\mathrm{NH}_{4}$

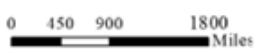

Figure 11. The local regression coefficient of influential factors for $\mathrm{NO}_{3}^{-}, \mathrm{NH}_{4}^{+}$, and $\mathrm{SO}_{4}^{2-}$.

vironment Kuznets curve denoted that the energy consumption displayed a positive relationship with per capita GDP in the early stage of development. However, the positive relationship tended to transform into negative relevance with the development of the economy because the reliance on energy-intensive industries would be reduced in the developed stage (Yang et al., 2017). It was assumed that the Xinjiang autonomous region kept at the early stage of the inverted $U$ curve and largely rested on energy-intensive industries as a less-developed province (Yang et al., 2017). However, some developed provinces in SEC such as Zhejiang and Jiangsu have sped up structural transformation of the economy and reduced the reliance on heavy industries. The influence of UGS and vehicle ownership peaked in Shandong Province (i.e. Qingdao, Jinan) and YRD (i.e. Shanghai, Hangzhou) (Fig. 11e-f). It was supposed that the UGS and vehicle ownership in these cities showed higher values among all of the 320 cities (National Bureau of Statistics of China). Apart from the effects of socioeconomic factors, meteorological factors also played significant roles in $\mathrm{NO}_{3}^{-}$. The influences of air temperature and WS both increased from east China to west China, and showed the highest values in Xinjiang Province (Fig. 11g-h). X.-X. Zhang et al. (2017) demonstrated that the strong dust events along with high WS contributed to the neutralization of $\mathrm{NO}_{3}^{-}$, although $\mathrm{NO}_{2}$ concentrations in some cities of Xinjiang Province were significantly higher than other regions of China.

\section{Conclusions}

This study newly reported spatio-temporal variation in nine water-soluble ions in the precipitation across China during 2011-2016. The mean $\mathrm{pH}$ and EC values varied significantly compared with those during 1980-2000 because the implementation of special air pollution control measures have mitigated the air pollution in China. The concentrations of $\mathrm{Na}^{+}$, $\mathrm{NO}_{3}^{-}$, and $\mathrm{SO}_{4}^{2-}$ increased from $7.26 \pm 2.51,11.56 \pm 3.71$, and $33.73 \pm 7.59 \mu \mathrm{eq} \mathrm{L}^{-1}$ to $11.04 \pm 4.64,13.59 \pm 2.63$, and $41.95 \pm 8.64 \mu \mathrm{eq} \mathrm{L}^{-1}$ during 2011 and 2014 , while they decreased from the highest in 2014 to $9.75 \pm 2.89,12.29 \pm 4.02$, and $30.57 \pm 7.43 \mu \mathrm{eq} \mathrm{L} \mathrm{L}^{-1}$ in 2016 , respectively. The concentrations of $\mathrm{Ca}^{2+}, \mathrm{NH}_{4}^{+}$, and $\mathrm{Mg}^{2+}$ increased by $86.26 \%$, $178.50 \%$, and $19.71 \%$ from 2011 to 2013 , whereas they decreased from $58.84 \pm 10.31,41.33 \pm 10.26$, and $10.49 \pm 3.07$ in 2013 to $31.20 \pm 8.48,18.13 \pm 4.84$, and $8.93 \pm 2.92 \mu \mathrm{eq} \mathrm{L}{ }^{-1}$ in 2016, respectively. The concentration of $\mathrm{F}^{-}$decreased linearly by $5.58 \% \mathrm{yr}^{-1}$ during 2012-2016. The mean concentrations of $\mathrm{SO}_{4}^{2-}, \mathrm{NO}_{3}^{-}$, and $\mathrm{F}^{-}$showed the highest val- 
ues in winter, followed by spring and autumn, and the lowest in summer. It was supposed that dense anthropogenic activities such as domestic combustion for heating and adverse meteorological conditions caused the higher secondary ions. The crustal ions $\left(\mathrm{Ca}^{2+}, \mathrm{Mg}^{2+}\right.$, and $\left.\mathrm{K}^{+}\right)$peaked in spring and summer, suggesting the contributions of fugitive dusts. $\mathrm{Na}^{+}$and $\mathrm{Cl}^{-}$were markedly affected by evaporation of sea salt. All of the water-soluble ions in the precipitation exhibited notable spatial variability. The secondary ions $\left(\mathrm{SO}_{4}^{2-}, \mathrm{NO}_{3}^{-}\right.$, and $\left.\mathrm{NH}_{4}^{+}\right)$and $\mathrm{F}^{-}$peaked in YRD (i.e. Changzhou, Hangzhou, and Nanjing) owing to the intensive energy consumption and industrial activities. The higher S content in coal and unfavourable diffusion conditions contributed to higher concentrations of secondary ions in SB (i.e. Chengdu, Leshan, and Dazhou). The crustal ions and sea salt ions showed the highest concentrations in semi-arid regions (i.e. Guyuan, Jiayuguan) and coastal cities (i.e. Qingdao, Lianyungang), respectively.

The EF method, geochemical index method, and FA-MLR method consistently suggested that $\mathrm{NO}_{3}^{-}, \mathrm{F}^{-}, \mathrm{NH}_{4}^{+}$, and $\mathrm{SO}_{4}^{2-}$ were dominated by anthropogenic activities. However, $\mathrm{Na}^{+}$and $\mathrm{Cl}^{-}$were closely associated with sea salt aerosol. $\mathrm{Ca}^{2+}, \mathrm{Mg}^{2+}$, and $\mathrm{K}^{+}$were mostly derived from crustal sources. The results of SR analysis and the GWR method implied that GIP, TEC, vehicle ownership, and $\mathrm{N}$ fertilizer use were the main factors for $\mathrm{SO}_{4}^{2-}, \mathrm{NO}_{3}^{-}, \mathrm{NH}_{4}^{+}$, and $\mathrm{F}^{-}$in precipitation. However, the crustal ions were significant affected by dust events. The correlation between influential factors and the ions in the wet deposition showed significantly spatial variability. The influence of dust days on the crustal ions increased from SEC to NWC, whereas the influence of socioeconomic factors on secondary ions showed the highest value in east China.

The present study validates the model estimations of the water-soluble ion deposition at a national scale, and provides the fundamental data for the prevention and control of acid deposition and air pollution. However, there were several plausible contributors to the uncertainty. First of all, the monitoring sites were distributed unevenly and relatively few sites were located in northwest China. Moreover, the limited independent variables were included in the models. Thus, further studies were required to establish more representative monitoring sites and incorporate more variables to reduce the uncertainty associated with the ion deposition.

Data availability. Meteorological data are publicly available from the website (http://data.cma.cn/, last access: 1 December 2016).

Supplement. The supplement related to this article is available online at: https://doi.org/10.5194/acp-19-11043-2019-supplement.
Author contributions. RL analysed the data and wrote the paper. LC, YZ, ZZ, TS, JL, WZ, YM, and KH organized the campaign and analysed data. HF revised the paper.

Competing interests. The authors declare that they have no conflict of interest.

Special issue statement. This article is part of the special issue "Regional assessment of air pollution and climate change over East and Southeast Asia: results from MICS-Asia Phase III". It is not associated with a conference.

Acknowledgements. This work was supported by the National Key R\&D programme of China (2016YFC0202700), National Natural Science Foundation of China (nos. 91744205, 21777025, 21577022, 21177026), international cooperation project of Shanghai municipal government (15520711200), and Marie SkłodowskaCurie Actions (690958-MARSU-RISE-2015). The meteorological data are available at http://data.cma.cn/. The socioeconomic data are collected from http://www.stats.gov.cn/.

Financial support. This research has been supported by the National Natural Science Foundation of China (grant nos. 91744205, 21777025, 21577022, 21177026) and Shanghai Tongji Gao Tingyao Environmental Science \& Technology Development Foundation (STGEF).

Review statement. This paper was edited by Joshua Fu and reviewed by two anonymous referees.

\section{References}

Abed, A. M., Kuisi, M. A., and Khair, H. A.: Characterization of the Khamaseen (spring) dust in Jordan, Atmos. Environ. 43, 2868 2876, https://doi.org/10.1016/j.atmosenv.2009.03.015, 2009.

AlKhatib, M. and Eisenhauer, A.: Calcium and strontium isotope fractionation during precipitation from aqueous solutions as a function of temperature and reaction rate; II. Aragonite, Geochim. Cosmochim. Ac., 209, 320-342, 2017.

Al-Khashman, O. A.: Study of chemical composition in wet atmospheric precipitation in Eshidiya area, Jordan, Atmos. Environ. 39, 6175-6183, https://doi.org/10.1016/j.atmosenv.2005.06.056, 2005.

Allen, H. M., Draper, D. C., Ayres, B. R., Ault, A., Bondy, A., Takahama, S., Modini, R. L., Baumann, K., Edgerton, E., Knote, C., Laskin, A., Wang, B., and Fry, J. L.: Influence of crustal dust and sea spray supermicron particle concentrations and acidity on inorganic $\mathrm{NO}_{3}^{-}$aerosol during the 2013 Southern Oxidant and Aerosol Study, Atmos. Chem. Phys., 15, 10669-10685, https://doi.org/10.5194/acp-15-10669-2015, 2015.

Aloisi, I., Cai, G., Faleri, C., Navazio, L., Serafini-Fracassini, D., and Del Duca, S.: Spermine regulates pollen tube 
growth by modulating $\mathrm{Ca}^{2+}$-dependent actin organization and cell wall structure, Front. Plant. Sci., 8, 1701, https://doi.org/10.3389/fpls.2017.01701, 2017.

Antony Chen, L. W., Doddridge, B. G., Dickerson, R.R., Chow, J. C., Mueller, P. K., Quinn, J., and Butler, W. A.: Seasonal variations in elemental carbon aerosol, carbon monoxide and sulfur dioxide: Implications for sources, Geophys. Res. Lett., 28, 17111714, https://doi.org/10.1029/2000GL012354, 2001.

Arimoto, R., Duce, R., Savoie, D., Prospero, J., Talbot, R., Cullen, J., Tomza, U., Lewis, N., and Ray, B.: Relationships among aerosol constituents from Asia and the North Pacific during PEM-West A, J. Geophys. Res., 101, 2011-2023, https://doi.org/10.1029/95JD01071, 1996.

Balasubramanian, R., Victor, T., and Chun, N.: Chemical and statistical analysis of precipitation in Singapore, Water Air Soil Poll., 130, 451-456, 2001.

Bian, S., Li, D., Gao, D., Peng, J., Dong, Y., and Li, W.: Hydrometallurgical processing of lithium, potassium, and boron for the comprehensive utilization of Da Qaidam lake brine via natural evaporation and freezing, Hydrometallurgy, 173, 80-83, 2017.

Cao, Y. Z., Wang, S., Zhang, G., Luo, J., and Lu, S.: Chemical characteristics of wet precipitation at an urban site of Guangzhou, South China, Atmos. Res., 94, 462-469, https://doi.org/10.1016/j.atmosres.2009.07.004, 2009.

Cabello, M., Orza, J. A. G., Duenas, C., Liger, E., Gordo, E., and Canete, S.: Back-trajectory analysis of African dust outbreaks at a coastal city in southern Spain: Selection of starting heights and assessment of African and concurrent Mediterranean contributions, Atmos. Environ., 140, 10-21, https://doi.org/10.1016/j.atmosenv.2016.05.047, 2016.

Chen, J., Li, C., Ristovski, Z., Milic, A., Gu, Y., Islam, M. S., Wang, S. X., Hao, J. M., Zhang, H. F., and He, C.: A review of biomass burning: Emissions and impacts on air quality, health and climate in China, Sci. Total Environ., 579, 1000-1034, https://doi.org/10.1016/j.scitotenv.2016.11.025, 2017.

Chen, J., Liu, G., Kang, Y., Wu, B., Sun, R., Zhou, C., and Wu, D.: Atmospheric emissions of $\mathrm{F}, \mathrm{As}, \mathrm{Se}, \mathrm{Hg}$, and $\mathrm{Sb}$ from coal-fired power and heat generation in China, Chemosphere, 90, 19251932, https://doi.org/10.1016/j.chemosphere.2012.10.032, 2013.

Chen, Y., Luo, B., and Xie, S. D.: Characteristics of the long-range transport dust events in Chengdu, Southwest China, Atmos. Environ., 122, 713-722, https://doi.org/10.1016/j.atmosenv.2015.10.045, 2015.

Chen, Z. J., Chen, C. X., Liu, Y. Q., and Lin, Z. S.: The background values and characteristics of soil elements in Fujian province, Environ. Monit. China, 8, 107-110, 1992.

Cheng, Y., Engling, G., He, K. B., Duan, F. K., Du, Z. Y., Ma, Y. L., Liang, L. L., Lu, Z. F., Liu, J. M., and Zheng, M.: The characteristics of Beijing aerosol during two distinct episodes: Impacts of biomass burning and fireworks, Environ. Pollut., 185, 149-157, https://doi.org/10.1016/j.envpol.2013.10.037, 2014.

Cheng, Y. Q. and Zhang, P.: Regional patterns changes of Chinese grain production and response of commodity grain base in northeast China, Sci. Geogr. Sinica, 25, 513-520, https://doi.org/10.3969/j.issn.1000-0690.2005.05.001, 2005.

China Meteorological Administration: The meteorological data over China during 2011-2016, available at: http://data.cma.cn/, last access: 1 December 2016.
Cong, Z., Kang, S., and Kawamura, K.: The long-range transport of atmospheric aerosols from South Asia to Himalayas, paper presented at EGU General Assembly Conference Abstracts, EGU General Assembly 2016, 17-22 April 2016 in Vienna Austria, EPSC2016-12380, 2016.

Clemens, S.: Toxic metal accumulation, responses to exposure and mechanisms of tolerance in plants, Biochimie, 88, 1707-1719, 2006.

Dai, S. and Ren, D.: Fluorine concentration of coals in China-an estimation considering coal reserves, Fuel, 85, 929-935, 2006.

Deshmukh, D. K., Deb, M. K., Tsai, Y. I., and Mkoma, S. L.: Water soluble ions in $\mathrm{PM}_{2.5}$ and $\mathrm{PM}_{10}$ aerosols in Durg city, Chhattisgarh, India, Aerosol Air Qual. Res, 11, 696-708, https://doi.org/10.4209/aaqr.2011.03.0023, 2011.

Ding, X., Kong, L., Du, C., Zhanzakova, A., Fu, H., Tang, X., Wang, L., Yang, X., Chen, J., and Cheng, T.: Characteristics of size-resolved atmospheric inorganic and carbonaceous aerosols in urban Shanghai, Atmos. Environ., 167, 625-641, https://doi.org/10.1016/j.atmosenv.2017.08.043, 2017.

Dong, Z. W., Kang, S. C., Guo, J. M., Zhang, Q. G., Wang, X. J., and Qi, D. H.: Composition and mixing states of brown haze particle over the Himalayas along two transboundary south-north transects, Atmos. Environ., 156, 24-35, https://doi.org/10.1016/j.atmosenv.2017.02.029, 2017.

Driscoll, C. T., Driscoll, K. M., Mitchell, M. J., and Raynal, D. $\mathrm{J}$.: Effects of acidic deposition on forest and aquatic ecosystems in New York State, Environ. Pollut., 123, 327-336, https://doi.org/10.1016/S0269-7491(03)00019-8, 2003.

Du, E. Z., Vries, W. D., Galloway, J. N., Hu, X. Y., and Fang, J. Y.: Changes in wet nitrogen deposition in the United States between 1985 and 2012, Environ. Res. Lett., 9, 095004, https://doi.org/10.1088/1748-9326/9/9/095004, 2014.

Emmett, B.: The impact of nitrogen on forest soils and feedbacks on tree growth, in Forest Growth Responses to the Pollution Climate of the 21st Century, Springer, 65-74, 1999.

Engelbrecht, J. P., Moosmüller, H., Pincock, S., Jayanty, R. K. M., Lersch, T., and Casuccio, G.: Technical note: Mineralogical, chemical, morphological, and optical interrelationships of mineral dust re-suspensions, Atmos. Chem. Phys., 16, 10809-10830, https://doi.org/10.5194/acp-16-10809-2016, 2016.

Fornaro, A. and Gutz, I. G. R.: Wet deposition and related atmospheric chemistry in the São Paulo metropolis, Brazil: Part 2 - Contribution of formic and acetic acids, Atmos. Environ. 37, 117-128, https://doi.org/10.1016/S1352-2310(02)00885-3, 2003.

Fu, H., Shang, G., Lin, J., Hu, Y., Hu, Q., Guo, L., Zhang, Y., and Chen, J.: Fractional iron solubility of aerosol particles enhanced by biomass burning and ship emission in Shanghai, East China, Sci. Total Environ., 481, 377-391, https://doi.org/10.1016/j.scitotenv.2014.01.118, 2014.

$\mathrm{Fu}, \mathrm{H}$. B. and Chen, J. M.: Formation, features and controlling strategies of severe haze-fog pollutions in China, Sci. Total Environ., 578, 121-138, https://doi.org/10.1016/j.scitotenv.2016.10.201, 2016.

Garland, J. A.: Dry and wet removal of sulphur from the atmosphere, Sulfur in the Atmosphere, 349-362, 1978.

Gerson, J. R., Driscoll, C. T., and Roy, K. M.: Patterns of nutrient dynamics in Adirondack lakes recovering from acid deposition, Ecol. Appl., 26, 1758-1770, 2016. 
Glavas, S. and Moschonas, N.: Origin of observed acidic-alkaline rains in a wet-only precipitation study in a Mediterranean coastal site, Patras, Greece, Atmos. Environ. 36, 3089-3099, https://doi.org/10.1016/S1352-2310(02)00262-5, 2002.

Gottwald, M. and Bovensmann, H.: SCIAMACHY: Exploring the Changing Earth's Atmosphere, 1 Edn., Springer, ISBN 978-9481-9895-5, 2011.

Grythe, H., Ström, J., Krejci, R., Quinn, P., and Stohl, A.: A review of sea-spray aerosol source functions using a large global set of sea salt aerosol concentration measurements, Atmos. Chem. Phys., 14, 1277-1297, https://doi.org/10.5194/acp-141277-2014, 2014.

Gu, J., Pitz, M., Schnelle-Kreis, J., Diemer, J., Reller, A., Zimmermann, R., Soentgen, J., Stoelzel, M., Wichmann, H. E., Peters, A., and Cyrys, J.: Source apportionment of ambient particles: comparison of positive matrix factorization analysis applied to particle size distribution and chemical composition data. Atmos. Environ. 45, 1849-1857, https://doi.org/10.1016/j.atmosenv.2011.01.009, 2011.

Gu, Y., Liao, H., and Bian, J.: Summertime nitrate aerosol in the upper troposphere and lower stratosphere over the Tibetan Plateau and the South Asian summer monsoon region, Atmos. Chem. Phys., 16, 6641-6663, https://doi.org/10.5194/acp-166641-2016, 2016.

Gupta, D., Eom, H.-J., Cho, H.-R., and Ro, C.-U.: Hygroscopic behavior of $\mathrm{NaCl}-\mathrm{MgCl}_{2}$ mixture particles as nascent seaspray aerosol surrogates and observation of efflorescence during humidification, Atmos. Chem. Phys., 15, 11273-11290, https://doi.org/10.5194/acp-15-11273-2015, 2015.

Hao, G. J., Zhou, J. Q., and Fang, H. L.: Applicability of AB-DTPA method for determining the available content of multi-element in typical soils in China, Acta Agr. Shanghai, 32, 100-107, 2016 (in Chinese).

Hua, S., Tian, H., Wang, K., Zhu, C., Gao, J., Ma, Y., Xue, Y., Wang, Y., Duan, S., and Zhou, J.: Atmospheric emission inventory of hazardous air pollutants from China's cement plants: Temporal trends, spatial variation characteristics and scenario projections, Atmos. Environ., 128, 1-9, https://doi.org/10.1016/j.atmosenv.2015.12.056, 2016.

Hunová, I., Maznová, J., and Kurfürst, P.: Trends in atmospheric deposition fluxes of sulphur and nitrogen in Czech forests, Environ. Pollut., 184, 668-675, https://doi.org/10.1016/j.envpol.2013.05.013, 2014.

Ito, M., Mitchell, M., and Driscoll, C. T.: Spatial patterns of precipitation quantity and chemistry and air temperature in the Adirondack region of New York, Atmos. Environ. 36, 10511062, https://doi.org/10.1016/S1352-2310(01)00484-8, 2002.

Jia, Y., Yu, G., He, N., Zhan, X., Fang, H., Sheng, W., Zuo, Y., Zhang, D., and Wang, Q.: Spatial and decadal variations in inorganic nitrogen wet deposition in China induced by human activity, Sci. Rep., 4, 3763, https://doi.org/10.1038/srep03763, 2014.

Jiang, Z., Lian, Y., and Qin, X.: Rocky desertification in Southwest China: impacts, causes, and restoration, Earth-Sci. Rev., 132, 112, https://doi.org/10.1016/j.earscirev.2014.01.005, 2014.

Kang, L. T., Huang, J. P., Chen, S. Y., and Wang, X.: Long-term trends of dust events over Tibetan Plateau during 1961-2010, Atmos. Environ., 125, 188-198, https://doi.org/10.1016/j.atmosenv.2015.10.085, 2016.
Kang, Y., Liu, M., Song, Y., Huang, X., Yao, H., Cai, X., Zhang, H., Kang, L., Liu, X., Yan, X., He, H., Zhang, Q., Shao, M., and Zhu, T.: High-resolution ammonia emissions inventories in China from 1980 to 2012, Atmos. Chem. Phys., 16, 2043-2058, https://doi.org/10.5194/acp-16-2043-2016, 2016.

Kabatas, B., Unal, A., Pierce, R. B., Kindap, T., and Pozzoli, L.: The contribution of Saharan dust in $\mathrm{PM}_{10}$ concentration levels in Anatolian Peninsula of Turkey, Sci. Total Environ., 488, 413421, https://doi.org/10.1016/j.scitotenv.2013.12.045, 2014.

Kchih, H., Perrino, C., and Cherif, S.: Investigation of desert dust contribution to source apportionment of $\mathrm{PM}_{10}$ and $\mathrm{PM}_{2.5}$ from a southern Mediterranean coast, Aerosol Air Qual. Res., 15, 454464, https://doi.org/10.4209/aaqr.2014.10.0255, 2015.

Keene, W. C., Pszenny, A. A. P., Galloway, J. N., and Hawley, M. E.: Sea-salt corrections and interpretation of constituent ratios in marine precipitation, J. Geophys. Res.-Atmos., 91, 6647-6658, https://doi.org/10.1029/JD091iD06p06647, 1986.

Kong, S., Ji, Y., Lu, B., Chen, L., Han, B., Li, Z., and Bai, Z.: Characterization of $\mathrm{PM}_{10}$ source profiles for fugitive dust in Fushun - a city famous for coal, Atmos. Environ., 45, 53515365, https://doi.org/10.1016/j.atmosenv.2011.06.050, 2011.

Kobbing, J. F., Patuzzi, F., Baratieri, M., Beckmann, V., Thevs, N., and Zerbe, S.: Economic evaluation of common reed potential for energy production: a case study in Wuliangsuhai Lake (Inner Mongolia, China), Biomass Bioenerg., 70, 315-329, 2014.

Kulshrestha, U. C., Sarkar, A. K., Srivastava, S. S., and Parashar, D. C.: Wet-only and bulk deposition studies at New Delhi (India), Water Air Soil Pollut., 85, 2137-2142, 1995.

Kuribayashi, M., Ohara, T., Morino, Y., Uno, I., Kurokawa, J. I., and Hara, H.: Long-term trends of sulfur deposition in East Asia during 1981-2005, Atmos. Environ., 59, 461-475, https://doi.org/10.1016/j.atmosenv.2012.04.060, 2012.

Kuang, F. H., Liu, X. J., Zhu, B., Shen, J., Pan, Y., and $\mathrm{Su}, \mathrm{M}$.: Wet and dry nitrogen deposition in the central Sichuan Basin of China, Atmos. Environ. 143, 39-50, https://doi.org/10.1016/j.atmosenv.2016.08.032, 2016.

Lawson, D. R. and Winchester, J. W.: A standard crustal aerosol as a reference for elemental enrichment factors, Atmos. Environ., 13, 925-930, 1979.

Larssen, T. and Carmichael, G.: Acid rain and acidification in China: the importance of base cation deposition, Environ. Pollut., 110, 89-102, https://doi.org/10.1016/S0269-7491(99)00279-1, 2000.

Larssen, T., Seip, H. M., Semb, A., Mulder, J., Muniz, I. P., Vogt, R. D., Lydersen, E., Angell, V., Dagang, T., and Eilertsen, O.: Acid deposition and its effects in China: an overview, Environ. Sci. Policy, 2, 9-24, 1999.

Leng, Q. M., Cui, J., Zhou, F. W., Du, K., Zhang, L. Y., Fu, C., Liu, Y., Wang, H. B., Shi, G. M., Gao, M., Yang, F. M., and He, D. Y.: Wet-only deposition of atmospheric inorganic nitrogen and associated isotopic characteristics in a typical mountain area, southwestern China, Sci. Total Environ., 616, 55-63, https://doi.org/10.1016/j.scitotenv.2017.10.240, 2018.

Le Bolloch, O. and Guerzoni, S.: Acid and alkaline deposition in precipitation on the western coast of Sardinia, Central Mediterranean $\left(40^{\circ} \mathrm{N}, 81^{\circ} \mathrm{E}\right)$, Water Air Soil Poll., 85, 2155-2160, 1995.

Li, C. L., Kang, S. C., Zhang, Q. G., and Kaspari, S.: Major ionic composition of precipitation in the Nam Co re- 
gion, Central Tibetan Plateau, Atmos. Res., 85, 351-360, https://doi.org/10.1016/j.atmosres.2007.02.006, 2007.

Li, R., Cui, L., Li, J., Zhao, A., Fu, H., Wu, Y., Zhang, L., Kong, L., and Chen, J.: Spatial and temporal variation of particulate matter and gaseous pollutants in China during 2014-2016, Atmos. Environ., 161, 235-246, https://doi.org/10.1016/j.atmosenv.2017.05.008, 2017a.

Li, R., Li, J. L., Cui, L. L., Wu, Y., Fu, H. B., Chen, J. M., and Chen, M. D.: Atmospheric emissions of $\mathrm{Cu}$ and $\mathrm{Zn}$ from coal combustion in China: Spatio-temporal distribution, human health effects, and short-term prediction, Environ. Pollut., 229, 724-734, https://doi.org/10.1016/j.envpol.2017.05.068, $2017 \mathrm{~b}$.

Li, X., Wang, L., Ji, D., Wen, T., Pan, Y., Sun, Y., and Wang, Y.: Characterization of the size-segregated water-soluble inorganic ions in the Jing-Jin-Ji urban agglomeration: Spatial/temporal variability, size distribution and sources, Atmos. Environ., 77, 250-259, https://doi.org/10.1016/j.atmosenv.2013.03.042, 2013.

Li, Y., Meng, J., Liu, J., Xu, Y., Guan, D., Tao, W., Huang, Y., and Tao, S.: Interprovincial reliance for improving air quality in China: a case study on black carbon aerosol, Environ. Sci. Technol., 50, 4118-4126, https://doi.org/10.1021/acs.est.5b05989, 2016.

Li, Z., Ma, Z., vander Kuijp, T., Yuan, Z. W., and Huang, L.: A review of soil heavy metal pollution from mines in China: Pollution and health risk assessment, Sci. Total Environ., 468, 843853, https://doi.org/10.1016/j.scitotenv.2018.06.068, 2014.

Li, Z. Y., Wang, Z. L., Li, R. J., and Xu, Q. H.: The analysis of element content in the soil of 29 provinces/municipality/autonomous region in China, Shanghai agriculture technology, 1992 (in Chinese).

Lim, B., Jickells, T., and Davies, T.: Sequential sampling of particles, major ions and total trace metals in wet deposition, Atmos. Environ. A-Gen., 25, 745-762, 1991.

Link, M. F., Kim, J., Park, G., Lee, T., Park, T., Babar, Z. B., Sung, K., Kim, P., Kang, S., and Kim, J. S.: Elevated production of $\mathrm{NH}_{4}-\mathrm{NO}_{3}$ from the photochemical processing of vehicle exhaust: Implications for air quality in the Seoul Metropolitan Region, Atmos. Environ., 156, 95-101, https://doi.org/10.1016/j.atmosenv.2017.02.031, 2017.

Liu, F., Zhang, Q., Tong, D., Zheng, B., Li, M., Huo, H., and He, K. B.: High-resolution inventory of technologies, activities, and emissions of coal-fired power plants in China from 1990 to 2010, Atmos. Chem. Phys., 15, 13299-13317, https://doi.org/10.5194/acp-15-13299-2015, 2015.

Liu, F., Beirle, S., Zhang, Q., van der A, R. J., Zheng, B., Tong, D., and He, K.: $\mathrm{NO}_{x}$ emission trends over Chinese cities estimated from OMI observations during 2005 to 2015, Atmos. Chem. Phys., 17, 9261-9275, https://doi.org/10.5194/acp-179261-2017, 2017.

Liu, L., Zhang, X. Y., Wang, S. Q., Zhang, W. T., and Lu, X. H.: Bulk sulfur deposition in China, Atmos. Environ., 135, 41-49, https://doi.org/10.1016/j.atmosenv.2016.04.003, 2016.

Liu, P., Zhang, C., Mu, Y., Liu, C., Xue, C., Ye, C., Liu, J., Zhang, Y., and Zhang, H.: The possible contribution of the periodic emissions from farmers' activities in the North China Plain to atmospheric water-soluble ions in Beijing, Atmos. Chem. Phys., 16, 10097-10109, https://doi.org/10.5194/acp-16-100972016, 2016.
Liu, P., Zhang, C., Xue, C., Mu, Y., Liu, J., Zhang, Y., Tian, D., Ye, C., Zhang, H., and Guan, J.: The contribution of residential coal combustion to atmospheric $\mathrm{PM}_{2.5}$ in northern China during winter, Atmos. Chem. Phys., 17, 11503-11520, https://doi.org/10.5194/acp-17-11503-2017, 2017.

Liu, X., Ju, X., Zhang, Y., He, C., Kopsch, J., and Fusuo, Z.: Nitrogen deposition in agroecosystems in the Beijing area, Agr. Ecosyst. Environ., 113, 370-377, 2006.

Liu, X., Duan, L., Mo, J., Du, E., Shen, J., Lu, X., Zhang, Y., and Zhou, X., He, C., Zhang, F.: Nitrogen deposition and its ecological impact in China: an overview, Environ. Pollut., 159, 22512264, https://doi.org/10.1016/j.envpol.2010.08.002, 2011.

Liu, X., Zhang, Y., Han, W., Tang, A., Shen, J., Cui, Z., Vitousek, P., Erisman, J. W., Goulding, K., and Christie, P.: Enhanced nitrogen deposition over China, Nature, 494, 459-462, https://doi.org/10.1038/nature11917, 2013.

Liu, Y. W., Xu-Ri, Wang, Y. S., Pan, Y. P., and Piao, S. L.: Wet deposition of atmospheric inorganic nitrogen at five remote sites in the Tibetan Plateau, Atmos. Chem. Phys., 15, 11683-11700, https://doi.org/10.5194/acp-15-11683-2015, 2015.

Lu, X., Li, L. Y., Li, N., Yang, G., Luo, D., and Chen, J.: Chemical characteristics of spring precipitation of Xi' an city, NW China, Atmos. Environ., 45, 5058-5063, https://doi.org/10.1016/j.atmosenv.2011.06.026, 2011.

Lu, X., Mao, Q., Gilliam, F. S., Luo, Y., and Mo, J.: Nitrogen deposition contributes to soil acidification in tropical ecosystems, Global Change Biol., 20, 3790-3801, https://doi.org/10.1111/gcb.12665, 2014.

Lu, Z., Streets, D. G., Zhang, Q., Wang, S., Carmichael, G. R., Cheng, Y. F., Wei, C., Chin, M., Diehl, T., and Tan, Q.: Sulfur dioxide emissions in China and sulfur trends in East Asia since 2000, Atmos. Chem. Phys., 10, 6311-6331, https://doi.org/10.5194/acp-10-6311-2010, 2010.

Luo, X. S., Xue, Y., Wang, Y. L., Cang, L., Xu, B., and Ding, J.: Source identification and apportionment of heavy metals in urban soil profiles, Chemosphere, 127, 152-157, https://doi.org/10.1016/j.chemosphere.2015.01.048, 2015.

Lyu, X., Chen, N., Guo, H., Zeng, L., Zhang, W., Shen, F., Quan, J., and Wang, N.: Chemical characteristics and causes of airborne particulate pollution in warm seasons in Wuhan, central China, Atmos. Chem. Phys., 16, 10671-10687, https://doi.org/10.5194/acp-16-10671-2016, 2016.

Lyu, Y., Qu, Z., Liu, L., Guo, L., Yang, Y., Hu, X., Xiong, Y., Zhang, G., Zhao, M., and Liang, B.: Characterization of dustfall in rural and urban sites during three dust storms in northern China, 2010, Aeolian Res., 28, 29-37, 2017.

McGlade, C. and Ekins, P.: The geographical distribution of fossil fuels unused when limiting global warming to $2^{\circ} \mathrm{C}$, Nature, 517, 187-190, https://doi.org/10.1038/nature14016, 2015.

Müller, W. E., Tolba, E., Feng, Q., Schröder, H. C., Markl, J. S., Kokkinopoulou, M., and Wang, X.: Amorphous $\mathrm{Ca}^{2+}$ polyphosphate nanoparticles regulate the ATP level in bone-like SaOS-2 cells, J. Cell Sci., 128, 2202-2207, 2015.

Migliavacca, D., Teixeira, E., Wiegand, F., Machado, A., and Sanchez, J.: Atmospheric precipitation and chemical composition of an urban site, Guaiba hydrographic basin, Brazil, Atmos. Environ., 39, 1829-1844, https://doi.org/10.1016/j.atmosenv.2004.12.005, 2005. 
Mikhailova, E., Goddard, M., Post, C., Schlautman, M., and Galbraith, J.: Potential contribution of combined atmospheric $\mathrm{Ca}^{2+}$ and $\mathrm{Mg}^{2+}$ wet deposition within the continental US to soil inorganic carbon sequestration, Pedosphere, 23, 808-814, 2013.

National Bureau of Statistics of China, available at: http://data.stats. gov.cn/, 2010-2016 (Chinese).

Négrel, P., Guerrot, C., and Millot, R.: Chemical and strontium isotope characterization of precipitation in France: influence of sources and hydrogeochemical implications, Isot. Environ. Healt., 43, 179-196, 2007.

Nayebare, S. R., Aburizaiza, O. S., Khwaja, H. A., Siddique, A., Hussain, M. M., Zeb, J., Khatib, F., Carpenter, D. O., and Blake, D. R.: Chemical characterization and source apportionment of $\mathrm{PM}_{2.5}$ in Rabigh, Saudi Arabia, Aerosol Air Qual Re., 16, 3114 3129, https://doi.org/10.4209/aaqr.2015.11.0658, 2016.

Niu, H. W., He, Y. Q., Lu, X. X., Shen, J., Du, J. K., Zhang, T., Pu, T., Xin, H. J., and Chang, L.: Chemical composition of precipitation in the Yulong Snow Mountain region, Southwestern China, Atmos. Res. 144, 195-206, https://doi.org/10.1016/j.atmosres.2014.03.010, 2014.

Okuda, T., Iwase, T., Ueda, H., Suda, Y., Tanaka, S., Dokiya, Y., Fushimi, K., and Hosoe, M.: Long-term trend of chemical constituents in precipitation in Tokyo metropolitan area, Japan, from 1990 to 2002, Sci. Total Environ. 339, 127-141, https://doi.org/10.1016/j.scitotenv.2004.07.024, 2005.

Padoan, E., Ajmone-Marsan, F., Querol, X., and Amato, F.: An empirical model to predict road dust emissions based on pavement and traffic characteristics, Environ. Pollut., 237, 713-720, https://doi.org/10.1016/j.envpol.2017.10.115, 2017.

Pan, Y. P., Wang, Y. S., Tang, G. Q., and Wu, D.: Spatial distribution and temporal variations of atmospheric sulfur deposition in Northern China: insights into the potential acidification risks, Atmos. Chem. Phys., 13, 1675-1688, https://doi.org/10.5194/acp13-1675-2013, 2013.

Prather, K. A., Bertram, T. H., Grassian, V. H., Deane, G. B., Stokes, M. D., DeMott, P. J., Aluwihare, L. I., Palenik, B. P., Azam, F., and Seinfeld, J. H.: Bringing the ocean into the laboratory to probe the chemical complexity of sea spray aerosol, P. Natl. Acad. Sci. USA, 110, 7550-7555, https://doi.org/10.1073/pnas.1300262110, 2013.

Pu, W., Quan, W., Ma, Z., Shi, X., Zhao, X., Zhang, L., Wang, Z., and Wang, W.: Long-term trend of chemical composition of atmospheric precipitation at a regional background station in Northern China, Sci. Total Environ., 580, 1340-1350, https://doi.org/10.1016/j.scitotenv.2016.12.097, 2017.

Qiao, T., Zhao, M., Xiu, G., Yu, J.: Seasonal variations of water soluble composition (WSOC, Hulis and WSIIs) in $\mathrm{PM}_{1}$ and its implications on haze pollution in urban Shanghai, China, Atmos. Environ., 123, 306-314, https://doi.org/10.1016/j.atmosenv.2015.03.010, 2015.

Qiao, X., Du, J., Kota, S.H., Ying, Q., Xiao, W. Y., and Tang, Y.: Wet deposition of sulfur and nitrogen in Jiuzhaigou National Nature Reserve, Sichuan, China during 2015-2016: Possible effects from regional emission reduction and local tourist activities, Environ. Pollut., 233, 267-277, https://doi.org/10.1016/j.envpol.2017.08.041, 2018.

Rao, W., Han, G., Tan, H., and Jiang, S.: Chemical and Sr isotopic compositions of precipitation on the Ordos Desert Plateau, Northwest China, Environ. Earth Sci., 74, 5759-5771, 2015.
Ren, D., Zhao, F., Dai, S., Zhang, J., and Luo, K.: Trace Element Geochemical in: Coal, Science Press, Beijing, China, 556 pp., 2006.

Russell, K. M., Galloway, J. N., Macko, S. A., Moody, J. L., and Scudlark, J. R.: Sources of nitrogen in wet deposition to the Chesapeake Bay region, Atmos. Environ., 32, 2453-2465, https://doi.org/10.1016/S1352-2310(98)00044-2, 1998.

Seinfeld, J. H.: Atmospheric Chemistry and Physics of Air Pollution John Wiley \& Sons, Inc., New York, 50-51, 1986.

Shen, Z., Sun, J., Cao, J., Zhang, L., Zhang, Q., Lei, Y., Gao, J., Huang, R.-J., Liu, S., and Huang, Y.: Chemical profiles of urban fugitive dust $\mathrm{PM}_{2.5}$ samples in Northern Chinese cities, Sci. Total Environ., 569, 619-626, https://doi.org/10.1016/j.scitotenv.2016.06.156, 2016.

Shi, C. W., Zhao, L. Z., Guo, X. B., Gao, S., Yang, J. P., and Li, J. H.: The distribution characteristic and influential factors of background values for elements in Shanxi province, Agroenvironmental Protection, 15, 24-28, 1996.

Shi, G. L., Liu, G. R., Peng, X., Wang, Y. N., Tian, Y. Z., Wang, W., and Feng, Y. C.: A comparison of multiple combined models for source apportionment, including the PCA/MLR-CMB, UNMIXCMB and PMF-CMB Models, Aerosol Air Qual. R., 14, 20402050, 2014.

Sickles II, J. E. and Shadwick, D. S.: Air quality and atmospheric deposition in the eastern US: 20 years of change, Atmos. Chem. Phys., 15, 173-197, https://doi.org/10.5194/acp-15-1732015, 2015.

Simkin, S. M., Allen, E. B., Bowman, W. D., Clark, C. M., Belnap, J., Brooks, M. L., Cade, B. S., Collins, S. L., Geiser, L. H., and Gilliam, F. S.: Conditional vulnerability of plant diversity to atmospheric nitrogen deposition across the United States, P. Natl. Acad. Sci. USA, 113, 4086-4091, https://doi.org/10.1073/pnas.1515241113, 2016.

Singh, A. and Agrawal, M.: Acid rain and its ecological consequences, J. Environ. Biol., 29, 15-24, 2008.

Smith, S. J., van Aardenne, J., Klimont, Z., Andres, R. J., Volke, A., and Delgado Arias, S.: Anthropogenic sulfur dioxide emissions: 1850-2005, Atmos. Chem. Phys., 11, 1101-1116, https://doi.org/10.5194/acp-11-1101-2011, 2011.

Song, F. and Gao, Y.: Chemical characteristics of precipitation at metropolitan Newark in the US East Coast, Atmos. Environ., 43, 4903-4913, https://doi.org/10.1016/j.atmosenv.2009.07.024, 2009.

Song, H., Zhang, K., Piao, S., and Wan, S.: Spatial and temporal variations of spring dust emissions in northern China over the last 30 years, Atmos. Environ., 126, 117-127, https://doi.org/10.1016/j.atmosenv.2015.11.052, 2016.

Song, Y., Zhang, Y., Xie, S., Zeng, L., Zheng, M., Salmon, L. G., Shao, M., and Slanina, S.: Source apportionment of $\mathrm{PM}_{2.5}$ in Beijing by positive matrix factorization, Atmos. Environ., 40, 1526-1537, https://doi.org/10.1016/j.atmosenv.2005.10.039, 2006.

Sun, L., Li, L., Chen, Z., Wang, J., and Xiong, Z.: Combined effects of nitrogen deposition and biochar application on emissions of $\mathrm{N}_{2} \mathrm{O}, \mathrm{CO}_{2}$ and $\mathrm{NH}_{3}$ from agricultural and forest soils, Soil Sci. Plant Nutr., 60, 254-265, 2014.

Sun, S. D., Jiang, W., and Gao, W. D.: Vehicle emission trends and spatial distribution in Shandong province, 
China, from 2000 to 2014, Atmos. Environ., 147, 190-199, https://doi.org/10.1016/j.atmosenv.2016.09.065, 2016.

Song, M. L., Zhang, W., and Wang, S. H.: Inflection point of environmental Kuznets curve in Mainland China, Energ. Policy, 57, 14-20, 2013.

Song, L., Kuang, F. H., Skiba, U., Zhu, B., Liu, X. J., Levy, P., Dore, A., and Fowler, D.: Bulk deposition of organic and inorganic nitrogen in southwest China from 2008 to 2013, Environ. Pollut., 227, 157-166, https://doi.org/10.1016/j.envpol.2017.04.031, 2017.

Tai, A. P., Mickley, L. J., and Jacob, D. J.: Correlations between fine particulate matter $\left(\mathrm{PM}_{2.5}\right)$ and meteorological variables in the United States: Implications for the sensitivity of $\mathrm{PM}_{2.5}$ to climate change, Atmos. Environ., 44, 3976-3984, https://doi.org/10.1016/j.atmosenv.2010.06.060, 2010.

Tao, J., Zhang, L., Zhang, R., Wu, Y., Zhang, Z., Zhang, X., Tang, Y., Cao, J., and Zhang, Y.: Uncertainty assessment of source attribution of $\mathrm{PM}_{2.5}$ and its water-soluble organic carbon content using different biomass burning tracers in positive matrix factorization analysis-A case study in Beijing, China, Sci. Total Environ., 543, 326-335, https://doi.org/10.1016/j.scitotenv.2015.11.057, 2016.

Teinilä, K., Frey, A., Hillamo, R., Tülp, H. C., and Weller, R.: A study of the sea-salt chemistry using size-segregated aerosol measurements at coastal Antarctic station Neumayer, Atmos. Environ., 96, 11-19, https://doi.org/10.1016/j.atmosenv.2014.07.025, 2014.

Teng, X., Hu, Q., Zhang, L., Qi, J., Shi, J., Xie, H., Gao, H., and Yao, X.: Identification of major sources of atmospheric $\mathrm{NH}_{3}$ in an urban environment in northern China during wintertime, Environ. Sci. Technol., 51, 6839-6848, https://doi.org/10.1021/acs.est.7b00328, 2017.

Tian, H., Gao, J., Lu, L., Zhao, D., Cheng, K., and Qiu, P.: Temporal trends and spatial variation characteristics of hazardous air pollutant emission inventory from municipal solid waste incineration in China, Environ. Sci. Technol., 46, 10364-10371, https://doi.org/10.1021/es302343s, 2012.

Tian, H., Liu, K., Hao, J., Wang, Y., Gao, J., Qiu, P., and Zhu, C.: Nitrogen oxides emissions from thermal power plants in China: Current status and future predictions, Environ. Sci. Technol., 47, 11350-11357, https://doi.org/10.1021/es402202d, 2013.

Tian, H., Liu, K., Zhou, J., Lu, L., Hao, J., Qiu, P., Gao, J., Zhu, C., Wang, K., and Hua, S.: Atmospheric Emission Inventory of Hazardous Trace Elements from China's Coal-Fired Power Plants Temporal Trends and Spatial Variation Characteristics, Environ. Sci. Technol., 48, 3575-3582, https://doi.org/10.1021/es404730j, 2014.

Turekian, K. K.: Oceans, Prentice-Hall, New Jersey, United States, 591 pp., 1968.

Tsai, Y. I., Hsieh, L. Y., Kuo, S. C., Chen, C. L., and Wu, P. L.: Seasonal and rainfall-type variations in inorganic ions and dicarboxylic acids and acidity of wet deposition samples collected from subtropical East Asia, Atmos. Environ. 45, 3535-3547, https://doi.org/10.1016/j.atmosenv.2011.04.001, 2011.

Vašát, R., Pavlů, L., Borůvka, L., Tejnecký, V., and Nikodem, A.: Modelling the impact of acid deposition on forest soils in north Bohemian Mountains with two dynamic models: The Very Simple Dynamic Model (VSD) and the Model of Acidification of
Groundwater in Catchments (MAGIC), Soil Water Res., 10, 10$18,2015$.

Velthof, G., Lesschen, J., Webb, J., Pietrzak, S., Miatkowski, Z., Pinto, M., Kros, J., and Oenema, O.: The impact of the nitrates directive on nitrogen emissions from agriculture in the EU-27 during 2000-2008, Sci. Total Environ., 468, 1225-1233, https://doi.org/10.1016/j.scitotenv.2013.04.058, 2014.

Wang, Q.: Effects of urbanisation on energy consumption in China, Energ. Policy, 65, 332-339, 2014.

Wang, W. X. and Xu, P. J.: Research Progress in Precipitation Chemistry in China, Progress in Chemistry, 16 pp., 2009.

Wang, F. Y., Liu, R. J., Lin, X. G., and Zhou, J. M.: Arbuscular mycorrhizal status of wild plants in saline-alkaline soils of the Yellow River Delta, Mycorrhiza, 14, 133-137, 2004.

Wang, H., An, J., Cheng, M., Shen, L., Zhu, B., Li, Y., Wang, Y., Duan, Q., Sullivan, A., and Xia, L.: One year online measurements of water-soluble ions at the industrially polluted town of Nanjing, China: Sources, seasonal and diurnal variations, Chemosphere, 148, 526-536, https://doi.org/10.1016/j.chemosphere.2016.01.066, 2016.

Wang, K., Tian, H., Hua, S., Zhu, C., Gao, J., Xue, Y., Hao, J., Wang, Y., and Zhou, J.: A comprehensive emission inventory of multiple air pollutants from iron and steel industry in China: temporal trends and spatial variation characteristics, Sci. Total Environ., 559, 7-14, https://doi.org/10.1016/j.scitotenv.2016.03.125, 2016.

Wang, J., Qiu, Y., He, S. T., Liu, N., Xiao, C. Y., and Liu, L. X.: Investigating the driving forces of $\mathrm{NO}_{x}$ generation from energy consumption in China, J. Clean. Prod., 184, 836-846, 2018.

Wang, Q., Zhuang, G., Huang, K., Liu, T., Deng, C., Xu, J., Lin, Y., Guo, Z., Chen, Y., and Fu, Q.: Probing the severe haze pollution in three typical regions of China: Characteristics, sources and regional impacts, Atmos. Environ., 120, 76-88, https://doi.org/10.1016/j.atmosenv.2015.08.076, 2015.

Wang, S., Luo, K., Wang, X., and Sun, Y.:, Estimate of sulfur, arsenic, mercury, fluorine emissions due to spontaneous combustion of coal gangue: An important part of Chinese emission inventories, Environ. Pollut., 209, 107-113, https://doi.org/10.1016/j.envpol.2015.11.026, 2016.

Wang, X., Pu, W., Shi, J., Bi, J., Zhou, T., Zhang, X., and Ren, Y.: A comparison of the physical and optical properties of anthropogenic air pollutants and mineral dust over Northwest China, Acta Meteorol Sin., 29, 180-200, 2015.

Wang, Y., Wang, R., Ming, J., Liu, G., Chen, T., Liu, X., Liu, H., Zhen, Y., and Cheng, G.:, Effects of dust storm events on weekly clinic visits related to pulmonary tuberculosis disease in Minqin, China, Atmos. Environ., 127, 205-212, https://doi.org/10.1016/j.atmosenv.2015.12.041, 2016.

Wang, Y., Xue, Y., Tian, H., Gao, J., Chen, Y., Zhu, C., Liu, H., Wang, K., Hua, S., and Liu, S.: Effectiveness of temporary control measures for lowering $\mathrm{PM}_{2.5}$ pollution in Beijing and the implications, Atmos. Environ., 157, 75-83, https://doi.org/10.1016/j.atmosenv.2017.03.017, 2017.

Wei, F. S., Chen, J. S., Wu, Y. Y., and Zheng, C. J.: The study of background value in soil across China, Environ. Sci., 12, 12-20, 1991 (in Chinese).

Wei, F. S., Yang, G. Z., Jiang, D. Z., Liu, Z. H., and Sun, B. M.: The basic statistics and characteristics of soil elements in China, Environ. Mon. China., 7, 1-6, 1991 (in Chinese). 
Wu, J., Li, P., Qian, H., Duan, Z., and Zhang, X.: Using correlation and multivariate statistical analysis to identify hydrogeochemical processes affecting the major ion chemistry of waters: a case study in Laoheba phosphorite mine in Sichuan, China, Arab. J. Geosci., 7, 3973-3982, 2014.

Wu, Q. and Han, G.: Sulfur isotope and chemical composition of the precipitation at the Three Gorges Reservoir, Atmos. Res., 155, 130-140, https://doi.org/10.1016/j.atmosres.2014.11.020, 2015.

Wu, J., Liang, G., Hui, D., Deng, Q., Xiong, X., Qiu, Q., Liu, J., Chu, G., Zhou, G., and Zhang, D.: Prolonged acid rain facilitates soil organic carbon accumulation in a mature forest in Southern China, Sci. Total Environ., 544, 94-102, https://doi.org/10.1016/j.scitotenv.2015.11.025, 2016a.

Wu, X. M., Wu, Y., Zhang, S. J., Liu, H., Fu, L. X., and Hao, J. M.: Assessment of vehicle emission programs in China during 1998-2013: achievement, challenges and implications, Environ. Pollut., 214, 556-567, https://doi.org/10.1016/j.envpol.2016.04.042, 2016b.

Xiao, H. W., Xiao, H. Y., Long, A. M., Wang, Y. L., and Liu, C. Q.: Sources and meteorological factors that control seasonal variation of $\delta^{34} \mathrm{~S}$ values in precipitation, Atmos. Res., 149, 154-165, https://doi.org/10.1016/j.atmosres.2014.06.003, 2014.

Xing, J., Song, J., Yuan, H., Li, X., Li, N., Duan, L., Kang, X., and Wang, Q.: Fluxes, seasonal patterns and sources of various nutrient species (nitrogen, phosphorus and silicon) in atmospheric wet deposition and their ecological effects on Jiaozhou Bay, North China, Sci. Total Environ., 576, 617-627, https://doi.org/10.1016/j.scitotenv.2016.10.134, 2017.

Xu, P., Liao, Y. J., Lin, Y. H., Zhao, C. X., Yan, C. H., Cao, M. N., Wang, G. S., and Luan, S. J.: High-resolution inventory of ammonia emissions from agricultural fertilizer in China from 1978 to 2008, Atmos. Chem. Phys., 16, 1207-1218, https://doi.org/10.5194/acp-16-1207-2016, 2016.

Xu, W., Luo, X. S., Pan, Y. P., Zhang, L., Tang, A. H., Shen, J. L., Zhang, Y., Li, K. H., Wu, Q. H., Yang, D. W., Zhang, Y. Y., Xue, J., Li, W. Q., Li, Q. Q., Tang, L., Lu, S. H., Liang, T., Tong, Y. A., Liu, P., Zhang, Q., Xiong, Z. Q., Shi, X. J., Wu, L. H., Shi, W. Q., Tian, K., Zhong, X. H., Shi, K., Tang, Q. Y., Zhang, L. J., Huang, J. L., He, C. E., Kuang, F. H., Zhu, B., Liu, H., Jin, X., Xin, Y. J., Shi, X. K., Du, E. Z., Dore, A. J., Tang, S., Collett Jr., J. L., Goulding, K., Sun, Y. X., Ren, J., Zhang, F. S., and Liu, X. J.: Quantifying atmospheric nitrogen deposition through a nationwide monitoring network across China, Atmos. Chem. Phys., 15, 12345-12360, https://doi.org/10.5194/acp-15-123452015, 2015.

Yan, W., Mayorga, E., Li, X., Seitzinger, S. P., and Bouwman, A.: Increasing anthropogenic nitrogen inputs and riverine DIN exports from the Changjiang River basin under changing human pressures, Global Biogeochem. Cy., 24, GB0A06, https://doi.org/10.1029/2009GB003575, 2010.

Yang, K., Zhu, J., Gu, J., Yu, L., and Wang, Z.: Changes in soil phosphorus fractions after 9 years of continuous nitrogen addition in a Larix gmelinii plantation, Ann. For. Sci., 72, 435-442, 2015.

Yang, X., Shen, S. H., Ying, F., He, Q., Ali, M., Huo, W., and Liu, X. C.: Spatial and temporal variations of blowing dust events in the Taklimakan Desert, Theor. Appl. Clim., 125, 669-677, 2016.

Yang, Y., Zhou, R., Yan, Y., Yu, Y., Liu, J., Du, Z., and $\mathrm{Wu}, \mathrm{D} .:$ Seasonal variations and size distributions of water-soluble ions of atmospheric particulate matter at Shigatse, Tibetan Plateau, Chemosphere, 145, 560-567, https://doi.org/10.1016/j.chemosphere.2015.11.065, 2016.

Yang, X., Wang, S., Zhang, W., and Yu, J.: Are the temporal variation and spatial variation of ambient $\mathrm{SO}_{2}$ concentrations determined by different factors?, J. Clean Prod., 167, 824-836, https://doi.org/10.1016/j.jclepro.2017.08.215, 2017.

Yu, H. L., He, N. P., Wang, Q. F., Zhu, J. X., Xu, L., Zhu, Z. L., and Yu, G. R.: Wet acid deposition in Chinese natural and agricultural ecosystems: Evidence from national-scale monitoring, J. Geophys. Res.-Atmos., 121, 1-11, https://doi.org/10.1002/2015JD024441, 2016.

Yu, H., He, N., Wang, Q., Zhu, J., Gao, Y., Zhang, Y., Jia, Y., and Yu, G.: Development of atmospheric acid deposition in China from the 1990s to the 2010s, Environ. Pollut., 231, 182-190, https://doi.org/10.1016/j.envpol.2017.08.014, 2017.

Yu, Y., Zhao, S., Wang, B., Fu, P., and He, J.: Pollution Characteristics Revealed by Size Distribution Properties of Aerosol Particles at Urban and Suburban Sites, Northwest China, Aerosol Air Qual Re., 17, 1784-1797, https://doi.org/10.4209/aaqr.2016.07.0330, 2017.

Zhai, P. M. and Li, X. Y.: On climate background of duststorms over northern China, Acta Geogr. Sinica, 58, 1-7, 2003 (in Chinese).

Zhan, Y., Luo, Y. Z., Deng, X. F., Zhang, K. S., Zhang, M. H., Grieneisen, M. L., and Di, B. F.: Satellited-based estimates of daily $\mathrm{NO}_{2}$ exposure in China using hybrid random forest and spatiotemporal Kriging model, Environ. Sci. Tech., 52, 4180 4189, 2018.

Zhang, S. L. and Yang, G. Y.: Changes of background values of inorganic elements in soils of gunagdong province, Soils, 44 1009-1014, 2012 (in Chinese).

Zhang, T., Cao, J., Tie, X., Shen, Z., Liu, S., Ding, H., Han, Y., Wang, G., Ho, K., and Qiang, J.: Water-soluble ions in atmospheric aerosols measured in Xi'an, China: seasonal variations and sources, Atmos. Res., 102, 110-119, https://doi.org/10.1016/j.atmosres.2011.06.014, 2011.

Zhang, X., Chai, F., Wang, S., Sun, X., and Han, M.: Chemical Characteristics of $\mathrm{PM}_{2.5}$ during 2015 Spring Festival in Beijing, China, Aerosol Air Qual. Re., 17, 1169-1180, https://doi.org/10.4209/aaqr.2016.08.0338, 2017.

Zhang, X.-X., Sharratt, B., Chen, X., Wang, Z.-F., Liu, L.-Y., Guo, Y.-H., Li, J., Chen, H.-S., and Yang, W.-Y.: Dust deposition and ambient $\mathrm{PM}_{10}$ concentration in northwest China: spatial and temporal variability, Atmos. Chem. Phys., 17, 1699-1711, https://doi.org/10.5194/acp-17-1699-2017, 2017.

Zhang, Y., Huang, W., Cai, T., Fang, D., Wang, Y., Song, J., Hu, M., and Zhang, Y.: Concentrations and chemical compositions of fine particles $\left(\mathrm{PM}_{2.5}\right)$ during haze and non-haze days in Beijing, Atmos. Res., 174, 62-69, https://doi.org/10.1016/j.atmosres.2016.02.003, 2016.

Zhang, Y., Huang, W., Cai, T., Fang, D., Wang, Y., Song, J., Hu, M., and Zhang, Y.: Observations of biomass burning tracers in $\mathrm{PM}_{2.5}$ at two megacities in North China during 2014 APEC summit, Atmos. Environ., 169, 54-64, https://doi.org/10.1016/j.atmosenv.2017.09.011, 2017.

Zhang, X., Chai, F., Wang, S., Sun, X., and Han, M.: Research progress of acid precipitation in China, Environ. Sci. Res., 23, 527-532, 2010 (in Chinese) 
Zhang, Y. Y., Liu, J. F., Mu, Y. J., Pei, S. W., Lun, X. X., and Chai, F. H.: Emissions of nitrous oxide, nitrogen oxides and ammonia from a maize field in the North China Plain, Atmos. Environ., 45, 2956-2961, https://doi.org/10.1016/j.atmosenv.2010.10.052, 2011.

Zhao, C. and Luo, K.: Sulfur, arsenic, fluorine and mercury emissions resulting from coal-washing byproducts: A critical component of China's emission inventory, Atmos. Environ., 152, 270278, https://doi.org/10.1016/j.atmosenv.2016.12.001, 2017.

Zhao, J., Zhang, F., Xu, Y., and Chen, J.: Characterization of water-soluble inorganic ions in size-segregated aerosols in coastal city, Xiamen, Atmos. Res., 99, 546-562, https://doi.org/10.1016/j.atmosres.2010.12.017, 2011.

Zhao, M., Wang, S., Tan, J., Hua, Y., Wu, D., and Hao, J.: Variation of urban atmospheric ammonia pollution and its relation with $\mathrm{PM}_{2.5}$ chemical property in winter of Beijing, China, Aerosol Air Qual. Res., 16, 1378-1389, https://doi.org/10.4209/aaqr.2015.12.0699, 2016.
Zheng, B., Huo, H., Zhang, Q., Yao, Z. L., Wang, X. T., Yang, X. F., Liu, H., and He, K. B.: High-resolution mapping of vehicle emissions in China in 2008, Atmos. Chem. Phys., 14, 9787-9805, https://doi.org/10.5194/acp-14-9787-2014, 2014.

Zhou, Y., Zhao, Y., Mao, P., Zhang, Q., Zhang, J., Qiu, L., and Yang, Y.: Development of a high-resolution emission inventory and its evaluation and application through air quality modeling for Jiangsu Province, China, Atmos. Chem. Phys., 17, 211-233, https://doi.org/10.5194/acp-17-211-2017, 2017a.

Zhou, Y., Xing, X., Lang, J., Chen, D., Cheng, S., Wei, L., Wei, $\mathrm{X}$., and Liu, C.: A comprehensive biomass burning emission inventory with high spatial and temporal resolution in China, Atmos. Chem. Phys., 17, 2839-2864, https://doi.org/10.5194/acp17-2839-2017, 2017b. 